\title{
STUDIES OF THE
}

ARGONNE INTEGRATED-PUFF MODEL

\author{
by \\ D. M. Rote, J. W. Gudenas, \\ and L. A. Conley
}

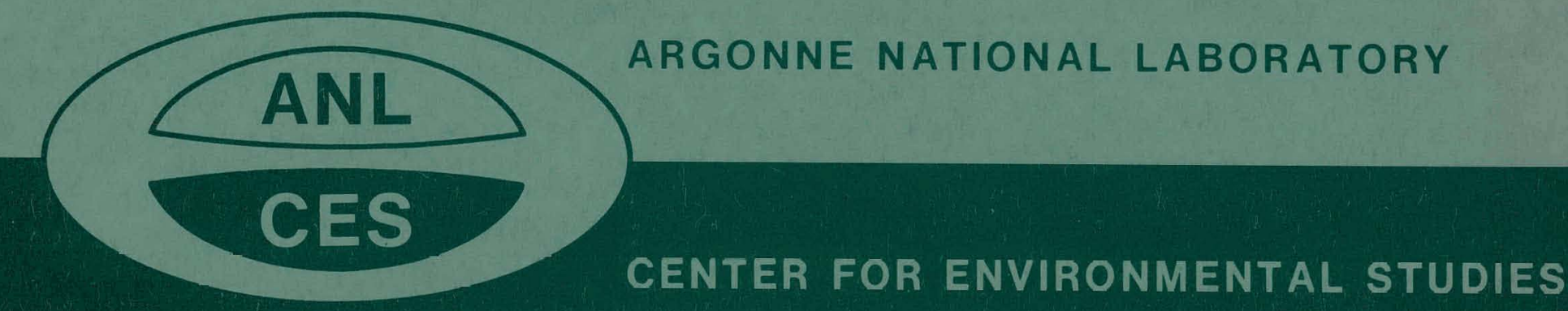

CENTER FOR ENVIRONMENTAL STUDIES 


\section{DISCLAIMER}

This report was prepared as an account of work sponsored by an agency of the United States Government. Neither the United States Government nor any agency Thereof, nor any of their employees, makes any warranty, express or implied, or assumes any legal liability or responsibility for the accuracy, completeness, or usefulness of any information, apparatus, product, or process disclosed, or represents that its use would not infringe privately owned rights. Reference herein to any specific commercial product, process, or service by trade name, trademark, manufacturer, or otherwise does not necessarily constitute or imply its endorsement, recommendation, or favoring by the United States Government or any agency thereof. The views and opinions of authors expressed herein do not necessarily state or reflect those of the United States Government or any agency thereof. 


\section{DISCLAIMER}

Portions of this document may be illegible in electronic image products. Images are produced from the best available original document. 
The facilities of Argonne National Laboratory are owned by the United States Government. Under the terms of a contract (W-31-109-Eng-38) between the U. S. Atomic Energy Commission, Argonne Universities Association and The University of Chicago, the University employs the staff and operates the Laboratory in accordance with policies and programs formulated, approved and reviewed by the Association.

\section{MEMBERS OF ARGONNE UNIVERSITIES ASSOCIATION}

The University of Arizona

Carnegie-Mellon Univer sity Case Western Reserve University

The University of Chicago

University of Cincinnati

Illinois Institute of Technology

University of Illinois

Indiana University

Iowa State University

The University of Iowa
Kansas State University

The University of Kansas

Loyola University

Marquette University

Michigan State University

The University of Michigan

University of Minnesota

University of Missouri

Northwestern University

University of Notre Dame
The Ohio State University

Ohio University

The Pennsylvania State University

Purdue. University

Saint Louis University

Southern Illinois University

The University of Texas at Austin

Washington University

Wayne State University

The University of Wisconsin

\section{NOTICE}

This report was prepared as an account of work sponsored by the United States Government. Neither the United States nor the United States Atomic Energy Commission, nor any of their employees, nor any of their contractors, subcontractors, or their employees, makes any warranty, express or implied, or assumes any legal liability or responsibility for the accuracy, completeness or usefulness of any information, apparatus, product or process disclosed, or represents that its use would not infringe privately-owned rights.

Printed in the United States of America

Available from

National Technical Information Service

U.S. Department of Commerce

5285 Port Royal Road

Springfield, Virginia 22151

Price: Printed Copy $\$ 3.00$; Microfiche $\$ 0.95$ 
ANL / ES-9

Meteorology

ARGONNE NATIONAL LABORATORY

9700 South Cass Avenue

Argonne, Illinois. 60439

STUDIES OF THE

ARGONNE INTEGRATED-PUFF MODEL

by

D. Mn Rote, J. W. Gudenas, and L。A. Conley

\section{Center for Environmental Studies}

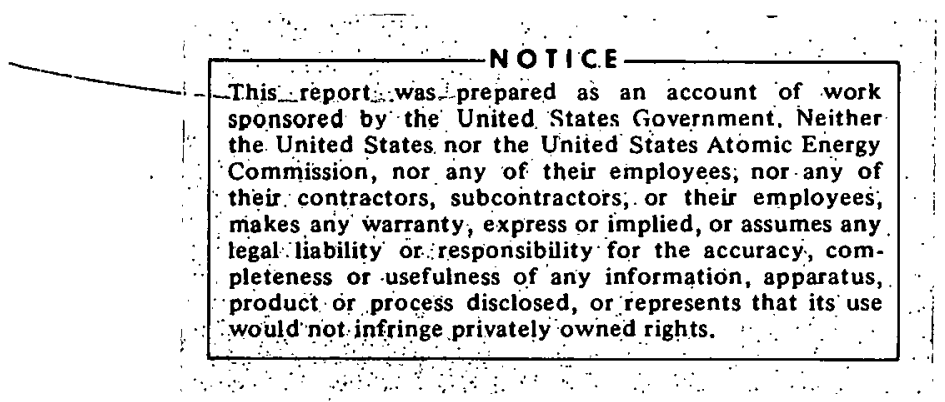

October 1971 
THIS PAGE

WAS INTENTIONALLY

LEFT BLANK 
TABLE OF CONTENTS

$\underline{\text { Page }}$

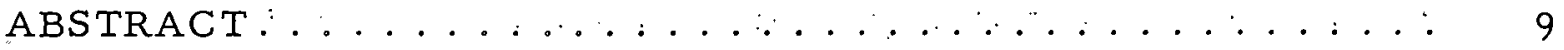

1. INTRODUCTION ..................... 10

2. DESCRIPTION OF THE ARGONNE INTEGRACTED-PUFF AND STEADY-STATE PLUME MODELS . . . . . . . . . . . 14

2.1 The Integrated-puff Transport Kernel . . . . . . . . 14

2.2 The Steady-state Plume Expression ........... 15

2.3 Dispersion Coefficients. . . . . . . . . 15

2.3.1 The "1/5 Law" .................. 17

2.3.2 Comment on Use of Travel-time-dependent Dispersion. Coefficients in Plume Model . . . . . . . . 19

2.4 Low-wind-speed Behavior of Steady-state-plume Expression. 19

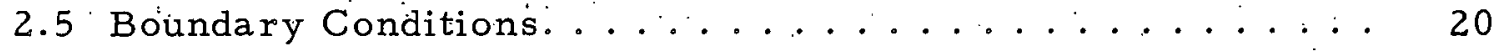

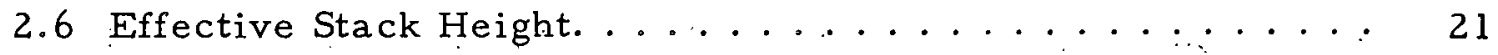

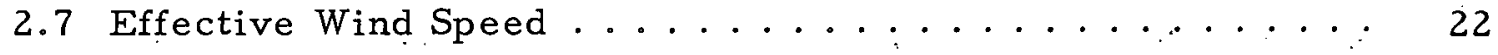

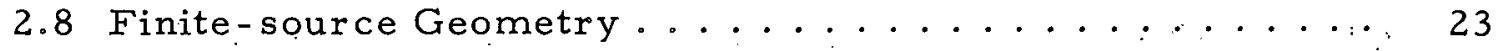

2.9 Relation between. Length of Side of an Area Source and. Initial Value of Lateral-dispersion Coefficient . . . . 24

3. DERTVATION OF CALM ALGORITHM............ 28

4. EFFECT OF CALM ALGORITIIM................. 31

5. COMPARISON OF RESULTS OF PUFF - AND PLUME-MODEL CALCULATIONS ........................... 34

5.1 Short-term Comparisons. . . . . . . . . . . . . . 34

5.2 Long-term Comparisons. . . . . . . . . . . . 36

6. DISCUSSION OF PLUME- AND PUFF-MODEL RESULTS . . . . . 39

7. RELATIONSHIP BETWEEN PUFF AND PLUME EXPRESSIONS. 41

7.1 Analytical Analysis of Relationship between Puff and

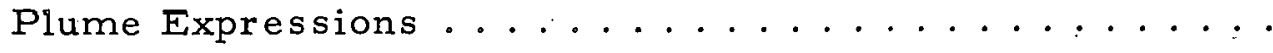


TABLE OF CONTENTS

$\underline{\text { Page }}$

7.2 Numerical Analysis of Relationship between Puff and

Plume Expressions. ................. 44

8. SENSITIVITY ANALYSIS OF STEADY-STATE

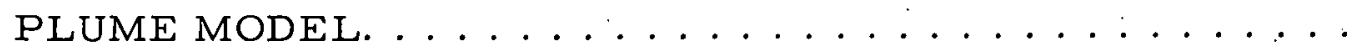

8.1 Use of the Midway Wind Field. . . . . . . . . . .

8.1.1 Direct Comparison of Observed with Calculated $\mathrm{SO}_{2}$ Concentrations Using Midway Winds and Ailso with Calculations Using TAM Winds...........

8.1.2 Comparison of Calculations Using Midway and TAM Winds........................ 52

8.2 Sensitivity to Changes in Wind Direction. . . . . . . 52

8.3 Sensitivity to Changes in Lid Height. . . . . . . . 55

9. STRUCTURE OF STEADY-STATE PLUME COMPUTER CODE . 58

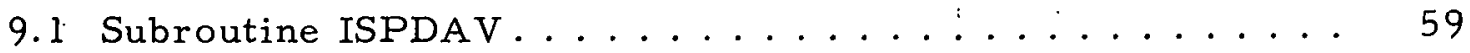

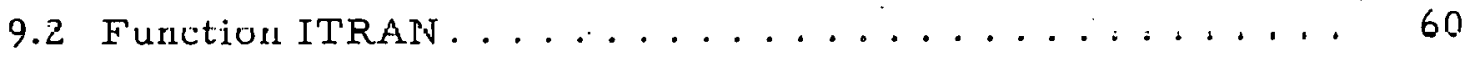

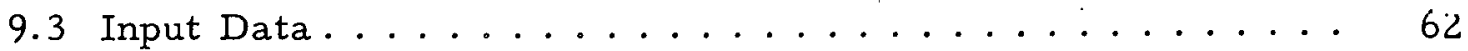

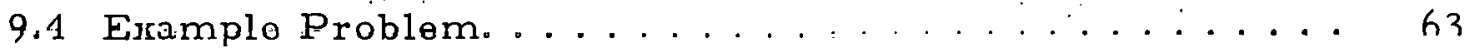

10. SUMMARY OF RESULTS AND RECOMMENDATIONS FOR

FURTHER INVESTIGATION . . . . . . . . . . . . .

APPF.NDTXF.S

A. Reduction of Computer Run-time Requirements of

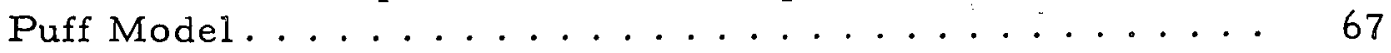

B. Listings of Steady-state Plume-model Computer Routines . 68

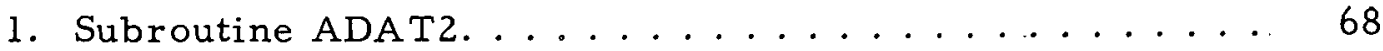

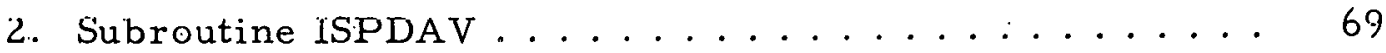

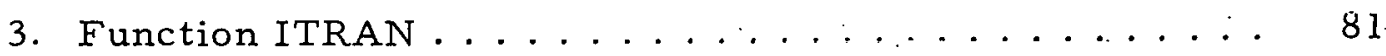

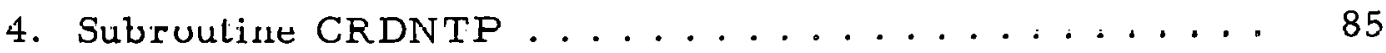

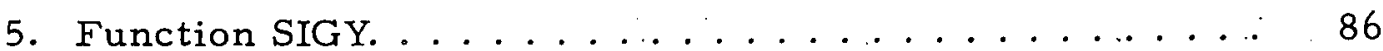

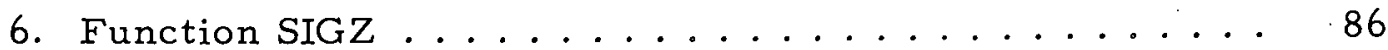




\section{TABLE OF CONTENTS}

Page

C. Example Computation of Hourly $\mathrm{SO}_{2}$ Concentrations at

TAM 5 for February 17, 1967, Using the Plume Code. . . . 88

D. Definitions of Quantities Used in Analysis of Results..... 102 ACKNOWLEDGMENTS . . . . . . . . . . . . . . . . 104

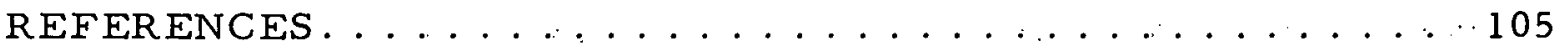




\section{LIST OF FIGURES}

No

Title

$\underline{\text { Page }}$

1. Map of City of Chicago ..................... 11

2. Time-dependent Transverse-dispersion Coefficients

Characteristic of 1 -hr Sampling Times . . . . . . . . 16

3. Time-dependent Vertical-dispersion Coefficients Characteristic of 1 -hr Sampling Times .......... 16

4. Downwind-distance-dependent Transverse-dispersion Coefficients Characteristic of l-hr Sampling Times. . . . . . .

5. Downwind-distance-dependent Vertical-dispersion Coefficients Characteristic of 1-hr Sampling Times. . . . . . . 17

6. A Row of Square Area Sources Perpendicular to the WD.... 25

7. Concentration Patterns along Line Passing through Center of Row of Square Area Sources . . . . . . . . . . . . 26

8. Wind Speed Measured at TAM 5 Aerovane vs Time of Day,

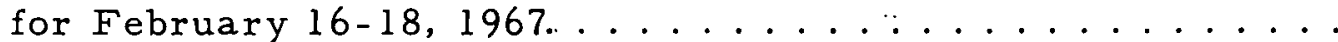

9. Observed and Calculated Hourly Concentrations at TAM 4 for February 16-18, 1967, Using Plume Model with and without

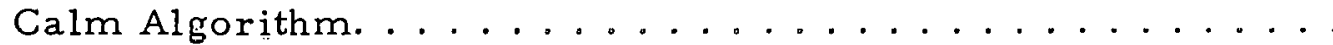

10. Observed and Calculated Hourly Concentrations at TAM 5 for February 16-18, 1967, Using Plume Model with and without Calm Algorithm. . . . . . . . . . . . . . .

11. Observed and Calculated Hourly Concentrations at TAM 2 for February 16-18, 1967, Using Plume Model with and without Calm Algorithm. . . . . . . . . . . . . . . .

12. $\mathrm{SO}_{2}$ Concentrations at TAM 2 vs Time of Day, for

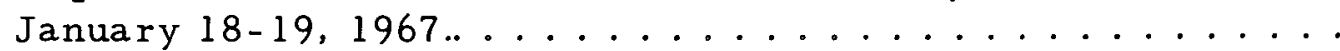

13. $\mathrm{SO}_{2}$ Concentrations at TAM 4 vs Time of Day, for

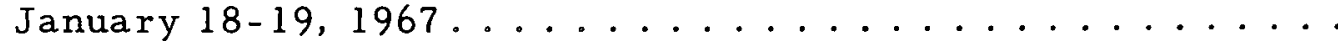

14. $\mathrm{SO}_{2}$ Concentrations at TAM 5 vs Time of Day, for

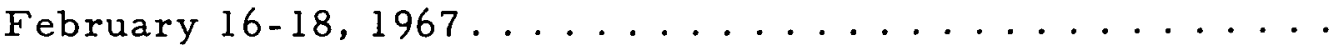

15. $\chi \mathrm{H} / \mathrm{Q}$ vs Time for the Integrated-puff Kernel as a Function of Stability Class and Downwind Distance; $u=5 \mathrm{mph}$, $\mathrm{y}=0.0 \ldots \ldots \ldots \ldots \ldots \ldots \ldots \ldots \ldots \ldots \ldots \ldots \ldots \ldots \ldots \ldots$

16. $\chi \mathrm{H} / \mathrm{Q}$ vs Time for the Integrated-puff Kernel as a Function of Stability Class and Downwind Distance; $u=5 \mathrm{mph}$, $\mathrm{y}=0.25$ mile $\ldots \ldots \ldots \ldots \ldots \ldots \ldots \ldots \ldots \ldots \ldots$ 
LIST OF FIGURES

No.

Title

Page

17. Measurements of WD at TAM 5 for January $12-15,1967 \ldots 54$

18. Effect of Reducing Lid Height on Plume-model Calculations . 56

19. Flow Chart of Plume-model Code.............. 58 
LIST OF TABLES

No.

Title

$\underline{\text { Page }}$

2.1. Restrictions on Plume-rise Formula ............ 22

2.2. Exponents for Wind-profile Law .............. 23

2.3. Parameters Used to Describe Area Sources in Chicago. . . . 24

4.1. Effect of Calm Algorithm on Hourly Calculations with Steadystate Plume Model for Episode of February 16-18, 1967. . . .

5.1. Comparison of Hourly Results of Puff, Plume, and Plume + CA Calculations with Observations for February 16-18,1967...

5.2. Comparison of Observed and Calculated $\mathrm{SO}_{2}$ Concentrations for January 1967......................

5.3. Comparison of Observed and Calculated $\mathrm{SO}_{2}$ Concentrations

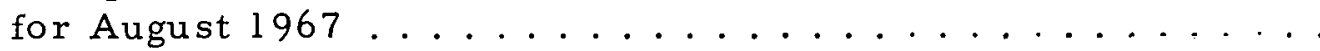

7:1. Relationship between Puff and Plume Expressions for Various Wind Speeds u, Crosswind Distances y, and Downwind

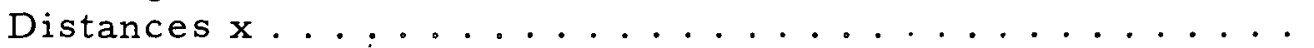

8.1. Calculated vs Observed Results Using TAM and Midway Winds, January $1967 \ldots \ldots \ldots$

8.2. Fercentıle Distribution of Differences between Calculated and Observed Results Using TAM and Midway Winds, January 1967.

8.3. Analysis of $\chi_{\text {TAM }}-\chi_{\text {M }}$ for January $1967 \ldots 52$

8.4. Comparison of Calculations for Different Wind-direction

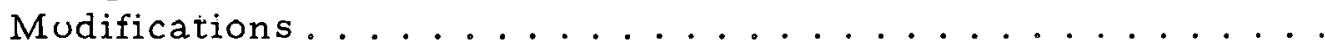

8.5. Comparison of Calculations for Different. Tid-height

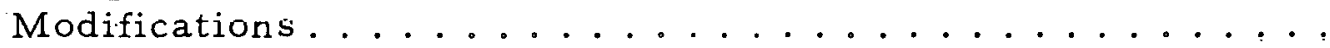

8.6. Percent Changes in Mean Concentration Calculated for Selected Short Periods when Lid Height Is Modified . . . . . . 57

C.1. PLANTSIM Output. ......................... 90

C.2. Stack loordinates and Physical Parameters .......... . 98

C.3. Meteorological Data for February 16-18, 1967....... 99

G.4. Results of Sample Computations of $\mathrm{SO}_{2}$ Concentrations at TAM 5 for February $16,18,1967 \ldots \ldots 100$ 


\section{STUDIES OF THE \\ ARGONNE INTEGRATED-PUFF MODEL}

by

D. M. Rote, J. W. Gudenas, and L. A. Conley

\section{ABSTRACT}

This is the final report on progress made under the air-pollution meteorology and dispersion modeling contract sponsored by NAPCA (now EPA)/Division of Meteorology entitled "Studies of the Argonne Integrated-puff Model."

Objectives of the program included the development of a simple steady-state dispersion model based on the Gaussian plume expression to be used for comparison with the Argonne Integrated-puff Model. This report includes a complete documentation of the plume model along with computer program listings and an example computation of $\mathrm{SO}_{2}$ concentrations.

To extend the applicability of the plume model to very low wind speeds, a special "calm algorithm"was developed.

The plume model was validated by comparing calculations both with observed concentrations and calculations using the puff model. When applied to a complete urban source emission inventory both the puff and plume models were found to be in relatively close agreement under a wide variety of circumstances. A good understanding of the relationship between the integrated puff kernel and the Gaussian plume expressions was obtained by performing detailed analytical and numerical analyses.

Finally a sensitivity analysis was carried out with the plume model. Sensitivity to the use of Midway measured winds instead of the more well defined TAM station winds was studied along with the effect of introducing systematic errors of $\pm 15^{\circ}$ in the TAM measured wind directions. In addition, the effect of introducing systematic errors into the lid height was also analyzed. A determination of the magnitude of expected errors in the lid height was obtained by making a comparioon study of several techniques for estimating the lid height from radiosonde measurements. 


\section{INTRODUCTION}

The City of Chicago, like many heavily industrialized metropolitan areas, has historically been plagued by high air-pollution concentrations of sulfur dioxide. This fact, coupled with the existence of a network of TAM stations (see Fig. 1) which continuously monitored $\mathrm{SO}_{2}$, suggested that Chicago would serve as a suitable region for a dispersion-modeling study. Such a program started about three years ago as the Chicago Air Pollution Systems Analysis Program.* Recognizing the substantial diurnal, as well as seasonal, variations in the weather elements and emission rates plus the need for reliable estimates of $\mathrm{SO}_{2}$ concentrations on a short-term basis for purposes of episode analysis and control, it was decided to develop a transient-type dispersion model. The Argonne Integrated-puff Model was subsequently designed to calculate $\mathrm{SO}_{2}$ concentrations on an hourly basis. This model is extensively documented in a number of reports, ${ }^{1-3}$ including ANL/ES-CC-007.' The Chicago Air Pollution Systems Analysis Program is summarized in Ref. 2 .

The central ingredient of the puff model is the puff kernel or pointsource Green's function, which has been used by several other authors as well.4-6 When applied to a complete urban-source emission inventory for an extended historical period, the puff model has the principal disadvantage of requiring a relatively large amount of computer core storage and run time. Consequently, a question that arose in connection with such an application of the puff model was, "Could the same quality of fit of the computed $\mathrm{SO}_{2}$ concentrations to the observed concentrations be achieved by a less sophis ticated model?" Or, to put the question somewhat differently, "Is the accuracy of the model attributable to the puff kernel or to some other component of the model, such as the source emission inventory, or the source simulation routine PLANTSIM (see Ref. 1) or, to some combination of the algorithms which describe the plume rise, virtual point-source location, treatment of boundary conditions, lid penetration, etc.?"

During the past year a dispexsion-mudeling program** entitled "Studies of the Argonne Integrated-puff Model" was carried out. One of the principal goals of this program was to answer the above questions. To this end, a simple alternative model was developed and compared in detail to the integrated-puff model. The alternative model was developed by replacing the integrated-puff algorithm with a steady-state plume expression essentially the same as that used in a number of other steady-state Gaussian-plume-type urban models such as that of $\mathrm{Clark}^{7}$ or Turner. ${ }^{8,9}$ (See Moses ${ }^{10}$ for a review of these and other references cited there.) The

\footnotetext{
*This program was sponsored jointly by the Atomic Energy Commission, the U.S. Department of Health, Education, and Welfare (National Air Pollution Control Administration, Division of Meteorology), and the Chicago Department of Environmental Control.

** Sponsored by the then-named "National Air Pollution Control Administration," Division of Meteorology.
} 


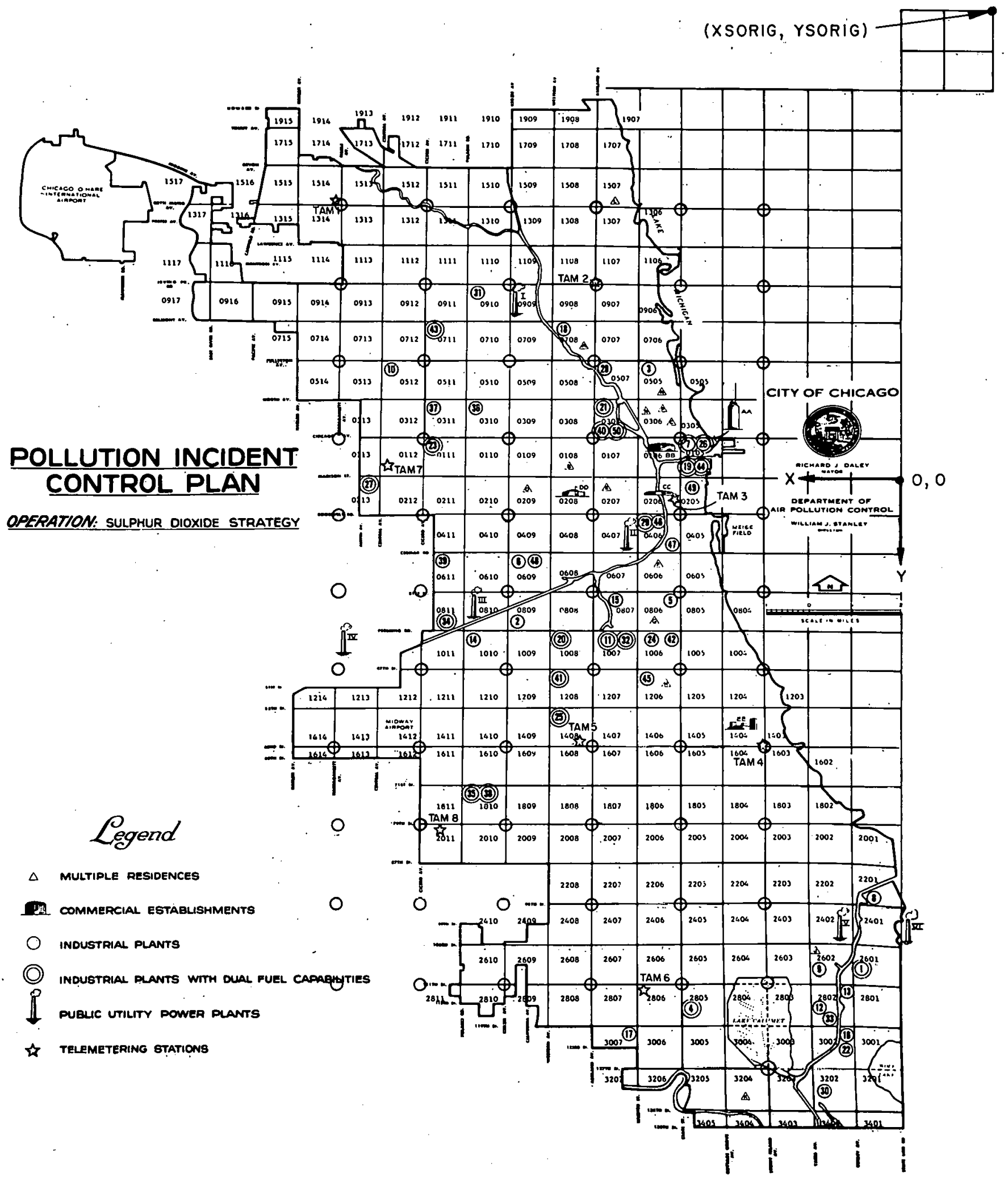

Fig. 1. Map of City of Chicago. Map shows origin of Cartesian-coordinate system $(0,0)$, origin of area-source array (XSORIG, YSORIG) $=(-2,-12)$, and $6 \times 11$ receptor grid denoted by $\oplus$. (Alapted from map prepared at the Department of Air Pollution by R. D. Colley, 1967.) ANL Neg. No. 112-8979 Rev. 4. 
computer coderesulting from this replacement, along with a few other minor changes in the original puff computer code, is referred to hereinafter as the "steady-state plume model" or "plume model" for short. By developing the plume model in this way, one could determine if the precision of the model when applied to an urban source inventory was limited by the degree of sophistication of the transport kernel or a combination of the remaining parts of the computer code as suggested above.

Another goal of the dispersion-modeling program was to establish the sensitivity of the puff or plume model to changes in various input parammeters. A third goal was to obtain a better understanding of the relationship between the integrated-puff and Gaussian steady-state plume expressions and to determine under what conditions the puff and plume models could be expected to yield similar or different results. An additionol gonl was to al= tcmpt to reduce the computer run time requirements of the puff model.

'The present report describes the results of the aforementioned program and includes a detailed description of the plume model as well as a copy of the computer code and an example of its use...

Early in the testing phase of the plume-model development, it was recognized that during periods of very low wind speed (calms) one obtained unrealistically high $\mathrm{SO}_{2}$ concentrations. To rectify this problem, a "calm algorithm" was developed and tested. This special low-wind-speed transport function was set up so that it could be used in place of the standard plume expression wherever the wind speed fell below a certain predetermined value.

The plume model and the calm algorithm are described in detail in Sects. 2 and 3 , respectively. For comparison, certain aspects of the puff model are also described in Sect. 2. However, since many algorithms are common to both the puff and plume models and since the puff model is already extensively described in Ref. l, the reader will be referred to Rof. l for various details. The effect on the calculated results of ueing the calm algorithm in the plume model is illustrated in Sect. 4. Section 5 compares the results of the puff and plume models on both the short-and long-term bases. The results of these comparisons are discussed in Sect. 6 . This is followed by an analysis (both numerical and analytical) of the relationship between the integrated puff and Gaussian plume mathematical expressions under special conditions in Sect. 7.

The results of a sensitivity analysis of the plume model to changes in certain input data are given in Sect. 8 .

Some comments regarding the reduction in computer run time of the puff model are given in Appendix A. 
Finally, a copy of the plume-model computer code, along with an example of its use, is included in Appendixes B and C, respectively. The code as: presented here is a modified version of the puff-model code presented in Ref. $l$ and is therefore not in its most efficient form. That is, the complications necessary to implement the puff kernel remain in the code, although they are not actually used by the plume model. 


\section{DESCRIPTION OF THE ARGONNE INTEGRATED-PUFF AND STEADY-STATE PLUME MODELS}

The Argonne Integrated-puff Model has been described in the literature ${ }^{3}$ and more extensively in Argonne topical reports, especially Ref. 1. Consequently, only a brief description will be given here for pur poses of comparison. Furthermore, since with the exception of the integrated puff kernel, the steady-state plume model is the same as the puff model, the reader is referred to Ref. 1 for a detailed description of the various model components common to both models, unless it is necessary to bring out a particular point of interest.

\subsection{The Integrated-puff Transport. Kernel}

The Argonne Integrated-puff Model, as with similar puff models described in the literature, is based upon the Gaussian puff kernel (pnint source Green's function), which for a wind vector pointing along the $x$ direction with magnitude $u$ is given by

$G\left(x, y, z, t-t^{\prime}\right)=\frac{\exp \left\{-\left[\frac{\left[x-u\left(t-t^{\prime}\right)\right]^{2}}{2 \sigma_{x}^{2}}+\frac{y^{2}}{2 \sigma_{y}^{2}}+\frac{z^{2}}{2 \sigma_{z}^{2}}-\frac{0.693\left(t-t^{\prime}\right)}{T_{1 / 2}}\right]\right\}}{(2 \pi)^{3 / 2} \sigma_{x} \sigma_{y} \sigma_{z}}$

where $t^{\prime}$ is the time of release nf an instantaneous puff at a point source located at $\left(x_{s}, y_{s}, z_{s}\right)$ and $t$ is any time $\left(\geq t^{\prime}\right)$ at the receptor located at $\left(x_{r}\right.$, $y_{r}, z_{r}$ ) so that $x=x_{r}-x_{s}$, etc. It is convenient to defins the travel time or delay time for a given puff as $T=t$ - $t$.* Note that, in general, the transit time $\mathrm{T}_{\mathrm{tr}}=\mathrm{x} / \mathrm{u}$ is quite distinct from the travel time $\mathrm{T} !$. Thc above Green's function includes an attenuation factor expressed in terms of a half-life $\mathrm{T}_{1 / 2}$, which is supposed to allow for the gradual removal of $\mathrm{SO}_{2}$ by some unspecified mechanisms. Now to calculate the concentration at the receptor at time $t$ resulting from a continuous release of pollutant starting at time $t^{\prime}=0$ from the source, we form the convolution of the emission rate $Q\left(t^{\prime}\right)$ with the Green's function as follows:

$$
\begin{aligned}
X(x, y, z, t) & =\int_{0}^{t} d t^{\prime} Q\left(t^{\prime}\right) \Gamma\left(x, y, z, t,-t^{\prime}\right) \\
& =\int_{0}^{t} d T Q(t-T) G(x, y, z, T),
\end{aligned}
$$

\footnotetext{
*Used in the context of the puff model, the travel or delay time $\mathrm{T}$ is the age of a particular puff and has nothing to do with the time required for a puff to be transported from a given source to a given receptor. The latter time is called the transit time $\mathrm{T}_{\mathrm{tr}}=\mathrm{x} / \mathrm{u}$.
} 
where $T=t-t^{\prime}$ is the delay time. In the present discussion, terms corresponding to reflections from the ground and lid are dropped for convenience. Causality is preserved by starting the latter integral at zero delay time (the present) and going backward in time to the maximum delay time of $t$ hours (in this case, the start of the release). Since, beyond some large delay time earlier releases will not contribute to the concentration, it is physically reasonable and economical of computer time to restrict the maximum delay or look-back time to some small number. The present puff computer code restricts the look-back time to $6 \mathrm{hr}$. Since the meteorological variables and emission rates are assumed piece-wise continuous, the concentration at hour $\mathrm{M}$ becomes

$$
\chi(M)=\sum_{N=1}^{M} Q_{M-N+i} \int_{(N-1) \Delta}^{N \Delta} d T G_{N}(x, y, z, T),
$$

where $Q_{M-N+1}$ is the emission rate between hours $M-N$ and $M-N+1$ and the subscript $N$ on the Green's function means that it should be evaluated with the meteorological parameters corresponding to the same time interval. As $\mathrm{N}$ increases from 1 to $\mathrm{M}$, we are effectively stepping backward in time in $l-h r$ steps.

\subsection{The Steady-state Plume Expression}

Following a number of other authors, we have used the standard plume expression given by the following equation for a point source in an unbounded atmosphere:

$$
\chi(y, z)=\frac{Q \exp \left[-\left(y^{2} / 2 \sigma_{y}^{2}+z^{2} / 2 \sigma_{z}^{2}\right)\right]}{2 \pi u \sigma_{y} \sigma_{z}}
$$

Boundary conditions are treated in Sect. 2.5.

No attempt is made to preserve causality in the plume model. That is, regardless of whether the transit time exceeds the time $\operatorname{step}(\mathrm{x} / \mathrm{u}>\mathrm{l} \mathrm{hr})$, the plume expression is applied as though steady-state conditions existed.

\subsection{Dispersion Coefficients}

The dispersion coefficients used in Eqs. 2.1 and 2.3, namely $\sigma_{x}, \sigma_{y}$, and $\sigma_{z}$, are discussed in Ref. 1. Briefly, they are calculated from

$$
\sigma(i, T)=\max \left\{\sigma^{T S L}(T), \sigma^{T W B}(u T)\right\}
$$

where $i$ and $T$ refer to the Turner stability class ${ }^{8}$ and travel time, respectively; TSL refers to the travel-time-dependent coefficients adapted from 
Turner's St. Louis study (see Figs. 2 and 3); and TWB refers to the downwind, distance-dependent coefficients adapted from Turner's Workbook, ${ }^{11}$ which are in turn adapted from Pasquill ${ }^{12}$ and Gifford ${ }^{13}$ (see Figs. 4 and 5). For a particular source-receptor pair, stability class, and wind speed, the maximum value obtained from these two families of curves is used to avoid unrealistically narrow beams of pollutant predicted by $\sigma^{\mathrm{TSL}}$ at high wind speed. For lateral dispersion with $\sigma_{x}=\sigma_{y}=\sigma_{\ell}$ (used by both models), $\sigma_{\ell}^{\mathrm{TSL}}(\mathrm{T})>\sigma_{\ell}^{\mathrm{T} W B}(\mathrm{uT})$ for $\mathrm{u} \lesssim 7 \mathrm{mph}$. Also, generally, $\sigma_{\mathrm{z}}^{\mathrm{T} S}(\mathrm{~T})<$ $\sigma_{\mathrm{T}}^{\mathrm{T} W B}(\mathrm{uT})$ for $\mathrm{u} \gtrsim 20-30 \mathrm{mph}$, except for short times $(<0.2 \mathrm{hr})$ and for the more unstable stability classes. The exact wind speed for which the coefficients are equal depends upon the stability class.

The TWB set of curves given in Turner's Workbook ${ }^{11}$ are characteristic of $10-$ min sampling times. The so-called "1/5 power law" (see Sect. 2.3.1) was used to convert these curves into those given in Figs. 4 and 5 , which are characteristic of $1-\mathrm{hr}$ sampling times.

The TSL set of curves used by Turner in his St. Louis study ${ }^{9}$ are characteristic of $2-\mathrm{hr}$ sampling times. We discovered that the St. Louis coefficients were treated in Ref. 1 and consequently in the calculations reported here as though they were in fact for $\underline{1-h r}$ sampling time. Hence,

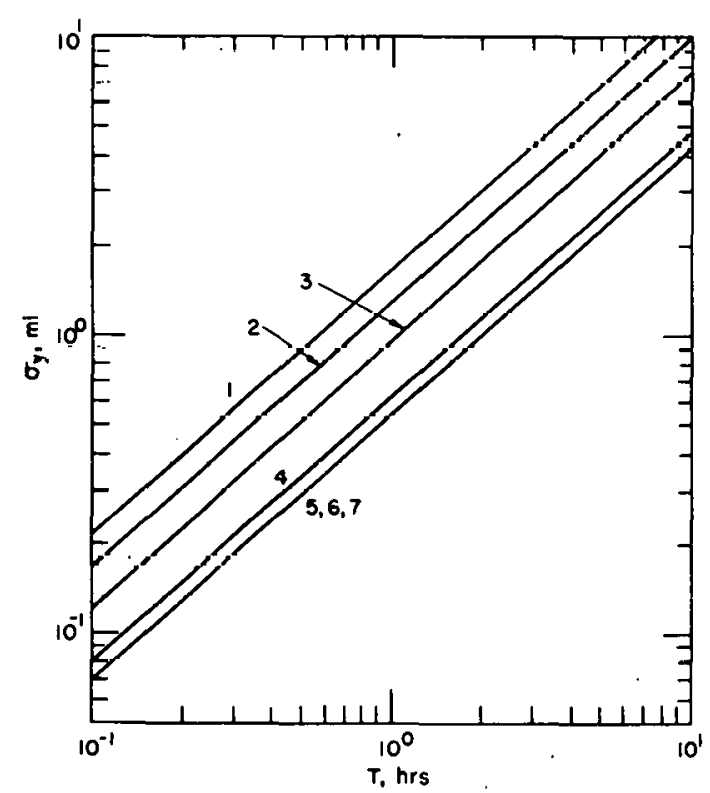

Fig. 2. Time-dependent Transverse-dispersion Coefficients Characteristic of 1 -hr Sampling Times (Turner ${ }^{9}$ ). ANL Neg. No. $113-2876$.

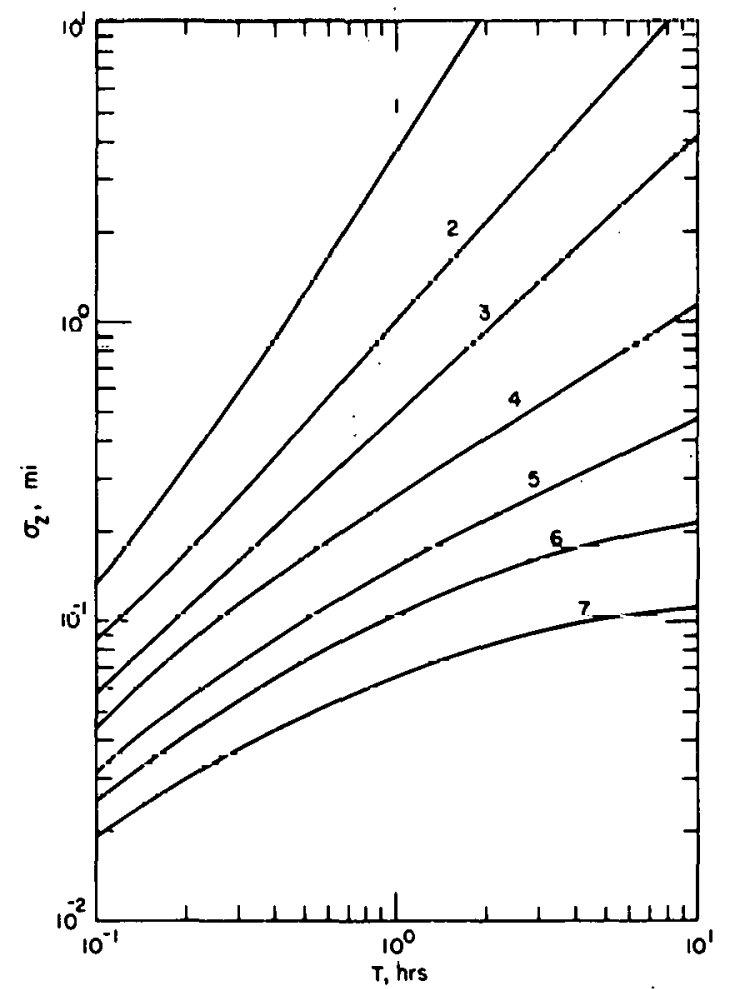

Fig. 3. Time-dependent Vertical-dispersion Coefficients Characteristic of $1-\mathrm{hr}$ Sampling Times (Turner ${ }^{9}$ ). ANL Neg. No. 113-2869. 


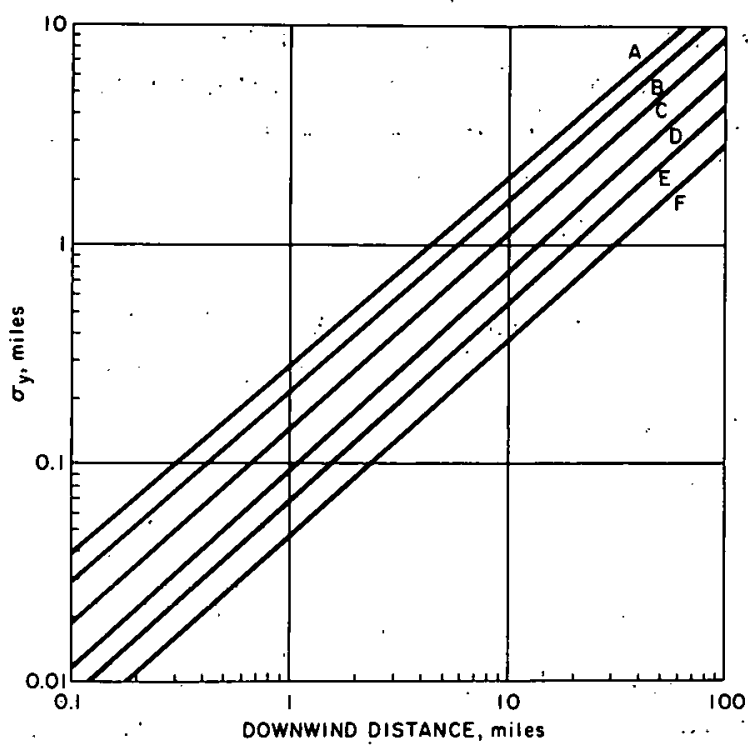

Fig. 4. Downwind-distance-dependent Transversedispersion Coefficients Characteristic of 1-hr Sampling Times (Turner ${ }^{11}$ ). ANL Neg. No. 113-1159.

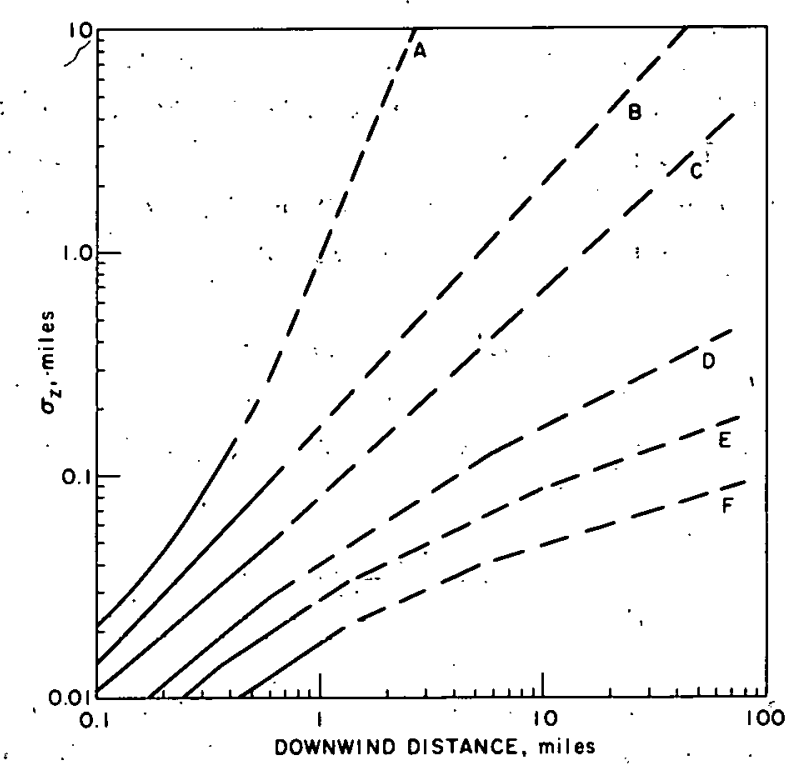

Fig. 5. Downwind-distance-dependent Verticaldispersion Coefficients Characteristic of 1-hr Sampling Times (Turner ${ }^{11}$ ). ANL Neg. No. 113-1160.

no' conversion to $\mathrm{l}$-hr sampling time was deemed necessary. However, recognition that the se coefficients are actually characteristic of $2-\mathrm{hr}$ sampling times means that they have been erroneously used: The values shown in Figs. 2 and 3 should be reduced by a factor $(60 / 120)^{1 / 5}=0.87$ : Fortunately, the erroneous use of $2-\mathrm{hr}$ instead of $\mathrm{l}$-hr sampling time coefficients is not serious, for several reasons. First, the error in the values of the coefficients is only $13 \%$, which is well within the accuracy of the coefficients to begin with. In addition, since the coefficients appear both in the exponentials and denominators of the transfer functions; small changes in their values tend to cancel at least partially. For a given set of meteorological conditions, depending upon the orientation of a given source-receptor pair, the concentration could increase, decrease, or remain roughly unchanged.

The travel-time-dependent coefficients labeled TLS and taken from Turner's St. Louis study9 are quite distinct from those used in his Nashville study. ${ }^{8}$ Both the characteristic sample time and the stability classification scheme are different. Whereas the Nashville time-dependent coefficients correspond closely to the downwind-distance-dependent coefficients from Turner's Workbook ${ }^{11}$ at $5 \mathrm{mps}$, there does not seem to be any simple relationship between the St. Louis and workbook coefficients at the same wind speed. Consequently, further investigation is required to unravel the relationship between the St. Louis and workbook coefficients.

\subsubsection{The "1/5 Law"}

Both the puff and plume models use a basic time step of $1 \mathrm{hr}$. That is, the meteorological parameters are assumed constant during that period 
so that concentrations are calculated on an hourly basis. Consequently, it is consistent to use dispersion coefficients that have been determined for $\mathrm{l}$-hr sampling times or are at least characteristic of $\mathrm{l}-\mathrm{hr}$ sampling times. Turner, in his Workbook, ${ }^{11}$ gives values of the downwind-distance-dependent coefficients characteristic of a 10 -min sampling time.

Several authors, including $\mathrm{Cramer}^{15}$ and his associates and Turner, ${ }^{11}$ have recommended the so-called " $1 / 5$ Law" for making adjustments to various sampling times. The law states that

$$
\sigma_{y}(\tau)=\sigma_{y}\left(T_{0}\right)\left(\frac{T}{\tau_{0}}\right)^{\dot{1} / 5}
$$

where $\sigma_{y}(\tau)$ is the lateral dispersion at a fixed distance downwind measured for a sampling time $\tau$, while $\sigma_{\mathrm{y}}\left(\tau_{0}\right)$ is measured at the same location for a different sampling time $\tau_{0}$. The $1 / 5$ Law, according to Cramer, apparently fits the data of several field experiments.

The same expression can be applied to the vertical dispersion, except that the data are not nearly so conclusive. This is especially true bccause most of the experiments were performed using ground-based sources, so: that the solid earth boundary restricts meandering of the vertical direction of the velocity.

Slade ${ }^{16}$ feels that for vertical distances below about $1000 \mathrm{ft}$ the vertical dispersion will be insensitive to sampling times greater than $20 \mathrm{~min}$.

The puff model assumes that both the lateral and vertical dispersinn coefficients that are functions of the downwind distance are modified with the $1 / 5$ Law; i.e.,

$$
\sigma_{y}(60)=\sigma_{y}(10)\left(\frac{60}{10}\right)^{i / 5}
$$

and

$$
\sigma_{z}(60)=\sigma_{z}(10)\left(\frac{60}{10}\right)^{\dot{I} / 5}
$$

If we take Slade's comments seriously, then we should only be using

$$
\sigma_{z}(60)=\sigma_{z}(20)=\sigma_{z}(10)\left(\frac{20}{10}\right)^{1 / 5}
$$

which means that at present $\sigma_{z}$ is being slightly overestimated. 
2.3.2 Comment on Use of Travel-time-dependent Dispersion Coefficients in Plume Mode1

The use of the travel-time-dependent dispersion coefficients in both the puff and plume models requires some explanation. Since the puff model is. formulated in terms of the travel or delay time $T$ of individual puffs, the dispersion coefficients are evaluated for values of this time. That is, one uses these coefficients to describe the growth of each puff about its own center. This is basically a Lagrangian formulation. However, as has already been pointed out by a number of people including Pasquill, ${ }^{14}$ the term "puff model" is really a misnomer because one is not actually employing diffusion coefficients characteristic of individual puffs (that is, instantaneous releases of pollutants).

On the contrary, the diffusion coefficients being used are essentially a measure of the size of the plume envelope formed by sampling a real me andering plume emitted from a continuous point source for $\mathrm{l} \mathrm{hr}$. Consequently, to the extent that the integrated-puff kernel represents that plume envelope, one is treating the envelope as though it were composed of a continuous train of effective circular puffs $\left(\sigma_{x}=\sigma_{y}\right)$ whose growth is specified by the above coefficients. This "decomposition" of the plume envelope into a continuous train of effective puffs is rigorously distinct from building up a plume envelope with an ensemble of isolated true puffs whose growth is specified by Lagrangian diffusion coefficients. This distinction arises because the effects of mutual interactions of overlapping puffs are taken into account in an average way in the effective puff picture but not in the true individual puff picture. It seems reasuriable that this distinction is not very significant in urban dispersion modeling.

In regard to the use of these coefficients in the plume model, one point is worth mentioning. Physically, one recognizes that in the puff model the overlapping train of effective puffs that influence a receptor at a particular time have a range of delay times associated with thes and therefore have undergone a range in degree of growth. For the steady-state plume model, there is, strictly speaking, only one time which can be defined, and that is the transit time $\dot{x} / u$, where $x=x_{r}-x_{\dot{s}}$. Consequently, the dis persion coefficients have been evaluated at the transit times corresponding to the various source-receptor pairs of interest, i.e., $\sigma_{l}^{\mathrm{TSL}}(\mathrm{i}, \mathrm{x} / \mathrm{u})$ and $\sigma_{\mathrm{z}}^{\mathrm{TSSL}}(\mathrm{i}, \mathrm{x} / \mathrm{u})$.

\subsection{Low-wind-speed Behavior of Steady-state-plume Expression}

The travel-time-dependent dispersion coefficients, namely $\sigma^{\mathrm{TSL}}(\mathrm{i}, \mathrm{T})$, can be expressed approximately as

$$
\sigma_{y}(\mathrm{~T}) \therefore=\mathrm{aT} \mathrm{T}^{\mathrm{b}}, \sigma_{z}(\mathrm{~T})=\mathrm{cT} \mathrm{T}^{\mathrm{d}}
$$


or alternatively, using the transit time, as

$$
\sigma_{y}(x / u)=a x^{b} u^{-b}, \sigma_{z}(x / u)=c x^{d} u^{-d}
$$

Substituting into the plume expression, we obtain

$$
\frac{\chi}{Q} \propto \propto f(u) g(u)
$$

where

$$
f(u)=u^{b+d-1} / x^{b+d}
$$

and

$$
g(u)=\exp \left[-\left(\frac{y^{2}}{2 a^{2} x^{2 b}} u^{2 b}+\frac{z^{2}}{2 c^{2} x^{2 d}} u^{2 d}\right)\right]
$$

Since $f(u)$ is a slowly increasing function of $u(b+d>1)$ and $g(u)$ is an exponentially decaying function of $u$, the product is a function that starts off at zero when $u=0$, rapidly rises to a peak at very small values of $u$ (as it turns out), and then falls off exponentially to zero again as $u \Rightarrow \infty$. Although $X / Q$ is consequently a well-behaved function of $u$ for all values of $u$, nevertheless, for small values of $u(\lesssim l \mathrm{mph})$, nne optains unrealiatically large values of the concentration.

On the other hand, if the downwind distance-dependent family of dispersion curves were used, namely,

$$
\sigma_{y}(x)=A x^{B} \text { and } \sigma_{z}(x)=C x^{D} \text {, }
$$

then $X / Q \propto 1 / \mathrm{u}$, which lead's, as experience shows, to unrealistically high concentrations for wind speeds even as high as $3-4 \mathrm{mph}$.

Consequently, even though the use of the travel-time-dependent coefficients is not rigorously justified, nevertheless their functional dependence upon $u$ is much more satisfactory than the duwnwind distance-dependent coefficients at low wind speeds and; when compared with observed concentrations, produce more realistic values of the concentration down to about $1 \mathrm{mph}$.

\subsection{Boundary Conditions}

In both the plume and puff models, the ground surface is assumed to be a perfect reflector of the pollutant and is therefore treated by the method of a virtual image source below the ground. In addition, if the mixing depth 
is finite, then the top of the mixing layer or lid height is also assumed to be a perfect reflector, so that the combination of two parallel reflectors is treated as an infinite sequence of virtual image source terms (limited to nine terms). (See Ref. I for a complete description of the procedure.) The lid height is determined by an objective estimate of the mixing -height technique. ${ }^{17}$ As part of the dispersion modeling program, results of this technique have been compared in detail with estimates of the lid height based on radiosondes performed at Midway Airport. This work is described in a separate report. ${ }^{18}$.

If the physical or effective stack height (see Sect. 2.6) is greater than the lid height; then the stability. class used to calculate plume dispersion is set equal to 5 (stable) and the lid height is set equal to infinity; i.e., no re flection from the lid is considered. For the puff model, the time dependence of the lid height that leads to such phenomena as fumigations is taken into consideration, as described in Ref. 1.'

\subsection{Effective Stack Height (taken from Ref. 1)}

The effective stack height $\mathrm{H}$ is the height above ground that best defines the centerline of the plume. The plume is assumed to originate as a point source at an altitude $\mathrm{H}$ ft above ground at the location of the stack. If aerodynamic downwash causes the plume to break up and mix rapidly downward in the vicinity of the stack, $H$ may be set equal to the actual phys ical height, $\mathrm{H}_{\mathbf{S}}$. Observations of a local utility indicate that this phenomenon occurs frequently for wind speeds greater than $15 \mathrm{mph}$. Otherwise, a plume rise $\Delta \mathrm{H}$ is added to the physical stack height $\mathrm{H}_{\mathrm{S}}$, so that

$$
\mathrm{H}=\mathrm{H}_{\mathbf{s}}+\Delta \mathrm{H}
$$

where $\Delta \mathrm{H}$ is estimated as described below.

Smoke plume-rise calculations in this model are based on a formula derived by Carson and Moses ${ }^{19}$ from observations at TVA stations and other power plants. (The momentum term in their original formulation is omitted in the equation since its contribution is generally negligible compared to the rmal buoyancy.).

$$
\Delta H^{\prime}=K Q_{S^{\prime}}^{1 / 2} / \mathrm{U},
$$

where

$$
\begin{aligned}
\Delta H & =\text { plume rise, } \mathrm{ft}, \\
\mathrm{Q}_{\mathrm{S}} & =\text { heat-emission rate from stack, Btu } / \mathrm{hr}, \\
\mathrm{U} & =\text { wind speed, mph, at height of stack, }
\end{aligned}
$$


and

$$
\begin{aligned}
K= & 0.870 \text { (unstable; class } 3), 0.354 \text { (neutral; class } 4 \text { ), } \\
& 0.222 \text { (stable; class } 5 \text { ). }
\end{aligned}
$$

Three restrictions placed on the use of Eq. 2.7 are listed in Table 2.1.

TABLE 2.1. Restrictions on Plume-rise Formula (Eq. 2.7)

1. Low Wind Speeds (U)

If $U$ is estimated to be less than $4 \mathrm{mph}$, the value $4 \mathrm{mph}$ is rised in Eq. 2.7.

\section{Stability $\mathrm{Class}$ and the Coefficient $\mathrm{K}$}

If the physical stack height $\left(\mathrm{H}_{\mathrm{s}}\right)$ is equal to or greater than $200 \mathrm{ft}, \mathrm{K}=0.354$ (neutral) is used, even though the stability index indicates unstable conditions. ( $K=0.222$ if conditions are stable.)

3. Mixing -layer or Lid Height $\left(\mathrm{H}_{m}\right)$

a. If the physical stack height $\mathrm{H}_{s}$ is greater than $\mathrm{H}_{m}$, an infinite value for $\mathrm{H}_{\mathrm{m}}$ is assumed, with plume rise and dispersion according to stable atmospheric conditions.

b. A minimum plume rise $\triangle H_{\text {min }}$ (DHMIN in subroutine ISPDAV) is calculated, based on the coefficients for stably stratified air. If this minimum effective stack height, $H=H_{s}+\Delta H_{m i n}$, is greater than the lid height $H_{m}$, it is used; the plume is then analyzed as described in restriction $3 \mathrm{a}$.

c. If $\mathrm{H}_{\mathrm{s}}+\Delta \mathrm{H}_{\min }<\mathrm{H}_{\mathrm{m}}$ and if the plume rise $\Delta \mathrm{H}$ based on the actual stability class yields an effective stack height greater than $H_{m}$, i.c., if $H_{s}+\Delta H_{m i n}<$ $\mathrm{H}_{m}$ and $\mathrm{H}_{\mathrm{S}}+\Delta \mathrm{H} \geq \mathrm{H}_{\mathrm{m}}$, the effective stack height is restricted to the lid height $\mathrm{H}_{\mathrm{m}}$.

\subsection{Effective Wind Speed}

The mean wind speed at the physical stack height $\mathrm{H}_{\mathrm{s}}$ should be uscd in the plume-rise equation (Eq. 2.7). In the evaluation of the puff kernel (Eq. 2.1), or the plume expression (Eq. 2.3), wind at the effective stack height $H$, corresponding to the plume renterline, is used. In cach sAse, the desired value for the wind speed will usually be greater than that measured at a local airport (typically 20-100 ft above the ground). The following equation provides a correction term for altitudes up to about $1000 \mathrm{ft}$ :

$$
U\left(\text { at height } \mathrm{Z}_{2}\right)=\mathrm{U}\left(\text { at height } \mathrm{Z}_{1}\right)\left(\mathrm{Z}_{2} / \mathrm{Z}_{1}\right)^{\mathrm{P}} \text {, }
$$

where the exponent $P$ is dependent on the stability class, as shown in Table 2.2. The ratio $\left(Z_{2} / Z_{1}\right)^{P}$ is limited to a value of 3 . 
TABLE 2.2. Exponents for Wind-profile Law (taken from DeMarrais $\left.{ }^{20}\right)^{a}$

\begin{tabular}{|c|c|}
\hline Stability Class & $P$ \\
\hline Stable $(\geq 5)$ & 0.5 \\
\hline Neutral (4) & 0.2 \\
\hline Unstable $(<3)$ & 0.2 \\
\hline
\end{tabular}

aThe experimental data from DeMarrais 20 indicated a slightly more uniform verticalwind-speed profile for unstable than for neutral conditions, but the model is not sensitive to this distinction.

\subsection{Finite-source Geometry (Adapted from Ref. l)}

The realistic modeling of residential, commercial, and industrial zones characterized by multiple sources too numerous to represent by individual plumes is critical to the success of a source-oriented atmospheric-dispersion model. A similar need for synthesizing emissions from these area sources arises in the design of regional implementation plans based on land use, a method whereby one seeks to assign emission-density limits $\left(1 \mathrm{~b} / \mathrm{hr}-\mathrm{mi}^{2}\right)$ to land in each of several zoning classes (Roberts and Croke ${ }^{21}$ ). Often major point sources can be modeled more realistically by assigning initial dimensions to the plume in order to approximate, for example, multiple stacks or aerodynamic downwash.

Be it an area source or a point source with initial dimensions, the source of finite initial volume is approximated by a pseudoupwind point source.

The location of this point source is determined as follows: First, the source is assigned some initial values of the dispersion coefficients namely, $\sigma_{x_{0}}, \sigma_{y 0}$, and $\sigma_{z 0}$ according to a prescriptiondefined below. For the plume model only $\sigma_{y_{0}}$ and $\sigma_{z_{0}}$ are relevant. In any case, because only circular puffs are presently considered, $\sigma_{\mathrm{x} 0}=\sigma_{\mathrm{yo}}$. Second, the equations

and

$$
\left.\begin{array}{l}
\sigma_{x_{0}}=\sigma_{y_{0}}=\sigma_{y}\left(i, T_{y}\right) \\
\sigma_{z_{0}}=\sigma_{z}\left(i, T_{z}\right)
\end{array}\right\}
$$

are solved by subroutine PSEUDO for the quantities $T_{y}$ and $T_{z}$. From these initial time intervals, we calculate $\delta_{x}=u T_{y}$ and $\delta_{y}=v T_{y}$, where $\mathrm{u}$ and $\mathrm{v}$ are the $\mathrm{x}$ and $\mathrm{y}$ components of the wind velocity. Finally, Eqs. 2.1 for the puff and 2.3 for the plume are modified by replacing $x, y$, and $T$ by $\mathrm{x}-\delta_{\mathrm{x}}, \mathrm{y}-\delta_{\mathrm{y}}$, and $\mathrm{T}+\mathrm{T}_{\mathrm{y}}, \mathrm{T}+\mathrm{T}_{\mathrm{z}}$, where appropriale'.

The prescription for assigning initial values to the dispersion coefficients depends upon the source type (whether point or area), wind speed (whether downwash conditions prevail or not), and source classification. Table 2.3 shows values of building height, critical wind speeds, plume rise, and $\sigma_{z_{0}}$ for the three classifications of area sources in Chicago. For example, if the wind speed is $10 \mathrm{mph}$, low-rise residential buildings are 
represented by a source at $z=50 \mathrm{ft}$ with $\sigma_{z_{0}}=50 \mathrm{ft}$, and industrial-area sources by $z=300 \mathrm{ft}$ and $\sigma_{z_{0}}=150 \mathrm{ft}$. The initial value of the lateral dispersion $\sigma_{x_{0}}=\sigma_{y_{0}}$ is defined in terms of the side length $\mathrm{n}$ ( $\mathrm{mi}$ ) of the area source as $\sigma_{y_{0}}=\mathrm{n} / 2.4$. (The factor 2.4 is discussed in Sect. 2.9 below.)

TABLE 2.3. Parameters Used to Describe Area Sources in Chicago

\begin{tabular}{|c|c|c|c|c|c|c|}
\hline \multirow[b]{2}{*}{ Source Class } & \multirow[b]{2}{*}{$\begin{array}{c}\text { Physical Stack } \\
\text { Height, ft }\end{array}$} & \multirow{2}{*}{$\begin{array}{c}\text { Critical Wind } \\
\text { Speed, WS } \\
\text {, mph }\end{array}$} & \multicolumn{2}{|c|}{$w S \leq w S_{c}$} & \multicolumn{2}{|c|}{$w s>w_{c}$} \\
\hline & & & $\begin{array}{c}\text { Plume Rise, } \\
\mathrm{ft}\end{array}$ & $\sigma_{z 0}, \mathrm{ft}$ & $\begin{array}{c}\text { Plume Rise, } \\
\mathrm{ft}\end{array}$ & $\sigma_{z_{0}}, \mathrm{ft}$ \\
\hline $\begin{array}{l}\text { Low-rise } \\
\text { Residential/ } \\
\text { Commercial }\end{array}$ & 50 & 6 & 50 & 50 & . & 50 \\
\hline $\begin{array}{l}\text { IIigli }- \text { lse } \\
\text { Residential/ } \\
\text { Commercial }\end{array}$ & 200 & 6 & 100 & 200 & 0 & 200 \\
\hline Industrial & 150 & 15 & 150 & 150 & 0 & 150 \\
\hline
\end{tabular}

Major point sources are also characterized by initial dimensions $\sigma_{x_{0}}\left(=\sigma_{y_{0}}\right)$ and $\sigma_{z_{0}}$, which, for properly designed stacks, depend upon whether a crittcal wind speed (here $15 \mathrm{mph}$ at $75 \mathrm{ft}$ ) is exceeded. Downwash conditions are assumed to occur always for sources with poor aerodynamic characteristics, such as vents or stubby stacks. Under normal plume-rise conditions, the parameters $\sigma_{x_{0}}, \sigma_{y 0}$, and $\sigma_{z_{0}}$ are each set at $100 \mathrm{ft}$ to describe the initial source volume. Under downwash conditions, $\sigma_{\mathbf{x} 0}$ and $\sigma_{\mathrm{yo}}$ are set at $750 \mathrm{ft}$ and $\sigma_{\mathrm{zo}}$ at $150 \mathrm{ft}$. As with area sources, these choices are somewhat intuitive and, since the downwash effect is a primarily local. one, really should be tailored to each source or source type. For example, one may assume that large commercial and residential establishmente are dominated by buildings with improperly designed stacks and that a good assumption for initial source dimensions to simulate downwash would then be the size of a representative building (Shieh ${ }^{5}$ ). In Chicago, major point sources in this category are typified by Union Station, approximately one city block wide and 100-150 ft high. This observation influenced our selection of initial source dimensions under downwash conditions. It is also worth noting that all sources homogenized and treated as area sources (with $\mathrm{n}=1 \mathrm{mi}$ ) are effectively given as $\sigma_{\mathrm{x}_{0}}=\sigma_{\mathrm{y}^{0}}=0.416 \mathrm{mi}$.

\subsection{Relation between Length of Side of an Area Source and Initial Value of Lateral-dispersion Coefficient}

In Sect. 2.8 the prescription for assigning initial values of the dispersion coefficients to square area sources said that for a source of side length $\mathrm{n}$, the initial value of the lateral dispersion coefficient $\left(\sigma_{\mathrm{x} 0}=\sigma_{\mathrm{yo}}\right)$ is given by $\sigma_{y_{0}}=\mathrm{n} / 2.4$.

The following discussion is taken from Ref. 1:

"Figure [6] depicts a row of square area sources of uniform strength. Pollutant concentrations along the line A-A are determined by 
summation of concentrations due to each individual area source. The concentration profile for each square is governed by $\sigma_{\text {yo. Uni- }}$ formity of emissions along A-A implies that, when the concentration fields for all squares are superimposed, the dose at point a in Fig. [6] should equal that at point b. [Choosing $\sigma_{y_{0}}=n / 2.4$ ] ensures this."

The statement that $\sigma_{\mathrm{yo}}=\mathrm{n} / 2.4$ ensures the uniformity of concentration along the line A-A was examined in detail with some numerical experiments.

There is an inherent uncertainty about the location relative to a square area source where one should set $\sigma_{\mathrm{yo}}=\sigma_{\mathrm{y}}$ and $\sigma_{\mathrm{z}_{0}}=\sigma_{\mathrm{z}}$. In both the puff and plume model codes, this location was chosen as the center of the square area source. Consequently, the quantities $\delta_{x}$ and $\delta_{y}$ (see Sect. 2.8) are the displacements of the virtual point source from the center of the square area source. Hence, in the discussion here, we shall refer to the concentration along a line passing through the center of a row of area sources (parallel to the row) rather than to the concentration along. line $\mathrm{A}-\mathrm{A}$ in Fig. 6.

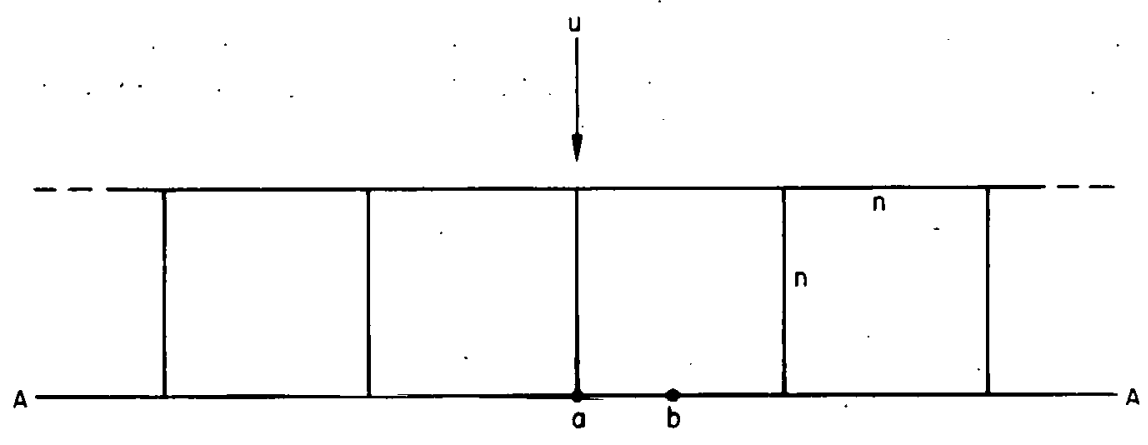

Fig. 6. A Row of Square Area Sources Perpendicular to the. Wh. ANL Neg, No, 113-2867 Rev. 1.

In the steady-state case, assuming a Gaussian distribution, the pollutant concentration for a point source is given by the expression

$$
\chi=\frac{Q}{2 \pi u \sigma_{y} \sigma_{z}} \exp \left(-y^{2} / 2 \sigma_{y}^{2}\right) \exp \left(-z^{2} / 2 \sigma_{z}^{2}\right)
$$

where, for convenience, we are ignoring the boundary conditions.

If we now represent a single square area source by a virtual upwind point source, then at the center of the square we have $\sigma_{y}=\sigma_{y 0}$ and $\sigma_{\mathrm{z}}=\sigma_{\mathrm{z} 0}$, so that, along the centerline passing through the single square area source perpendicular to the wind direction, the concentration is proportional to 


$$
\frac{\exp \left(-\mathrm{y}^{2} / 2 \sigma_{\mathrm{yo}}^{2}\right)}{\sigma_{\mathrm{yo}}}
$$

The emission pattern from a square area source is a square step function of width $\mathrm{n}$ (the side length). Hence, what we are attempting to do is fit a Gaussian to this square step function at the center of the square as well as possible. A reasonable approach is to require that the width $w$ of the Gaussian at half-maximum should equal the side length $n$ of the area source, i.e., $w=n$. But $w=2 \sigma_{y_{0}} \sqrt{\ell n 4} \approx 2.4 \sigma_{\text {yo }}$, so that we have $\sigma_{\mathrm{yo}}=\mathrm{n} / 2.4$.

Now we may inquire as to what happens when several arca sources are lined up in a row. The concentration along the centerline parallel to the row of $\mathrm{N}$ sources is proportional to

$$
\sum_{i=1}^{N} \frac{\exp \left[-\left(y=y_{i}\right)^{2} / 2 \sigma_{y v}^{2}\right]}{\sigma_{y 0}}
$$

where $y_{i}$ is the location of the center of the ith area source. Figure 7 shows plots of this quantity for various choices of $N$ and $\sigma_{y o}$. The variable $y$ is given in units of the side length $n$. Superimposed on these curves are the corresponding square step functions, which are normalized so that the areas under the curves are equal.

Note:

$$
\int_{-\infty}^{+\infty} d y \frac{\operatorname{cxp}\left(-y^{2} / 2 \sigma_{y 0}^{2}\right)}{\sigma_{y 0}}=\sqrt{2 \pi} \approx 2.5 .
$$
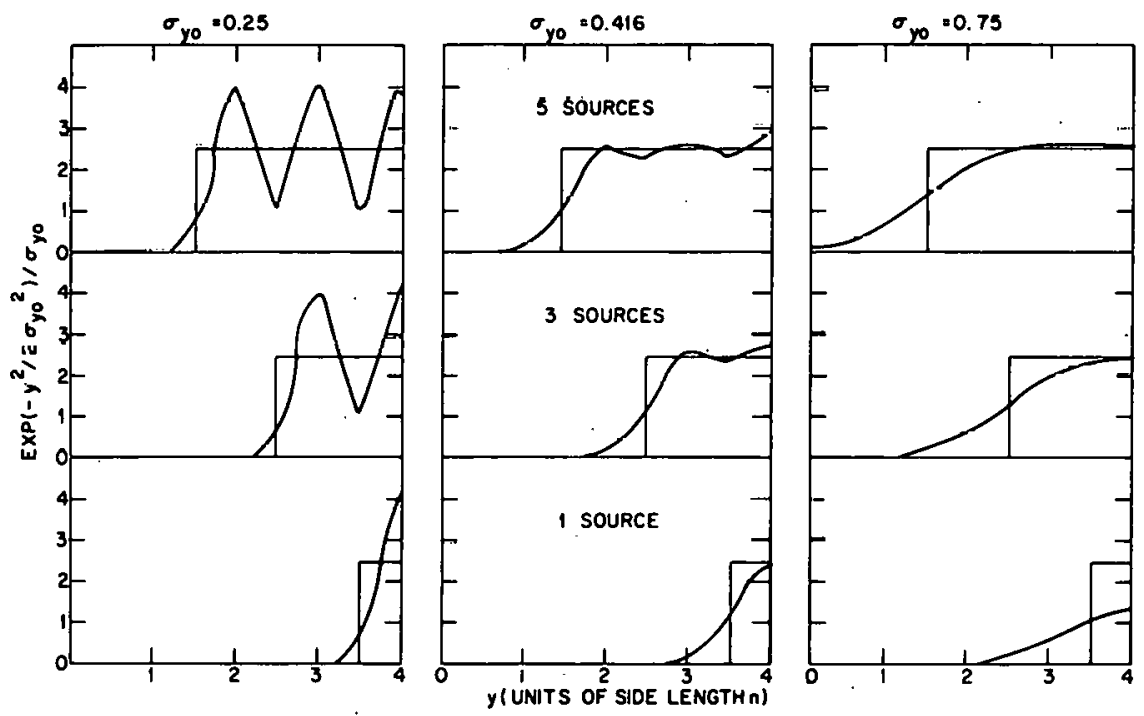

Fig. 7. Concentration Patterns along Line Passing through Center of Row of Square Area Sources. Note: symmetry about $y=4$. ANL Neg. No. 190-165. 
The source pattern is centered at $y=4$. Since $\chi(y)$ is symmetrical about $\mathrm{y}=4$, only the region $0 \leq \mathrm{y} \leq 4$ is shown.

The choice $\sigma_{y_{0}}=0.25$ (in units of $n$ ) corresponds to $n / 4$ as used by Turner in his St. Louis study. This choice not only distorts the single area source considerably, but does not provide a good approximation to the step function for several sources in a row.

Using $\sigma_{\text {yo }}=0.417(=\mathrm{n} / 2.4)$ clearly provides a reasonable approximation to the single square area source as mentioned earlier and also provides a good fit to the sequence of sources.

The choice $\sigma_{\mathrm{yo}}=0.75(=3 \mathrm{n} / 4)$ provides a smooth distribution for a row of sources, but tends to spread the edges out too far and clearly distorts a single area source by quite a bit. Consequently, the choice $\sigma_{\text {yo }}=0.417$ seems to provide the best compromise to fitting an arbitrary number of sources. By using a value of $\sigma_{\text {yo }}$ somewhat greater than 0.417 , we could get an idea of what the concentration will look like along the line A-A in Fig. 6. Without actually carrying out this exercise, we see that along the latter line the concentration pattern will fall somewhere between that of

$$
\sigma_{y_{0}}=0.417 \text { and } \sigma_{y 0}=0.75
$$

One can extend the numerical experiment to include several rows of area sources. The results are not essentially changed. Fortak ${ }^{22}$ has performed similar numerical experiments in an attempt to determine the density of individual point sources (with fixed initial dispersion) required to simulate a single area source with uniform distribution (a step function). 


\section{DERIVATION OF CALM ALGORITHM}

For very low wind speed ( $\leqslant l \mathrm{mph}$ ), the concentrations predicted by the steady-state model tend to become quite large. This is true even when the travel-time-dependent dispersion coefficients are used (see Sect. 2.3). To implement the steady-state model under such conditions, it was therefore necessary to develop a calm algorithm which would be used whenever $\mathrm{u}<\mathrm{u}_{\text {critical }}$, where $\mathrm{u}_{\text {critical }}$ was some small velocity to be determined.

The concentration due to a point source with constant emission rate $Q$ takes the general form, for the puff model,

$x(x, y, z, \tau)=\int_{0}^{T} \operatorname{QdT} \frac{\exp \left\{-\left[(x-u T)^{2} / 2 \sigma_{x}^{2}+y^{2} / 2 \sigma_{y}^{2}+z^{2} / 2 \sigma_{z}^{2}\right]\right\}}{(2 \pi)^{3 / 2} \sigma_{x}(T) \sigma_{y}(T) \sigma_{z}(T)}$,

where the exponential attenuation factor has been ignored for simplicity and where the dispersion coefficients are of the TSL type.

By assuming $\sigma_{x}(T)=\sigma_{y}(T)=\alpha T$ and $\sigma_{z}(T)=\gamma T$, and by taking the limiting case where $\tau \rightarrow \infty$ and $u \rightarrow 0$, we can analytically perform the integration to obtain

$$
\chi(r, z)=Q\left[(2 \pi)^{3 / 2} \alpha^{2} \gamma\left(\frac{r^{2}}{\alpha^{2}}+\frac{z^{2}}{\gamma^{2}}\right)\right]^{-1} .
$$

Tu use this expression, we must nhtain the values for the parameters $\alpha$ and $\gamma$. However, these are just the slopes of the curves $\sigma_{\mathbf{X}}(\mathrm{T})$ and $\sigma_{z}(T)$, which can be approximately calculated within the computer code as follows:

$$
\alpha=\sigma_{x}(T=1 h r)-\sigma_{x}(T=0),
$$

with a similar expression for $\gamma$. The beauty of this algnrithm is that thror. are no arbitrary constants to be evaluated and it can be easily implemented within the original code.

Now Eq. 3.1 for $\chi$ is true only for the source in a boundary-free region. If images formed by reflection of the plume from both the ground and the lid are to be taken into account, the expression for $\chi$ must be augmented by a sum of multiple-image terms which are identical to the source term, except that $z$ must be replaced by $z_{i}$, where $z_{i}$ is the vertical distance between the receptor and the ith image.

Calculations with this multiple-image series (using three terms) unfortunately showed poor convergence most of the time, so that the results 
were in fact underestimates of the true calculated concentrations. To . rectify this problem, an average was performed over the mixing layer to obtain a uniform vertical concentration field,

$$
\bar{\chi}=\frac{1}{L} \int_{0}^{L} \sum_{i=1}^{\infty} \chi_{i}(r, z) d z,
$$

where $\mathrm{L}=$ lid height and $\chi_{\mathrm{i}}(\mathrm{r}, \mathrm{z})$ is the concentration due to the ith image.

It can be shown that Eq. 3.3 can be equivalently written as

$$
\bar{\chi}=\frac{1}{L} \int_{-\infty}^{+\infty} \chi(r, z) d z,
$$

where $z$ is allowed to range over the entire interval from $-\infty$, to $+\infty$, and where $\chi(r, z)$ is given by Eq. 3.2. This integral is straightforwàd, and the result is

$$
\bar{\chi}=\frac{Q}{L \sqrt{2 \pi} 2 \alpha r}
$$

The $1 / \mathrm{r}$ dependence is characteristic of a cylindrically symmetric case with an infinite line source in the vertical direction. It results from setting the upper limit of the integral in Eq. $3.1(\tau)$ equal to infinity.

Use of Eq. 3.5 reveals that the $1 / \mathrm{r}$ dependence especially for distant sources is unrealistic. If an infinite time is permitted for.the estab-: lishment of steady-state conditions, then the simple $1 / \mathrm{r}$ dependence is not unreasonable. This is precisely one case in which the puff model properly allows for the "true" buildup time for a given concentration. It is possible to approximate the true buildup by using a finite value for $\tau$. That is, we assume that a calm condition lasts only for a finite time $\tau$, perhaps 1 or $2 \mathrm{hr}$. If we make this assumption, we can obtain a more realistic calm algorithm which, however, is really only applicable to cases where indeed $\tau=1$ or $2 \mathrm{hr}$. Provided that we are willing to ignore the variations in buildup times or calm durations, which is made partially acceptable by the decay time of $\mathrm{SO}_{2}$ anyway, we can use some fixed value of $\tau=1$ or $2 \mathrm{hr}$. Carrying out the puff integral for a finite time $\tau$ yields

$$
\chi(r, z, \tau)=\frac{Q \exp \left[-f(r, z) / \tau^{2}\right]}{2(2 \pi)^{3 / 2} \alpha^{2} \gamma f(r, z)}
$$

where

$$
f(r, z)=\frac{r^{2}}{2 \alpha^{2}}+\frac{z^{2}}{2 \gamma^{2}} .
$$


Clearly, as $t \rightarrow \infty$, the original calm algorithm is obtained. For finite values of $\tau$, the exponential factor improves the convergence rate of the image series. However, calculation still shows that under certain circumstances the convergence will be poor. Again, fọ those cases we can resort to a uniform vertical distribution in the mixing layer by averaging over the variable $z$, as follows:

$$
\begin{aligned}
\bar{\chi}(r, \tau) & =\frac{1}{L} \int_{-\infty}^{+\infty} \chi(r, z) d z \\
& =\frac{Q}{L \sqrt{2 \pi} 2 \alpha r}[1-\operatorname{erf}(r / \sqrt{2} \alpha \cdot \tau)],
\end{aligned}
$$

where erf stands for error function. Note that erf $(0)=0$, so that

$$
\ddot{\bar{\chi}}(r, \tau) \underset{\tau \rightarrow \infty}{\longrightarrow} \bar{\chi}(r) \text {. }
$$

Also, erf $(\infty)=1$, so that, in general, for finite values of $\tau, \bar{\chi}(r, \tau)$ falls off more rapidly than $\bar{\chi}(r)$, as is physically desirable for finite-duration calm periods. In addition to the source term given by Eq. 3.6, the first groundreflected image and the first lid-reflected image are also calculated and the convergence is tested. If the convergence is poor, then $\bar{\chi}(r, \tau)$ is used.

There is somewhat of an inconsistency in the way this special lowwind-speed function is used in the present computer code, whereas, the calm algorithm is used whenever $u<l \mathrm{mph}$. The plume-rise formula user (see Sect. 2.6) is not really valid for $u<4 \mathrm{mph}$, Up to the praeent, no uttempt has been made to incorporate one of the more recent plume-rise formulas especially designed for calm periods as given, for example, by Briggs. ${ }^{23}$ 


\section{EFFECT OF CALM ALGORITHM}

To illustrate the effect of the use of the calm algorithm (CA) given by Eqs. 3.6 and 3.7, we have selected a historical air-pollution episode: February 16-18,1967. The wind speeds recorded at TAM:5 (see Fig. I) are shown in Fig. 8. Table 4.1 shows the analys is of the results for three different choices of the parameter $T$ (see Eqs. 3.6 and 3.7), which depict the effective duration of the calm. (See Appendix $D$ for the definition of the symbols labeling the columns of the table.) For $\tau=0$, the CA is suppressed. Because only a relatively small percentage of the total number

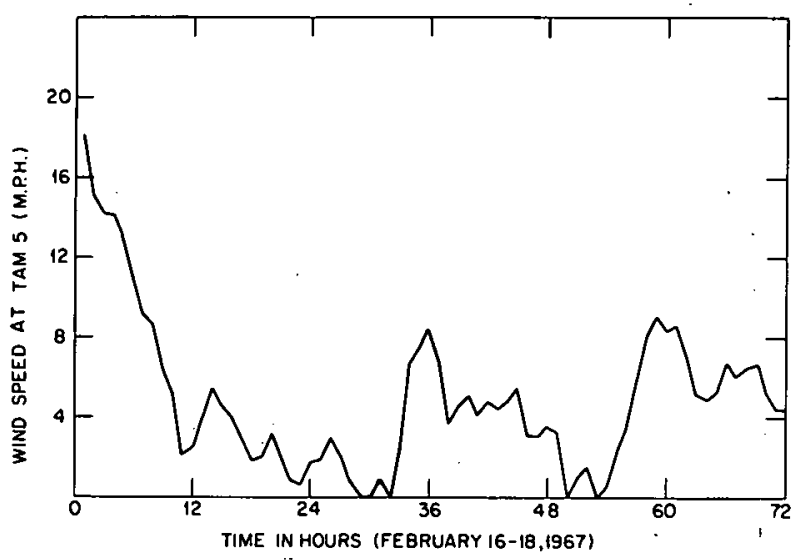

Fig. 8. Wind Speed Measured at TAM 5 Aerovane vs Time of Day, for February 16-18, 1967. ANL Neg. No. 190-141 Rev. 1. of hours have $\mathrm{u} \leq 1 \mathrm{mph}$ (when the CA is turned on), the percentile dis tribution is not very sensitive to the changes in the calculated results brought about by the use of the calm expressions: However, the relative standard deviations $\sigma_{o e} / \mu_{o}{ }^{*}$ and, in these cases, the means* are quite sensitive to the changes in the results. The reductions in means follow from the reduction in the peak values of the concentrations occurring during calms. The fact that for TAM 2 and 4 the means were in better agreement without the CA arises from the general

TABLE 4.1. Effect of Calm Algorithm on Hourly Calculations with Steady-state Plume Model for Episode of February 16-18, 1967a

\begin{tabular}{cccccccc}
\hline TAM & Code $^{b}$ & $\mu_{\mathrm{o}}$ & $\mu_{\mathrm{e}}$ & $\sigma_{\mathrm{oe}} / \mu_{\mathrm{o}}$ & PN025 & PN05 & PN1 \\
\hline 2 & 1 & 0.19 & 0.18 & 0.81 & 0.29 & 0.50 & 0.65 \\
& 2 & & 0.15 & 0.75 & 0.29 & 0.49 & 0.62 \\
& 3 & & 0.16 & 0.73 & 0.29 & 0.49 & 0.63 \\
4 & 1 & 0.26 & 0.25 & 1.31 & 0.06 & 0.14 & 0.41 \\
& 2 & & 0.14 & 0.65 & 0.07 & 0.14 & 0.42 \\
& 3 & & 0.15 & 0.61 & 0.07 & 0.14 & 0.43 \\
5 & 1 & 0.09 & 0.25 & 5.07 & 0.32 & 0.58 & 0.68 \\
& 2 & & 0.10 & 0.97 & 0.38 & 0.64 & 0.78 \\
& 3 & & 0.10 & 0.93 & 0.38 & 0.67 & 0.78 \\
\hline
\end{tabular}

${ }^{a}$ See Appendix $D$ for definitions of column headings.

bCodes 1,2 , and 3 mean no calm algorithm and calm algorithm with $\tau=1$ and $\tau=2$, respectively.

*See Appendix D for definitions of these quantities. 
underprediction of the plume model during the period which was compensated by the greatly overpredicted concentrations during the calms (because of the ill behavior of the plume expression as $u \rightarrow 0$ ). Although this compensation of errors is tolerable in long-term analysis, it is undesirable for an episode or short-term model. The reduction in the relative standard deviation of differences between the hourly observed and calculated results as the $\mathrm{CA}$ is turned on clearly indicates how the results are improved. Figures 911 show graphs of the calculated and observed hourly concentrations. The solid curves are the observed results, the open squares are the calculated plume results without the CA, and the stars are the plume model results with the CA (using $\tau=2 \mathrm{hr}$ ). The stars overlap the open squares when $\mathrm{u}>\mathrm{lmph}$.

The narrow peaks shown in these curves are the result of power plants, which happen to be upwind of the stations for the particular wind directions. The narrowness of these peaks results from the extreme sensitivity to small changes in the wind direction. The small displacement in time of the calculated from the observed power plant plume peaks results from the fact that, due to inhomogeneities in the wind field, the wind direction, which is slowly changing, is not the same, even synoptically, at the receptor and power plants. This is discussed further in Sect. 8.2.

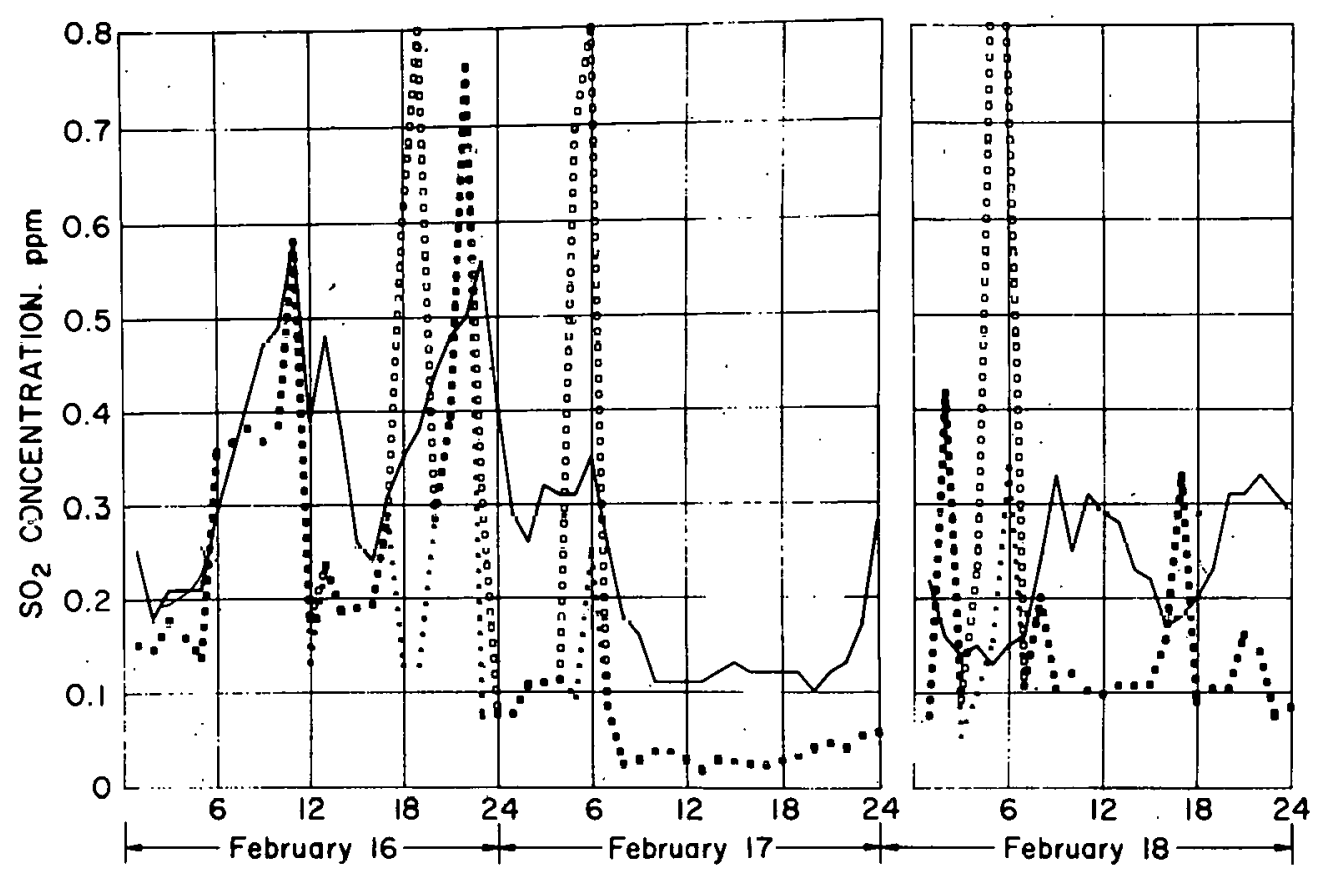

Fig. 9. Observed (solid curve) and Calculated Hourly Concentrations at TAM 4 for February 16-18, 1967, Using Plume Model with (stars) and without (open squares) Calm Algorithm. Stars overlap squares when $u>1 \mathrm{mph}$. Symbol spacing not related to plotted points. 


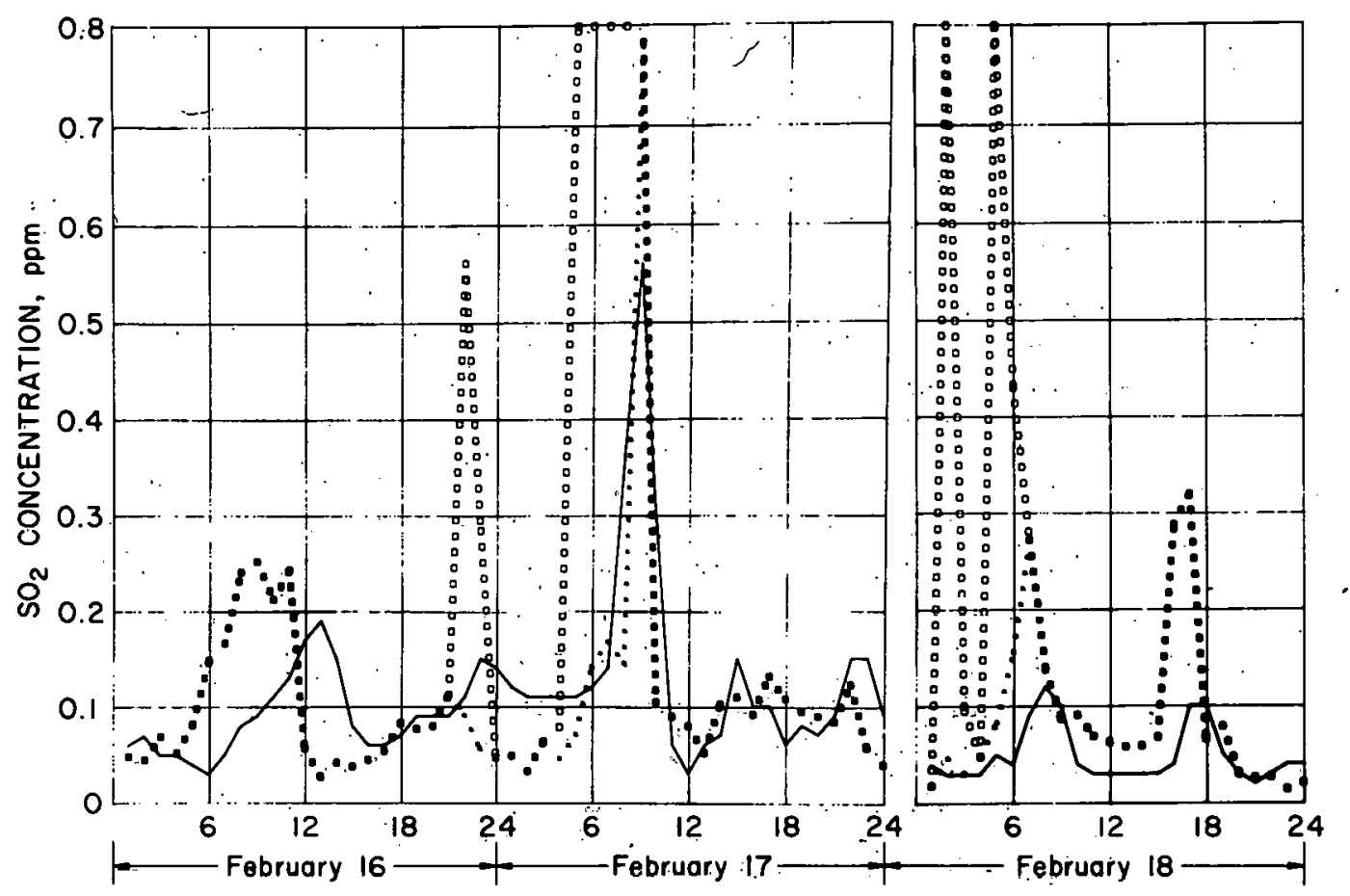

Fig. 10. Observed (solid curve) and Calculated Hourly Concentrations at TAM 5 for February 16-18, 1967, Using Plume Model with (stars) and without (open squares) Calm Algorithm. Stars overlap squares when $u>1 \mathrm{mph}$. Symbol spacing not related to plotted points:

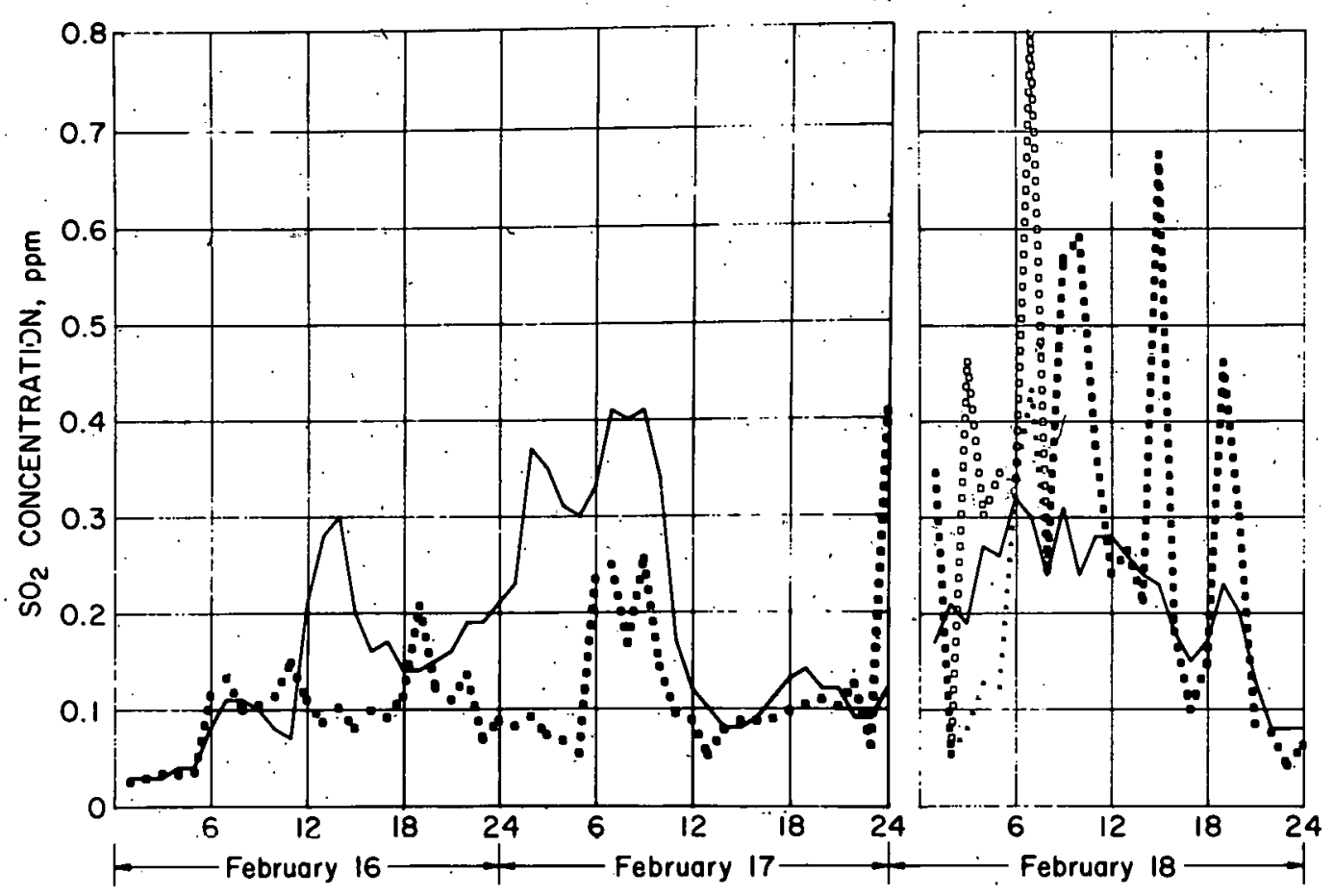

; Fig. 11. Observed (solid curve) and Calculated Hourly Concentrations at TAM 2. for February 16-18, 1967, Using Plume Model with (stars) and without (open squares) Calm Algorithm. Stars overlap squares when $\mathrm{u}>1 \mathrm{mph}$. Symbol spacing not related to plotted points. 


\section{COMPARISON OF RESULTS OF PUFF - AND PLUME-MODEL CALCULATIONS}

To compare the performance of the plume with the more sophisticated puff model (which requires substantially more computer time), we have selected a variety of historical periods which include a wide range of meteorological conditions. In particular, we have carried out statistical analyses on the short- and long-term basis.

The two models share all but one small part of a substantial computer code in common, so that a similarity in the quality of fit of the puffand plume-model calculations to the observed data is to a large extent indicative of the quality of simulation produced by the common aspects of the computer codes. One expects at the onset that only where the steadystate conditions are far from the truth will there be any substantial dis crepancies between the two models. We first present the results of some short-term calculations, followed by the results of calculation on a monthly basis. (The symbols used to depict various statistical quantities are defined in Appendix D.)

\subsection{Short-term Comparisons}

We first present a situation which is not atypical, where the puff and plume models show similar results. Figures 12 and $13^{*}$ compare the $\mathrm{SO}_{2}$ concentrations observed (solid curves) at TAM 2 and 4 on January 18 19, 1967, with those calculated with the puff model (open squares) and with the plume model (stars). The corresponding wind speeds were $\geq 2.5 \mathrm{mph}$. so that the calm algorithm was not used. TAM 2 showed a minimum wind speed of $5 \mathrm{mph}$ from 1000 to 1400 on January 18; TAM 4 indicated a minimum wind speed of $2.5 \mathrm{mph}$ on the same day at 1200 and 2000 . Note that the agreement between the two models is quite close.

By way of contrast with January 18-19. the period of February 16 18, 1967, which was used to evaluate the calm algorithm in Sect. 4 , includes a number of hours of very low wind speed (see Fig. 8). Figure 14 shows the hourly concentrations calculated at TAM 5 with the puff and plume (with the calm algorithm) models for this period. Calculations at TAM 2, 4, and 5 are compared statistically in Table 5.1. This analys is indicates that in the absence of the CA the two models differ substantially, whereas with the inclusion of the CA both models are in good agreement on the short-term basis.

*In Figs. 12 and 13,3-hr average concentrations are plotted. For example, the average of the concentrations at hours 1,2 , and 3 is plotted at hour 2 , the average of the concentrations at hours 4,5 , and 6 is plotted at hour 5 , etc. 


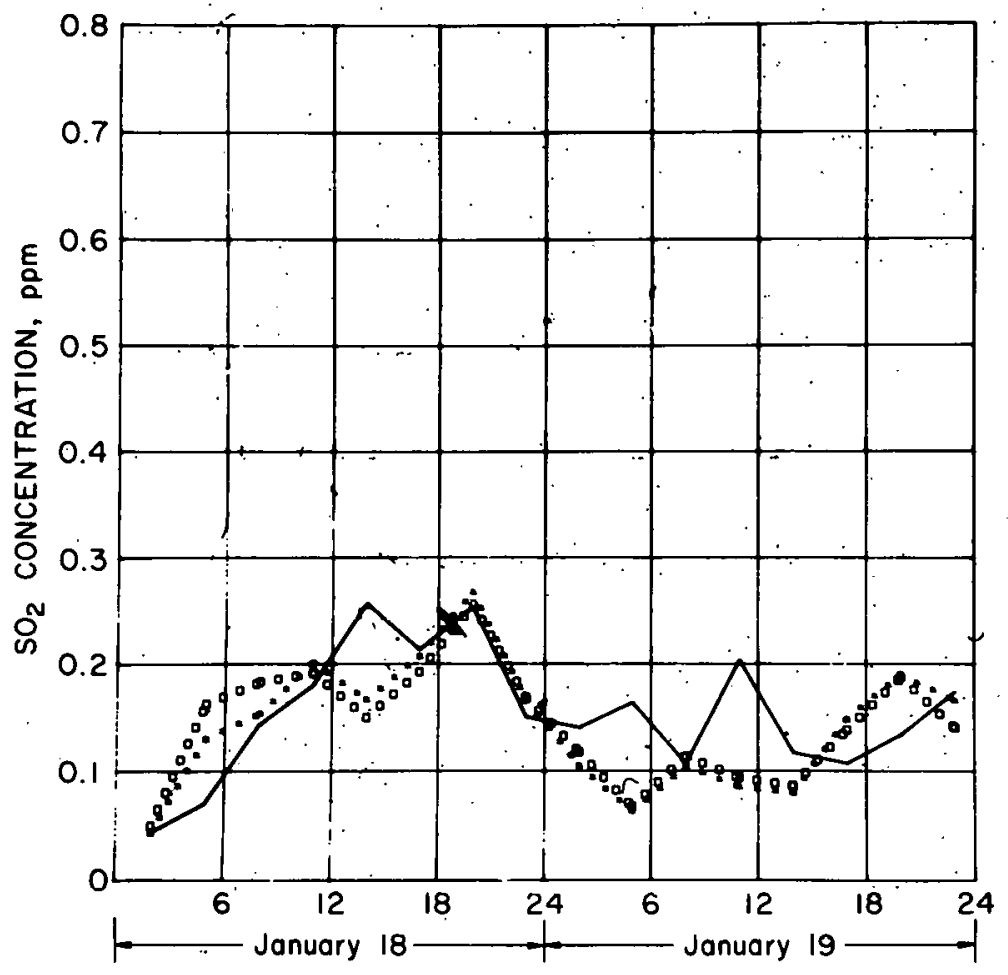

Fig. 12

$\mathrm{SO}_{2}$ Concentrations at TAM 2 vs Time of Day, for January 18-19,1967. Threehour average concentrations are plotted. The solid curve is the observed, the open squares the puff-model, and the stars the plume-model calculations.

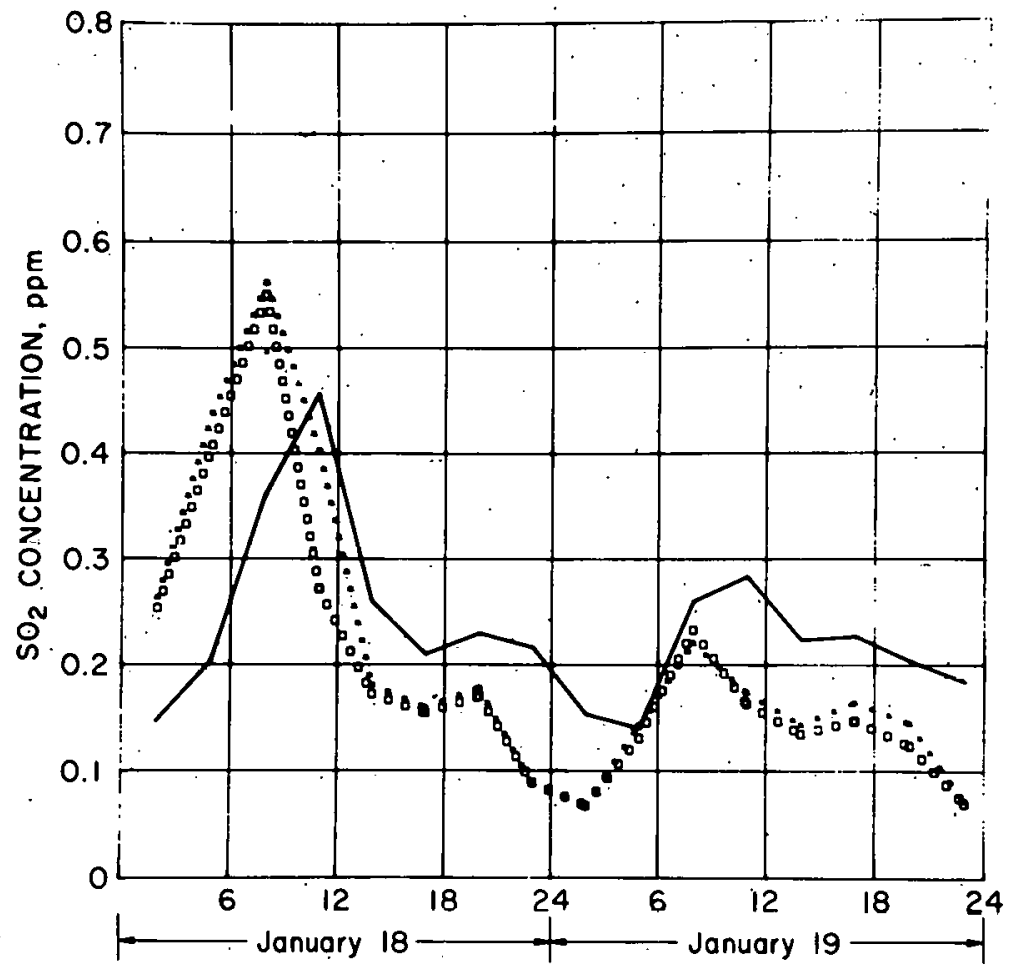

Fig. 13. $\mathrm{SO}_{2}$ Concentrations at TAM 4 vs Time of Day, for January 18-19, 1967. Three-hour average concentrations are plotted. The solld curve is the observed, the open squares the puff-model, and the stars the plume-model calculations. 


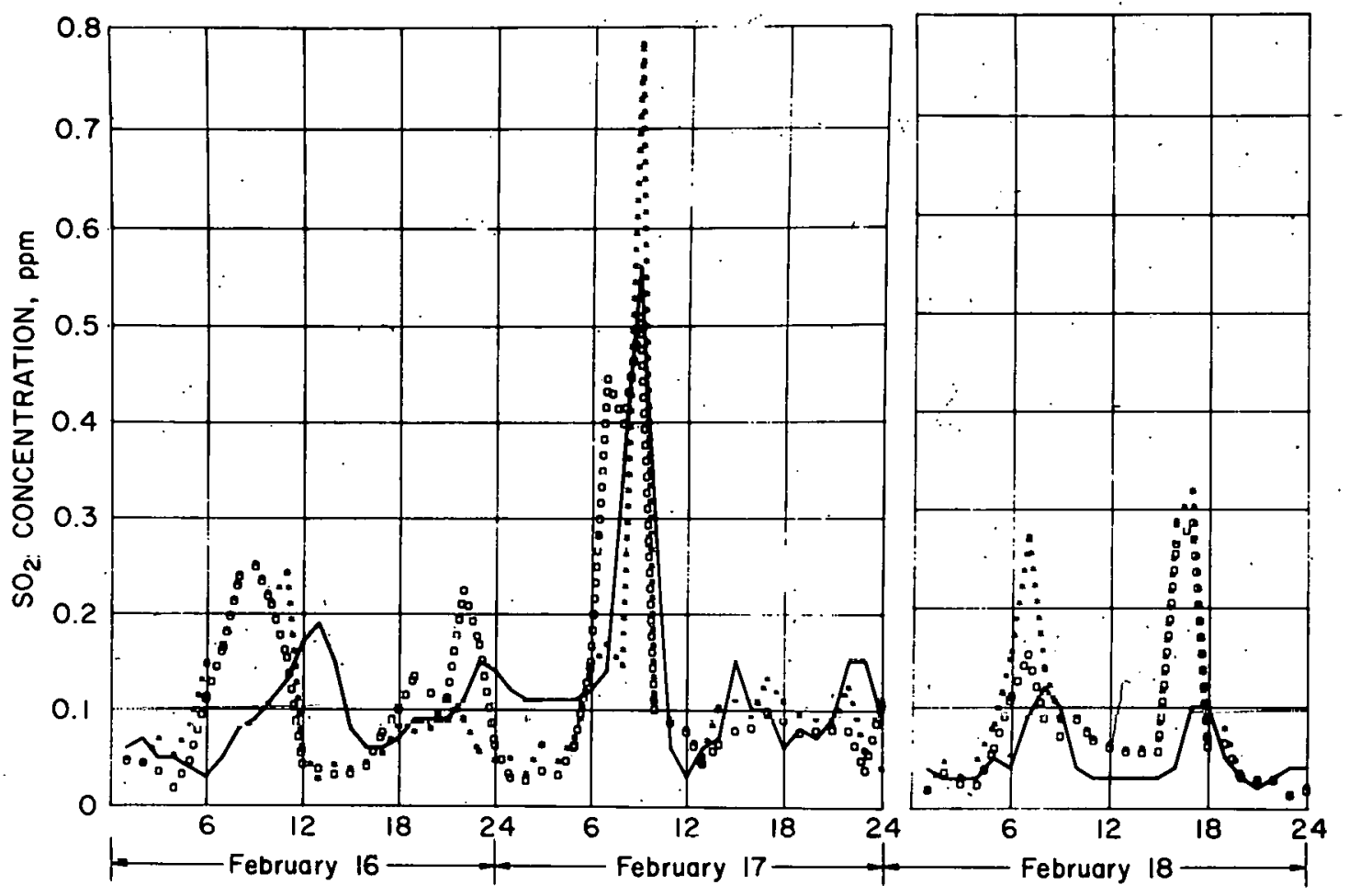

Fig. 14. $\mathrm{SO}_{2}$ Concentrations at TAM 5 vs Time of Day, for February $16-18,1967$. Hourly average concentrations are plotted. The solid curve is the observed, the open squares the puffmodel, and the stars the plume-model calculations with the calm algorithm.

TABLE 5.1. Comparison of Hourly Results of. Puff (1), Plume (2), and Plume + CA (3) Calculations with Observations for February 16-18, 1967

\begin{tabular}{ccccccccc}
\hline TAM & $\mu_{U}$ & Model & $\mu_{\rho}$ & $\sigma_{\text {ne }} / \mu_{0}$ & su\% & PNO25 & PN05 & PNI \\
\hline \multirow{2}{*}{5} & 0.09 & 1 & 0.10 & $0.8 \%$ & 56 & 36 & 68 & 82 \\
& & 2 & 0.25 & 5.07 & 47 & 32 & 58 & 68 \\
& & 3 & 0.10 & 0.93 & 53 & 38 & 67 & 78 \\
2 & 0.19 & 1 & 0.13 & 0.61 & 60 & 30 & 51 & 72 \\
& & 2 & 0.18 & 0.81 & 60 & 30 & 50 & 65 \\
& & 3 & 0.16 & 0.73 & 56 & 29 & 49 & 63 \\
4 & 0.26 & 1 & 0.14 & 0.65 & 21 & 3 & 10 & 40 \\
& & 2 & 0.25 & 1.32 & 28 & 6 & 14 & 42 \\
& & 3 & 0.15 & 0.61 & 28 & 7 & 14 & 43 \\
\hline
\end{tabular}

\subsection{Long-term Comparisons}

Table 5.2 compares puff- and plume-model calculations for Tanuary (only one-half month of data was available for TAM 5). The comparisons were carried out for $\mathrm{n}=1-, 6-$, and 24-hr average concentrations. With the exception of the relative standard deviations for TAM 5, all indications are that both models produce similar results on the long-term basis. Note that the calm algorithm was not used in the steady-state plume model. Actually there were only $\mathrm{l}$ or $2 \mathrm{hr}$ during January when it would have been 
used anyway. There were $2 \mathrm{hr}$ during which $\mathrm{u} \leq 1 \mathrm{mph}$ at TAM 5 and the peak concentrations that occurred during these periods, along with a few other narrow but grossly overestimated power-plant peaks, resulted in the distortion of the values of $\sigma_{\mathrm{oe}} / \mu_{\mathrm{o}}$ indicated for TAM 5 in Table 5.2. The quantity $\sigma_{o e} / \mu_{0}$ is sensitive to the occurrence of a few large discrepancies, which generally will not show up very clearly in the percentile figures given.

TABLE 5.2. Comparison of Observed and Calculated $\mathrm{SO}_{2}$ Concentrations for January $1967^{\mathrm{a}}$

\begin{tabular}{|c|c|c|c|c|c|c|c|c|}
\hline TAM & $\begin{array}{c}\text { Averaging } \\
\text { Interval, } \\
\mathrm{hr}\end{array}$ & $\begin{array}{l}\mu_{0}, \\
\mathrm{ppm}\end{array}$ & $\begin{array}{c}\mu_{\mathrm{e}}, \\
\mathrm{ppm}\end{array}$ & $\sigma_{\text {oe }} / \mu_{0}$ & $50 \%$ & PN025 & PN0 5 & PN 1 \\
\hline 2 & $\begin{array}{r}1 \\
6 \\
24\end{array}$ & 0.12 & $\begin{array}{l}0.10 / 0.11 \\
\ddots\end{array}$ & $\begin{array}{l}0.65 / 0.69 \\
0.52 / 0.48 \\
0.35 / 0.33\end{array}$ & $\begin{array}{l}59 / 63 \\
66 / 71 \\
79 / 84\end{array}$ & $\begin{array}{l}39 / 44 \\
50 / 54 \\
53 / 53\end{array}$ & $\begin{array}{l}71 / 67 \\
75 / 78 \\
90 / 84\end{array}$ & $\begin{array}{l}86 / 86 \\
92 / 92 \\
95 / 100\end{array}$ \\
\hline 4 & $\begin{array}{r}1 \\
6 \\
24\end{array}$ & 0.15 & $0.15 / 0.17$ & $\begin{array}{l}0.56 / 0.66 \\
0.41 / 0.47 \\
0.28 / 0.30\end{array}$ & $\begin{array}{l}6.9 / 73 \\
85 / 83 \\
93 / 100\end{array}$ & $\begin{array}{l}30 / 32 \\
38 / 33 \\
60 / 47\end{array}$ & $\begin{array}{l}53 / 52 \\
65 / 58 \\
80 / 73\end{array}$ & $\begin{array}{c}83 / 83 \\
92 / 88 \\
100 / 100\end{array}$ \\
\hline 5 & $\begin{array}{r}1 \\
6 \\
24\end{array}$ & 0.06 & $0.06 / 0.08$ & $\begin{array}{l}0.91 / 1.70 \\
0.63 / 1.01 \\
0.41 / 0.75\end{array}$ & $\begin{array}{l}51 / 53 \\
65 / 60 \\
80 / 67\end{array}$ & $\begin{array}{l}54 / 52 \\
60 / 53 \\
73 / 47\end{array}$ & $\begin{array}{l}72 / 73 \\
83 / 75 \\
93 / 87\end{array}$ & $\begin{array}{r}93 / 90 \\
95 / 93 \\
100 / 93\end{array}$ \\
\hline
\end{tabular}

${ }^{a}$ The calculated results are given as PUFF/PLUME.

In general, the plume-model concentrations tend to be greater than those of the puff model.

Table 5.3 shows the results of calculations for August 1967, using both the puff and plume models compared with observed results.

TABLE 5.3. Comparison of Observed and Calculated $\mathrm{SO}_{2}$ Concentrations for August $1967^{\mathrm{a}}$

\begin{tabular}{cccccccc}
\hline & $\begin{array}{c}\text { Averaging } \\
\text { Interval, } \\
\text { hr }\end{array}$ & $\begin{array}{c}\mu_{\mathrm{o}}, \\
\mathrm{ppm}\end{array}$ & $\begin{array}{c}\mu_{\mathrm{e}}, \\
\mathrm{ppm}\end{array}$ & $\sigma_{\text {oe }} / \mu_{0}$ & $50 \%$ & PN025 & PN05 \\
\hline 2 & 1 & 0.02 & $0.03 / 0.03$ & $1.37 / 1.87$ & $35 / 33$ & $75 / 71$ & $90 / 87$ \\
& 6 & & & $1.04 / 1.45$ & $42 / 46$ & $82 / 75$ & $96 / 91$ \\
& 24 & & & $0.71 / 1.05$ & $58 / 42$ & $95 / 79$ & $100 / 100$ \\
4 & 1 & 0.04 & $0.02 / 0.03$ & $1.06 / 1.11$ & $28 / 33$ & $71 / 74$ & $86 / 87$ \\
& 6 & & & $0.90 / 0.75$ & $31 / 40$ & $72 / 79$ & $85 / 90$ \\
& 24 & & & $0.71 / 0.51$ & $35 / 58$ & $65 / 81$ & $96 / 96$ \\
5 & 1 & 0.02 & $0.02 / 0.04$ & $1.45 / 3.01$ & $27 / 29$ & $70 / 60$ & $89 / 80$ \\
& 6 & & & $1.19 / 2.41$ & $38 / 28$ & $72 / 60$ & $92 / 83$ \\
& 24 & & & $0.94 / 1.73$ & $50 / 59$ & $91 / 77$ & $96 / 86$ \\
\hline
\end{tabular}

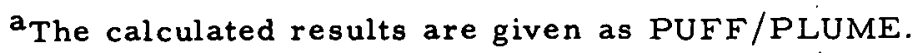

Unfortunately, the steps used in the percentile distribution analysis having been chosen for wintertime concentrations were much too large for 
the substantially smaller summertime values, which are often close to the limits of observational accuracy $( \pm 0.01 \mathrm{ppm})$. The puff model is superior, especially for TAM 5, which generally has very low summertime concentrations, except when TAM 5 comes under the influence of power-plant : plumes. The nearest power plant is about 3 miles away. The plume model did not include the calm algorithm, so that on several occasions when the wind speed fell below $1 \mathrm{mph}$, the calculated concentrations became unrealistically high.

The relative standard deviation is probably not a good quantity to use when $\mu_{0} \rightarrow 0$, since it blows up. For concentrations averaging $0.02 \mathrm{ppm}$, it is probably more reasonable to look at absolute errors as, for example, indicated by PN025 (the percent of the total number of differences between observed and calculated values within $0.025 \mathrm{ppm}$ ). The $50 \%$ figure, which is the percent of all differences within $50 \%$ of the corresponding observed values, is also somewhat misleading because many observed values are zero, and a.nonzero calculated value no matter how small obviously would not be within $50 \%$ of zero. 


\section{DISCUSSION OF PLUME-AND PUFF-MODEL RESULTS}

In Sect. 5 we have presented several comparisons of the results of the steady-state plume model with observed $\mathrm{SO}_{2}$ concentrations. We have also compared these results with those of puff-model calculations, which consume substantially more computer time. The general conclusions that can be drawn. from these comparisons are, first, that both models perform very well when compared with observations on both the short- and longterm basis. Marsh and Withers ${ }^{24}$ have made a comparative study of several dispersion models, including their own versions plus those of several other authors. Comparing the results of $6-\mathrm{hr}$ average concentrations in terms of $\sigma_{o e} / \mu_{0}$, they found that the minimum value was 1.12 . For January, the corresponding values for the puff model range from 0.41 to 0.63 , and for the plume model from 0.47 to 1.01 (see Table 5.2). Second, the use of the calm algorithm for very low wind speeds ( $\leq 1 \mathrm{mph}$ ) makes à significant improvement in the plume model on the short-term basis. Third, by including the calm algorithm with the plume model, there is remarkably little difference between the calculated results of the latter model with those of the puff model, even when $\mathrm{u} \leq 1 \mathrm{mph}$.

Considering the increased sophistication of the puff model as well as its physical reasonableness, it is worth commenting on the relationship between the two models. Unfortunately, the puff kernel cannot be integrated analytically: in general. However, under special conditions, one can treat the integral analytically in an approximate way. This is done in Sect. 7. In the present discussion, only some rather general remarks will be made.

The near equivalence of the puff- and plume-model results has been shown only for a complete urban source-emission inventory. In particular, the Chicago inventory is characterized by source-receptor distances averaging less than 10 miles, so that at a wind speed of $10 \mathrm{mph}$, one expects, on the average, that steady-state conditions will be established within $\mathrm{l}$ hr or less between most source-receptor pairs and certainly between a receptu and its corresponding local sources. Furthermore, a receptor within the urban area is subject to a superposition of a nearly isotropic distribution of local area sources as well as a very direction-dependent array of major point sources, generally $1-10$ miles away. Unless one or more of these point sources are upwind of the receptor, most of the concentration will be due to the more local area sources. Consequently, except for certain wind directions, one is primarily concerned with transport distances of only a few miles and corresponding transit times substantially under $1 \mathrm{hr}$. Hence, the time step of $\mathrm{l} \mathrm{hr}$ is more than adequate to establish steady-state conditions, assuming, of course, that the meteorological conditions and emission rates remain constant for the entire l-hr interval. The establishment of steady-state conditions implies that one does not have to worry about causality, that is, the delay time required for transport of a plume segment from source to receptor. The question of causality only arises when the 
transit time is equal to or greater than the time step since, then, not enough time will have elapsed during the time step to allow sufficient overlapping of a consecutive train of puffs to produce a steady-state condition. This point will be illustrated fully in Sect. 7 .

Since the wind direction frequently remains constant for periods longer than $\mathrm{l} \mathrm{hr}$, one could allow for longer transit times in the plume model by increasing the time step accordingly at the expense of reduced time and spatial resolution. Alternatively, one could invoke the causality condition and simply ignore a source-receptor pair whenever $\mathrm{x} / \mathrm{u}>$ the time step. Unfortunately, if the wind continues to blow in the same direction during the next hour, then during that hour the plume may reach the receptor. Frall, one would be forced to track the plume in some effective way hour by hour, as is done. in the model of Koogler et al..$^{25}$ or in the more sophisticated pivoting plume model of. Turner." However, as the present study indicates, at least for source distributions such as is found in Chicago, it does nnt. seem to be the degree of sophistication of the transfer function that limits the accuracy of the model (the puff model is even more sophisticated than either of the above referenced models), but rather the combination of the remaining computer-code components plus the source inventory and meteorological input data.

Hence, for a given urban area, provided that $x / u$ does not exceed $1 \mathrm{hr}$ very often, the plume model with the calm algorithm to take care of cases in which $u \leq 1 \mathrm{mph}$ has been shown to be a reliable source-oriented dispersion model, useful for both short- and long-term analysis. 


\section{RELATIONSHIP BETWEEN PUFF AND PLUME EXPRESSIONS}

The similarity of the results of the integrated-puff and plume models indicates that there must be an underlying relationship between the basic mathematical expressions given by Eqs. 2.2 and 2.3. To better understand this relationship, we have analytically and numerically investigated the se expressions applied to a single source-receptor pair. The underlying basis for these investigations is the recognition that the primary ingredient of the puff kernel, namely,

$$
\exp \left\{-\left[(x-u T)^{2} / 2 \sigma_{x}^{2}(T)\right]\right\}
$$

is peaked about the value of the delay time $T=x / u$, which is just the transit time. Furthermore, this expression falls off exponentially for longer or shorter travel times $T$. Consequently, the major contribution to the concentration at a receptor in Eq. 2.2 comes from a range of values of $\mathrm{T}$ given roughly by $\mathrm{x} / \mathrm{u}-\sigma(\mathrm{x} / \mathrm{u})<\mathrm{T}<\mathrm{x} / \mathrm{u}+\sigma(\mathrm{x} / \mathrm{u})$. This expression is not really symmetric about $x / u$ because of the distortion caused by $\sigma_{x}(T)$. That is, the older puffs are larger than the younger ones. By rewriting the exponential argument as $(\mathrm{x} / \mathrm{u}-\mathrm{T})^{2} /\left[2\left(\sigma_{\mathrm{x}}(\mathrm{T}) / \mathrm{u}\right)^{2}\right]$ we can see that the wind speed $u$ scales the rate of fall-off of the integrand from its peak value. The smaller $u$ is, the larger will be the range of $T$ over which the integrand in Eq. 2.2 will contribute significantly. Hence, at low wind speed not only does the transit time $\mathrm{x} / \mathrm{u}$ become large but; so does the time required to achieve steady state. Consequently, the plume model is less satisfactory than the puff model at low wind speeds, both because of the wind-speed dependence of the plume expression (see Sect. 2.4) and because of the effect of the transit time described above, which is really a causality condition.

Section 7.1 presents an analytical analysis of the relationship between the puff and plume expressions under rather specialized conditions. This is followed by some numerical experiments.

\subsection{Analytical Analysis of Relationship between Puff and Plume Expressions}

For this analysis, we shall consider the case of constant meteorological conditions and a constant emission rate. For convenience, we average over the mixing layer (of depth $H$ ) to remove the dependence on the coordinate $\mathrm{z}$. Finally, we ignorc the exponential decay factor. Under these conditions, Eq. 2.2 for the integrated puff becomes

$$
\frac{\mathrm{H} X}{\mathrm{Q}}=\int_{0}^{T} \frac{\mathrm{dT}}{2 \pi \sigma_{\mathrm{y}}^{2}(\mathrm{~T})} \exp \left[-\frac{(\mathrm{x}-\mathrm{uT})^{2}+\mathrm{y}^{2}}{2 \sigma_{\mathrm{y}}^{2}(\mathrm{~T})}\right] \text {. }
$$


The corresponding plume expression is

$$
\frac{H \cdot \chi}{Q}=\frac{1}{\sqrt{2 \pi} u \sigma_{y}(x / u)} \exp \left\{-\left[y^{2} / 2 \sigma_{y}^{2}\left(\frac{x}{u}\right)\right]\right\} \text {. }
$$

For convenience, we as sume

$$
\sigma_{\mathbf{x}}(T)=\sigma_{y}(T)=a T^{b}
$$

A Taylor expansion of the puff kernel about the delay time $T=\frac{\mathbf{x}}{\mathrm{u}}$ is given by

$$
\begin{aligned}
\exp \left[-\frac{(\mathrm{x}-\mathrm{u} T)^{2}+\mathrm{y}^{2}}{2 \mathrm{a}^{2} \mathrm{~T}^{2 b}}\right] & =\mathrm{e}^{-\eta}\left\{1+\frac{\mathrm{T}-\mathrm{x} / \mathrm{u}}{\mathrm{x} / \mathrm{u}} 2 \mathrm{~b} \eta+\frac{1}{2}\left(\frac{\mathrm{T}-\mathrm{x} / \mathrm{u}}{\mathrm{x} / \mathrm{u}}\right)^{2}\right. \\
& \left.\mathrm{x}\left[(2 \mathrm{~b} \eta)^{2}-\frac{14}{4}(2 \mathrm{~b})^{2} \eta-\frac{2 \mathrm{x}^{2}}{2 \mathrm{a}^{2}\left(\frac{\mathrm{x}}{\mathrm{u}}\right)^{2 \mathrm{~b}} i}\right]+\ldots\right\}
\end{aligned}
$$

where

$$
\eta=y^{2} /\left[2 a^{2}\left(\frac{x}{u}\right)^{2 b}\right]
$$

We now assume, consistent with the Taylor expansion, that the major contribution to the integral comes from the range $\mathrm{x} / \mathrm{u}-\delta_{-} \leq \mathrm{T} \leq \mathrm{x} / \mathrm{u}+\delta_{+}$. Where the small quantities $\delta_{-}$and $\delta_{+}$are yet to be determined.

Substituting Eq. 7.4 into Eq. 7.1 yields

$$
\frac{\chi_{H}}{Q}=\int_{\frac{x}{u}-\delta}^{\frac{x}{u}+\delta_{+}} \frac{a T}{2 \pi a^{2} T^{2 b}} e^{-\eta}\left(1+\frac{T}{x / u} 2 b \eta+\ldots\right) .
$$

If we assume that $\delta .-\delta_{+}=\delta$, then buly the first tcrm in the expansion will contribute to lowest order in $\delta$ since it can be shown that, to order $\delta$,

$$
\int_{\frac{x}{u}-\delta}^{\frac{x}{u}+\delta} \frac{d T}{T^{2 b}}(T-x / u)^{n}=0 \text { for } n \geq 1
$$


Consequently, to order $\delta$,

$\frac{\chi H}{Q}=\frac{e^{-\eta}}{\pi \sigma^{2} \frac{x}{u}} \delta$.

Assuming $\delta_{+} \not \neq \delta_{-}$, what values should one use? Two conditions assist in the specification of the se quantities.

(1) Since $(T-x / u) /(x / u)<1$ for convergence of the Taylor expansion, and since $x / u-\delta$, and $x / u+\delta_{+}$are the limiting values of $T$, it follows that both $\delta_{+} /(\mathrm{x} / \mathrm{u})$ and $\delta_{-} /(\mathrm{x} / \mathrm{u})$ must be $<1$.

(2) The quantities $\delta_{-}$and $\delta_{+}$must be sufficiently large so that a substantial portion of the entire integral is contained within the integration limits.

Consider now the integrand

$I(T)=\exp \left[-\frac{(x-u T)^{2}}{2 a^{2} T^{2 b}}\right]$.

Obviously,

$\mathrm{I}(\mathrm{T}=\mathrm{x} / \mathrm{u})=1$,

and

$$
I(T=x / u \pm \epsilon)=\exp \left\{-\left[\frac{\epsilon}{\frac{\sqrt{2 a}}{u}\left(\frac{x}{u}\right)^{b}\left(1 \pm \frac{\epsilon}{x / u}\right)^{b}}\right]^{2}\right\}
$$

The values of $\epsilon$ for which

$$
\mathrm{I}(\mathrm{x} / \mathrm{u} \pm \epsilon)=\frac{1}{\mathrm{e}}(\mathrm{e}=2.71 \ldots)
$$

are now designated by $\delta_{-}$and $\delta_{+}$, where

$$
\text { and } \left.\begin{array}{rl}
\delta & =\delta\left(1-\frac{\delta-}{x / u}\right)^{b}=\delta\left[1-b\left(\frac{\delta}{x / u}\right)+b^{2}\left(\frac{\delta}{x / u}\right)^{2}-\ldots\right] \\
\delta_{+} & =\delta\left[1+b\left(\frac{\delta}{x / u}\right)+b^{2}\left(\frac{\delta}{x / u}\right)^{2}+\ldots\right]
\end{array}\right\}
$$

and where

$$
\delta=\frac{\sqrt{2} a}{u}\left(\frac{x}{u}\right)^{b}
$$


Again, if we only keep terms of order $\delta$ in Eqs. 7.9 then only the first term in Eq. 7.6 contributes.

To lowest order in. $\delta_{-}$and $\delta_{+}$, the first term in Eq. 7.6 gives

$$
\frac{\chi_{H}}{Q}=\frac{\exp \left[-y^{2} / 2 \sigma y^{2}(x / u)\right]}{\frac{\pi}{\sqrt{2}} \sigma_{y}(x / u) u}\left[1+\frac{b^{2} \delta^{2}}{x^{2} / u^{2}}+\ldots\right] \text {. }
$$

The important point about this expression is that the general, form, in particular the $1 / \mathrm{u}$ dependence, is the same as that of the plume expres sion. In addition, as long as $\delta$ remains small, the resemblance is quite close. The smallness of $\delta$ means that

$$
\frac{\delta}{\mathrm{x} / \mathrm{u}}<1
$$

which is the same criterion required for convergence of the Taylor expansion. Substituting Egs: 7.9 into Eq. 7.11 gives

$$
\sqrt{2} a\left(\frac{x}{u}\right)^{L}<\frac{x}{u}
$$

or

$$
\sqrt{2} \sigma_{y}\left(\frac{x}{u}\right)<x
$$

That is, the spread of the individual puffs is small compared to the downwind distance, or alternatively the diffusion rate is small compared to the advection rate. Evidently the lower the wind speed the worse the equivalence between the puff and plume expressions.

\subsection{Numerical Analysis of Relationship between Puff and Plume}

\section{Expressions}

To augment the anlytical analysis of Sect. 7.1, we have performed vevcral numerical experiments in which we calculate the concentrations for given source-receptor pairs (values of $x$ and $y$ ) and various values of thc wind speed $u$ and stability class (which determine the parameters $a$ and $b$ in Eq. 7.3). We calculate the concentration using, first, the plume expression (Eq. 7.2), and then the puff expression (Eq.7.1). The puff integral is evaluated at 5 -min intervals from the start of a continuous release of pollutant. Performing the calculations in this way, one is able to see the time dependence of the puff kernel and, in particular, the approach of the integrated puff kernel to the steady-state expression as time increases. 
Figures 15 and 16 show the value of $\chi_{H} / Q$ calculated from the puff expression given by Eq. 7.1 at receptors located 1, 5, and 10 miles downwind from a point source as a function of the time after start of a continuous release. The crosswind distance $y$ is zero in Fig. 15 and $1 / 4$ mile in Fig. 16. The wind speed $u$ is $5 \mathrm{mph}$ in both figures. Two values of the stability class (SC) are given, namely, I (very unstable) and 5 (quite stable). Several things are worth noting in these figures. First, the time required for the integrated-puff expression to reach steady state is strongly dependent on the downwind distance $x$ and somewhat less strongly dependent upon the crosswind distance y and stability class. Consequently, if one were working with a time step of $1 \mathrm{hr}$, then for $\mathrm{x}$ less than about 4 miles, steady-state conditions would essentially have been achieved, so that the puff and plume models would yield rather similar results. On the other hand, for distances $x$ in excess of 5 miles, the causality requirement be comes important and the assumption of steady state would clearly lead to an overprediction. Such would be the case for important distant sources such as power plants. Another point worth noting is that the rise time from essentially zero to maximum value of $\chi_{\mathrm{H}} / \mathrm{Q}$ depends both upon the stability class (increasing with decreasing stability) and the value of $\mathrm{x} / \mathrm{u}$. The dependence of the rise time on $x / u$ comes about from the fact that the greater the travel time the more adjacent puffs tend to overlap, so that the significant values of the integrand are spread over a wider time span. For $y=0.25$ mile, the concentration is actually greater at $x=1$ mile for the more unstable case, whereas at $x=5$ miles the concentration is greater for the more stable case. This is as one would expect.

Table 7.1 shows the results of a number of numerical experiments in which the puff and plume expressions (Eqs. 7.1 and 7.2 ; respectively) have been evaluated for a variety of values of $u, x, y$, and stability class. Both expressions agree over a remarkably wide range of these parameters, provided that an ample amount of time is permitted for steady-state conditions to be achieved. For $\mathrm{x}=1 \mathrm{mile}$ and $\mathrm{u}=5 \mathrm{mph}$, steady-state condi tions are reached in about $20-25 \mathrm{~min}$, whereas for $\mathrm{x}=5$ miles it takes about $1 \frac{1}{2} \mathrm{hr}$. In the latter case, using a basic time step of $1 \mathrm{hr}$, the. steady-state-model result would be greater than the puff-model result. However, if the same input conditions persisted for the next hour, then both the puff and plume models would agree. On the other hand, if there were a wind-direction shift after $1 \mathrm{hr}$, then again the plume model would overpredict the puff model. Hence, for the puff and plume models to produce substantially different results, two things are necessary. First, $x / u \geq$ basic time step, and second, the wind direction or other input data must change significantly from hour to hour. 


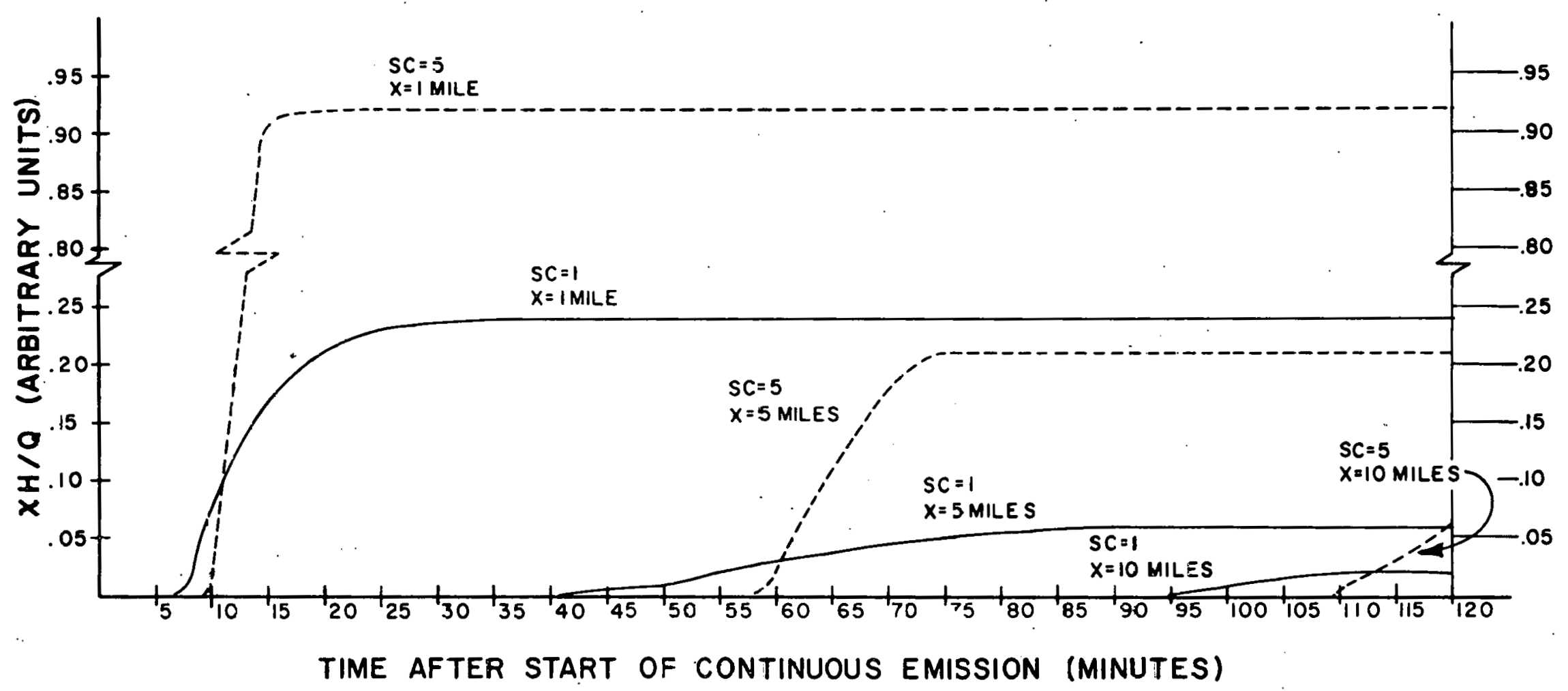

Fig. 15. $X \mathrm{H}_{.}^{\prime} \mathrm{Q}$ vs Time for the Integrated-puff Kernel as a Function of Stability Class $(\mathrm{S})$ and Downwind Eistance $(X)$ isæe Eq. 7.1); $u=5 \mathrm{mph}, \mathrm{y}=0.0$. ANL Neg. IJo. 130-169. 


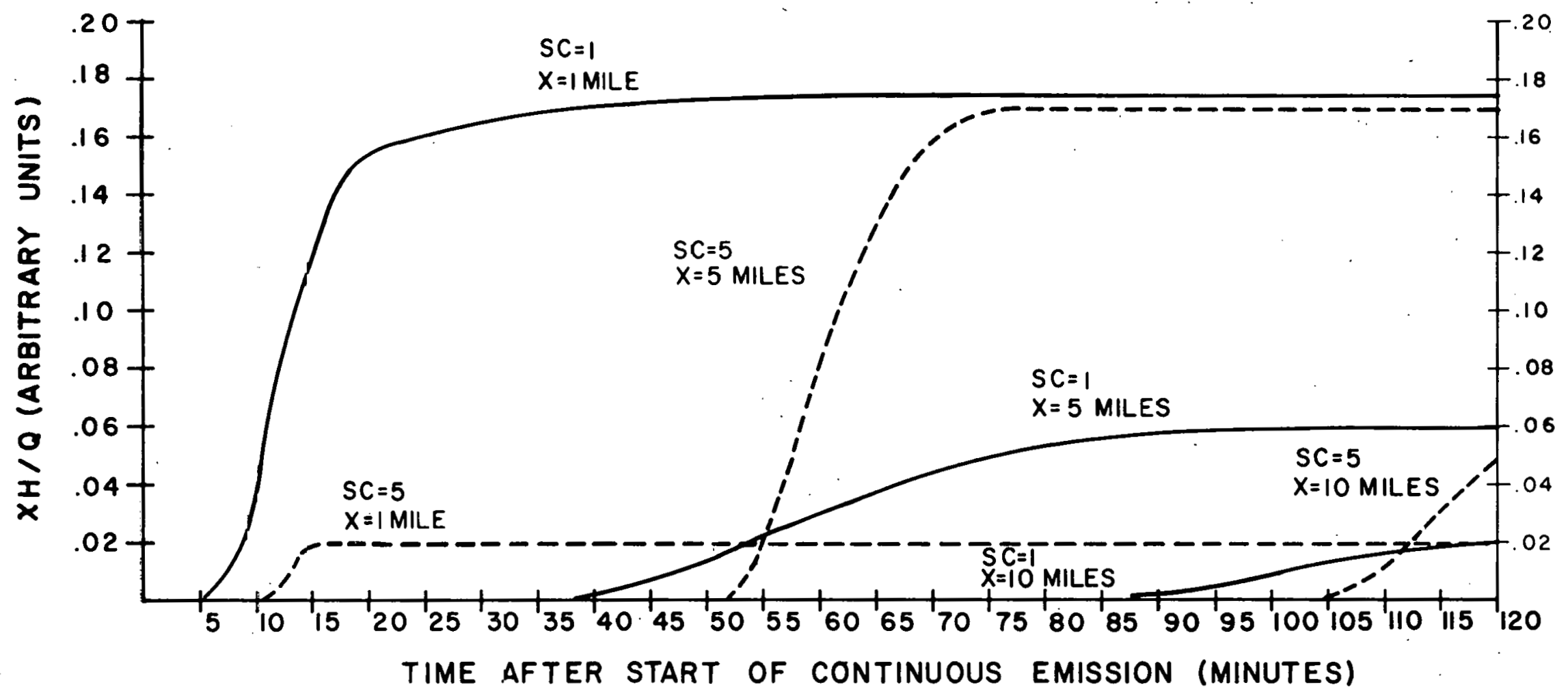

Fig. 16. $\mathrm{XH}_{\mathrm{H}} \mathrm{Q}$ vs -ime for the Integrated-puff Kernel as a Function of Stability Class (SC) and Downwind Distance $(X)$ (see Eq. 7.1); $u=5 \mathrm{mph}, y=0.25$ mile. ANL Neg. No. $190-171$. 
TABLE 7.1. Relationship between Puff and Plume Expressions for Various

Wind Speeds $u, C r o s s w i n d$ Distances $y$, and Downwind Distances $x$

\begin{tabular}{|c|c|c|c|c|c|c|c|c|c|c|c|c|c|}
\hline \multirow{3}{*}{$\begin{array}{c}\mathrm{u}, \\
\mathrm{mph}\end{array}$} & \multirow{3}{*}{ y, } & \multirow{3}{*}{$\begin{array}{l}\mathrm{x} \\
\mathrm{mi}\end{array}$} & \multirow{3}{*}{$\frac{\delta a}{x / u}$} & \multicolumn{5}{|c|}{ STABILITY CLASS 1} & \multicolumn{5}{|c|}{ STABILITY CLASS 5} \\
\hline & & & & \multirow{2}{*}{$\begin{array}{l}\mathrm{T} 10, \mathrm{~b} \\
\min \end{array}$} & \multirow{2}{*}{$\begin{array}{l}\mathrm{TP} \mathrm{P}_{1} \mathrm{c} \\
\min \end{array}$} & \multirow{2}{*}{$\begin{array}{l}\mathrm{T} 90, \mathrm{~b} \\
\min \end{array}$} & \multicolumn{2}{|c|}{$\chi_{H} / \Omega$} & \multirow{2}{*}{$\begin{array}{l}\mathrm{T} 10, \mathrm{~b} \\
\min \end{array}$} & \multirow{2}{*}{$\begin{array}{l}T P, C \\
\text { min }\end{array}$} & \multirow{2}{*}{$\begin{array}{c}\mathrm{T} 90^{\mathrm{b}} \\
\min \end{array}$} & \multicolumn{2}{|c|}{$\chi_{\mathrm{H}} / \mathbf{Q}$} \\
\hline & & & & & & & Puff & Plume & & & & Puff & Plume \\
\hline \multirow[t]{12}{*}{5} & 0 & 0.5 & 0.52 & 1 & 10 & 12 & 0.423 & 0.434 & 6 & $<10$ & $\therefore 10$ & 1.698 & 1.713 \\
\hline & & 1 & 0.47 & 7 & 15 & 17 & 0.236 & 0.241 & 12 & $<15$ & $<15$ & 0.922 & 0.918 \\
\hline & & 5 & 0.36 & 45 & 55 & 87 & 0.060 & 0.061 & 59 & 60 & 68 & 0.213 & 0.216 \\
\hline & & 10 & 0.33 & 92 & 115 & 160 & 0.032 & 0.034 & 111 & 120 & 132 & 0.114 & 0.116 \\
\hline & 0.25 & 0.5 & 0.52 & 3 & 10 & 13 & 0.174 & 0.172 &.- & - & - & 0 & 0 \\
\hline & & 1 & 0.47 & 9 & 15 & 22 & 0.175 & 0.181 & 12 & $<15$ & $<15$ & 0.017 & 0.014 \\
\hline & & 5 & 0.36 & 38 & 55 & 86 & 0.059 & 0.060 & 54 & 60 & 66 & 0.169 & 0.172 \\
\hline & & 10 & 0.33 & 87 & 115 & 161 & 0.032 & 0.034 & 110 & 120 & 129 & 0.107 & 0.108 \\
\hline & 0.50 & 0.5 & 0.52 & 7 & 10 & 19 & 0.033 & 0.011 & - &. & - & 0 & 0 \\
\hline & & 1 & 0.17 & 10 & 15 & 24 & 0.081 & 0.077 & - & $=$ & $=$ & 0 & 0 \\
\hline & & 5 & 0.36 & 43 & 55 & 89 & 0.056 & 0.057 & 56 & 65 & 67 & 0.086 & 0.087 \\
\hline & & 10 & 0.33 & 87 & $115^{\circ}$ & $: 162$ & 0.032 & 0.033 & 112 & 120 & 133 & 0.088 & 0.089 \\
\hline \multirow[t]{6}{*}{10} & 0 & 0.5 & 0.29 & $<5$ & $<5$ & $<5$ & 0.390 & 0.392 & 1 & $<5$ & $<5$ & 1.598 & 1.598 \\
\hline & & 1 & 0.26 & 4 & $<10$ & $<10$ & 0.213 & 0.217 & 7 & $<10$ & $<10$ & 0.856 & 0.856 \\
\hline & & 5 & 0.20 & 26 & 30 & 38 & 0.055 & 0.055 & 29 & 30 & 33 & 0.197 & 0.201 \\
\hline & $0 . \angle 3$ & 0.5 & $0.2 y$ & 1 & 5 & $y$ & 0.026 & 0.019 & - & - & - & 0 & 0 \\
\hline & & 1 & 0.26 & 6 & $<10$ & $<10$ & 0.086 & 0.085 & - & - & - & 0 & 0 \\
\hline & & 3 & 0.20 & 27 & 30 & 36 & 0.051 & U. U5L & 29 & $3 b$ & 33 & ن. نو & U.ن் I \\
\hline
\end{tabular}

a $\delta /(x / u)$ is the expansion parameter in the Taylor expansion (see Sect. 7.1 ).

${ }^{\mathrm{b}} \mathrm{T} 10$ and $\mathrm{T} 90$ are the times measured from the start of a continuous emission when the puff integral (evaluated at 5 -min intervals) reaches 10 and $90 \%$ of its final value, respectively.

${ }^{C} \mathrm{TP}$ is the time when the integrand reaches its peak value. 


\section{SENSITIVITY ANALYSIS OF STEADY-STATE PLUME MODEL}

This section presents an analysis of the effects of changing various meteorological input data on the calculated $\mathrm{SO}_{2}$ concentrations using the plume model. In particular, we have investigated the sensitivity of the results to replacing the TAM station aerovane measured winds with the Midway Airport measured winds. In addition, we have also studied the specific effects of changes in the wind direction measured at various TAM winds on calculated concentrations at those TAM stations. We also determined the effect of modifying the mixing height in accordance with the expected errors obtained in the comparative study ${ }^{18}$ of techniques for. estimating the mixing height.

\subsection{Use of Midway Wind Field}

The Chicago area is fortunate in having a network of TAM stations which continuously monitor the wind speed(WS) and wind direction (WD) as well as $\mathrm{SO}_{2}$ concentrations (and other pollutant species).* (See Ref. 1 for a description of the location of each TAM station.) Advantage is taken of these wind measurements in both the puff and plume models by using the winds. measured at the TAM station where $\mathrm{SO}_{2}$ concentrations are being calculated. (The wind-profile law is used to convert the wind at the TAM aerovane height to the effective stack height for each source.) In this way, some of the inhomogeneity in the Chicago area wind field (to the extent that any inhomogeneity exists; see Sect. 8.2 ) is taken into account. That an inhomogeneity in the wind field on a scale of several miles can be important comes about because the concentration at a particular receptor is the result of the superposition of pollutants emitted from a roughly isotropic distribution of local area sources plus a very direction-sensitive distribution of point sources. In fact, experience shows that peaks in the concentrations resulting from a gradual change in the wind direction that slowly sweeps a powerplant plume across a particular receptor are frequently calculated to occur at a WD several degrees displaced from the corresponding directions for which the peaks are actually observed. This could arise because the wind direction at the source is somewhat different from that at the receptor, which in turn could be due to an inhomogeneity in the wind field and/or possible local effects due to poor siting of the TAM aerovanes.

In any case, we wished to examine the eftect of using a wind field even less well defined than that which is specified by the TAM network. For this purpose, we chose to use the wind measurements taken at Midway Airport (see Fig . 1).

The effect of using the Midway winds instead of the TAM winds is examined in two ways. First, we compare calculations using Midway winds with observations to see statistically how the agreement between calcula:tions using TAM winds and observations is modified. Second, we compare 
Midway results directly with TAM results in the more usual sensitivity test fashion to see what difference the use of a less well-defined wind field makes.

In performing these comparisons, it became apparent that the windprofile law plays a significant part in this type of sensitivity study. Whereas the Midway winds are measured $20 \mathrm{ft}$ above ground, in a completely open area (the center of the Midway Airport), unobstructed by buildings for at least $1 / 4$ mile in all directions, the TAM aerovanes are located on $20-30-\mathrm{ft}$. masts atop three:- or four-story school buildings in an urban environment.

Consequently, not only are the heights substantially different, but so are the surface-roughness conditions and therefore the degree and character of mechanical turbulence. In addition, whereas the Midway winds are 1 -min averages; the TAM winds are continuously recorded and averaged over 15 -min intervals. Strong, ${ }^{26}$ however, claims that statistical analyses have shown that the 1 -min readings at the Midway aerovane are quite satisfactory.

We determined that the fairest way to perform the calculations was to apply the same wind-profile law to the Midway winds as to the TAM winds. The form of the wind-profile law used in our computer code is

$$
\frac{U\left(h_{\text {eff }}\right)}{U\left(h_{\text {aero }}\right)}=\left(\frac{h_{\text {eff }}}{h_{\text {aero }}}\right)^{P} \text {, }
$$

where eff and aero refer to the effective stack height and aerovane height, respectively, and $P$ varies from 0.2 to 0.5 as the stability increases from 1 to 5 . This law is assumed to be valid to a height of approximately $1000 \mathrm{ft}$ (De Marrais ${ }^{20}$ ). Beyond $1000 \mathrm{ft}$, the velocity is assumed independent of height.

For the TAM acrovancs, the law was effectively restricted appioximately to $1000 \mathrm{ft}$ by setting an upper limit of 3 to the ratio $U\left(h_{\text {eff }}\right) / U\left(h_{\text {aern }}\right)$. However, because of the substantial difference between the heights of the TAM aerovane and the Midway aerovane, it was necessary to increase this upper limit to 5.6 in the latter case.

\subsubsection{Direct Comparison of Observed with Calculated $\mathrm{SO}_{2}$. Concentrations Using Midway Winds and Also with Calculations Using TAM Winds}

Table 8.1 compares calculated and observed $\mathrm{SO}_{2}$ concentrations using alternatively TAM and Midway winds for January.1967. The statistics are calculated using $1-, 6-$, and 24-hr interval averages. Whereas the calculated monthly means using either the TAM or Midway winds appear to be about equally close to the observed means, the relative standard deviations for the Midway wind calculations are substantially larger than for the TAM wind calculations.. 
TABLE 8.1. Calculated vs Observed Results

Using TAM and Midway Winds, January 1967

\begin{tabular}{|c|c|c|c|c|c|c|c|}
\hline TAM & No. & $\mu_{0}$ & $\stackrel{\text { TAM, }}{\mu_{\mathbf{e}}}$ & $\underset{\mu_{\mathrm{e}}}{\text { Midway, }}$ & $\begin{array}{c}\text { TAM, } \\
\sigma_{\mathrm{oe}} / \mu_{\mathrm{o}}\end{array}$ & $\begin{array}{l}\text { Midway, } \\
\sigma_{\text {oe }} / \mu_{0}\end{array}$ & $\begin{array}{c}\text { Average } \\
\text { Interval, } \\
\text { hr }\end{array}$ \\
\hline 2 & .456 & 0.12 & $\because 0.11$ & 0.14 & $\begin{array}{l}0.69 \\
0.48 \\
0.33\end{array}$ & $\begin{array}{l}1.02 \\
0.51 \\
0.34\end{array}$ & $\begin{array}{r}1 \\
6 \\
24\end{array}$ \\
\hline 4 & 360 & 0.15 & 0.17 & 0.15 & $\begin{array}{l}0.66 \\
0.47 \\
0.30\end{array}$ & $\begin{array}{l}1.07 \\
.0 .77 \\
0.53\end{array}$ & $\begin{array}{r}1 \\
6 \\
24\end{array}$ \\
\hline 5 & 360 & 0.06 & 0.08 & 0.08 & $\begin{array}{l}1.70 \\
1.01 \\
0.75\end{array}$ & $\begin{array}{l}3.10 \\
2.14 \\
1.11\end{array}$ & $\begin{array}{r}1 \\
6 \\
24\end{array}$ \\
\hline
\end{tabular}

On the other hand, in terms of the percentile distributions of the differences $\chi_{0}-\chi_{e}$ shown in Table 8.2 , there is relatively little effect in changing from the TAM to the Midway winds.

TABLE 8.2. Percentile Distribution of Differences between Calculated and Observed Results Using TAM and Midway Winds, January 1967

\begin{tabular}{|c|c|c|c|c|c|c|c|c|c|}
\hline TAM & $\begin{array}{c}\text { TAM } \\
\text { PN025 }\end{array}$ & $\begin{array}{l}\text { Midway } \\
\text { PN025 }\end{array}$ & $\begin{array}{l}\text { TAM } \\
\text { PNO5 }\end{array}$ & $\begin{array}{c}\text { Midway } \\
\text { PN05 }\end{array}$ & $\begin{array}{l}\text { TAM } \\
\text { PN } 1\end{array}$ & $\begin{array}{c}\text { Midway } \\
\text { PN l }\end{array}$ & $\begin{array}{l}\text { TAM, } \\
50 \%\end{array}$ & $\begin{array}{c}\text { Midway, } \\
50 \%\end{array}$ & $\begin{array}{c}\text { Average } \\
\text { Interval, } \\
\mathrm{hr}\end{array}$ \\
\hline \multirow[t]{3}{*}{2} & 0.44 & 0.3 .9 & 0.67 & 0.65 & 0.86 & 0.82 & 0.63 & 0.64 & 1 \\
\hline & 0.54 & 0.46 & 0.78 & 0.74 & 0.92 & 0.91 & 0.71 & 0.77 & 6 \\
\hline & & 0.42 & & 0.95 & & 0.95 & 0.84 & 0.8 .9 & 24 \\
\hline \multirow[t]{3}{*}{4} & 0.32 & $0: 30$ & 0.52 & 0.51 & 0.83 & 0.77 & 0.73 & 0.58 & 1 \\
\hline & 0.33 & 0.40 & 0.58 & 0.55 & 0.88 & 0.83 & 0.83 & 0.70 & 6 \\
\hline & & 0.47 & & 0.80 & & 0.87 & 1.00 & 0.80 & 24 \\
\hline \multirow[t]{3}{*}{5} & 0.52 & 0.54 & 0.74 & 0.75 & 0.90 & 0.93 & 0.53 & 0.48 & 1 \\
\hline & 0.60 & 0.58 & $0: 83$ & 0.83 . & 0.95 & 0.97 & 0.60 & 0.68 & 6 \\
\hline & & 0.73 & & 0.93 & & 0.93 & 0.67 & 0.80 & 24 \\
\hline
\end{tabular}

The conclusions that one can draw from the direct comparison of observed results with calculations using Midway winds instead of TAM wind $s$ are:

(1) As far as monthly averages are concerned, there is relatively little effect.

(2) In terms of percentile distributions of the differences $\chi_{0}-\chi_{e}$, there is also relatively little difference.

(3) To the extent that one is interested in long-term statistics, it makes little difference whether one uses. TAM or Midway measured winds. 
(4) In terms of short-term analysis, the quality of fit of calculated to observed results, as expressed by the relative standard deviations $\sigma_{o e} / \mu_{0}$; is significantly better for the TAM winds.

\subsubsection{Comparison of Calculations Using Midway and TAM Winds}

A comparison of the Midway wind-based calculations directly with the TAM wind-based calculations is also rather interesting from the classical sensitivity point of view. Table 8.3 compares these calculations. The magnitude of the error obtained in using the Midway winds (assuming the TAM winds to be exact at the TAM stations) depends significantly on the TAM station. Figure l shows a map of Chicago including the locations of the TAM stations and Midway Airport. TAM 5 is seen to be the closest to Midway, and TAM 2 the furthest away. "LAM 4 is about 0.6 mile from the lake, whereas TAM 2 is 1.6 miles from the lake.

TABLE 8.3. Analysis of $\chi_{\text {TAM }}-\chi_{\text {Mid }}$ for January 1967

\begin{tabular}{|c|c|c|c|c|c|c|}
\hline TAM & $\mu \mathrm{d}$ & $\sigma($ TAM - Mid $)$ & PN025 & PN05 & PN 1 & $\begin{array}{c}\text { Interval, } \\
\mathrm{hr}\end{array}$ \\
\hline \multirow[t]{3}{*}{2} & -0.03 & 0.13 & 47.1 & 63.4 & 81.1 & 1 \\
\hline & -0.03 & 0.08 & 43.4 & 64.5 & 84.2 & 6 \\
\hline & -0.03 & 0.07 & 38.6 & 68.4 & 94.7 & 24 \\
\hline \multirow[t]{3}{*}{4} & 0.02 & 0.16 & 37.5 & 66.4 & 88.6 & 1 \\
\hline & 0.02 & 0.1 & 35.0 & 73.3 & 93.3 & 6 \\
\hline & 0.02 & 0.06 & 26.7 & 73.3 & 93.3 & 21 \\
\hline \multirow[t]{3}{*}{5} & 0 & 0.21 & 67.2 & 81.1 & 89.2 & 1 \\
\hline & 0 & 0.13 & 75.0 & 86.7 & 91.7 & 6 \\
\hline & 0 & 0.03 & 73.3 & 86.7 & 93.3 & 24 \\
\hline
\end{tabular}

In terms of the mean difference, $\mu_{d}$, or the percentile distribution of the differences $\chi_{\text {TAM }}-\chi_{M i d}$, TAM 5 is seen to be in best agreement with the Midway wind calculations, presumably because it is also the closest and occupies the most similar environment (i.e., is farthest from the lake).

\section{L Sensitivity to Changes in Wind Direction}

In order to examine the sensitivity of the plume model to changes in the wind direction (WD) somewhat more explicitly than in the Sect. 8.1, we compared calculations using the 'IAM WD modified by first adding then subtracting $15^{\circ}$ with the calculations using the original TAM WD for selected short periods. 
Table 8.4 compares the results of calculations using the three different choices for WD. The means are seen to be somewhat sensitive to changes of $\pm 15^{\circ}$ in the WD. Changes in WD of this magnitude produced changes in $\mu_{\mathrm{e}}$ of the order of $15-30 \%$. The original values of WD provided about the best overall fit to the observed means. However, there are some significant exceptions. The values of $\sigma_{o e} / \mu_{0}$ corresponding to the three different calculations are quite interesting. First, there appears to be a general asymmetry between the $\theta+15^{\circ}$ and $\theta-15^{\circ}$ calculations as compared to the $\theta$ (original $W D$ ) results. With the exception to TAM 5, January $12-15$, there is a definite deterioration in the $\sigma_{\text {oe }} / \mu_{\mathrm{o}}$ values when $\theta \rightarrow \theta+15^{\circ}$. On the other hand, when $\theta \rightarrow \theta-15^{\circ}$, there are significant improvements in the results at least for TAM 2, January 12-15, and TAM 4, January $12-15$ and January 18-19. The fact that it was actually possible to improve the results averaged over 2 - and 4-day periods (in these cases) is a bit remarkable.

Since the improvement only occurred for some periods but not others, one can make two plausible deductions. First, there may have been something special about those particular periods, and second, for long-term analysis (one or more months) such short-term special conditions would be unimportant. The special circumstances could, for example, be that the prevailing wind directions combine with systematic wind-direction errors caused by real nonuniformities in the wind field. To explore the situation somewhat further, we analyzed the WD measurements at Midway and TAM stations 2, 4, and 5. Note that whereas the Midway aerovane is located on a 20 -ft mast isolated from all other structures, the TAM aerovanes are placed on 20-40-ft masts on top of three-or four-story buildings in urban areas. Consequently, the effects of local obstructions to air-flow, including that of the building on which the TAM aerovane is mounted itself, cannot be ruled out.

TABLE 8.4. Comparison of Calculations for Different WindDirection (WD) Modifications ( $\theta$ is the original wind direction)

\begin{tabular}{|c|c|c|c|c|c|c|c|c|c|}
\hline \multirow[b]{2}{*}{ TAM } & \multirow{2}{*}{$\begin{array}{c}\text { Dates, } \\
\text { January } 1967\end{array}$} & \multirow{2}{*}{$\begin{array}{c}\text { Interval, } \\
\mathrm{hr} \mathbf{r}\end{array}$} & \multirow[b]{2}{*}{$\mu_{0}$} & \multicolumn{3}{|c|}{$\mu_{\mathbf{e}}$} & \multicolumn{3}{|c|}{$\sigma_{\mathrm{oe}} / \mu_{\mathrm{o}}$} \\
\hline & & & & $\theta-15^{\circ}$ & $\theta$ & $\theta+15^{\circ}$ & $\theta-15^{\circ}$ & $\theta$ & $\theta+15^{\circ}$ \\
\hline \multirow[t]{4}{*}{2} & $12-15$ & 1 & 0.13 & 0.12 & 0.10 & 0.09 & 0.54 & 0.67 & 0.84 \\
\hline & & 6 & & & & & 0.35 & 0.53 & 0.78 \\
\hline & $18-21$ & 1 & 0.17 & 0.18 & 0.16 & 0.12 & 0.54 & 0.49 & 0.60 \\
\hline & & 6 & & & & & 0.34 & 0.34 & 0.53 \\
\hline \multirow[t]{4}{*}{4} & $12-15$ & 1 & 0.17 & 0.15 & 0.17 & 0.22 & 0.46 & 0.52 & 0.62 \\
\hline & & 6 & & & & & 0.32 & 0.40 & 0.49 \\
\hline & $18-19$ & 1 & 0.24 & 0.18 & 0.21 & 0.24 & 0.39 & 0.51 & 0.60 \\
\hline & & 6 & & & & & 0.35 & 0.46 & 0.54 \\
\hline \multirow[t]{2}{*}{5} & $12-15$ & 1 & 0.07 & 0.06 & 0.06 & 0.08 & 0.88 & 0.76 & 0.76 \\
\hline & & 6 & & & & & 0.56 & 0.49 & 0.51 \\
\hline
\end{tabular}


Figure 17 shows plots of the wind direction measured at TAM 4 and 5 and at Midway Airport for the 4-day period January $12-15,1967$. Figure 1 shows that Midway Airport, TAM 5, and TAM 4, are roughly in line as one travels east toward the lake. TAM 2, on the other hand, is several miles to the north of TAM 5. The convention that a northerly wind (i.e., one coming from the north) has a direction of zero degrees, with the angular direction increasing in a clockwise rotation, is used in the following discussion.

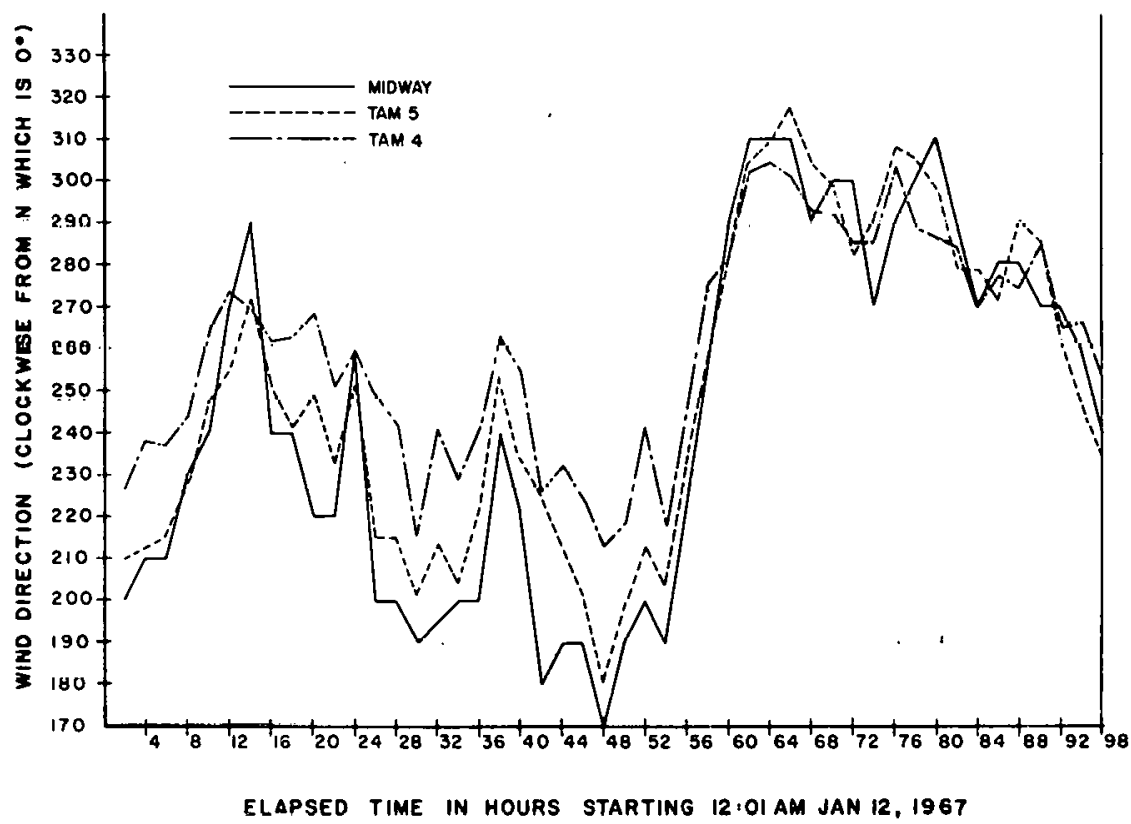

Fig. 17. Measurements of WD ar TAM 5 for January 12-15, 1967. ANL Neg. No. 190-170.

With the exception of a few hours on the 12 th day, the WD systematically increases in the clockwise sense as one moves from Midway toward the lake during the entire period between hours 0 and 60 . This strongly implies that wind coming out of the south-to-southwest sectors is gradually shifted to a more westerly direction as it moves closer toward the lake. 'L'his turther suggests the existence of a convergence zone of northerly and southerly winds in the vicinity of the Chicago area during that period. The consequences of such small-scale nonuniformities in the WD on dispersion modeling can be substantial. Suppose, for example, we consider a major point source and a receptor several miles away. Whereas the wind direction measured at the receptor might imply that the point source was upwind, due to a nonuniformity in the wind field the plume trajectory could actually miss the receptor completely. Detailed analysis of the results of the January $12-15$ calculations revealed that this is precisely what happened during those periods where subtracting $15^{\circ}$ from the WD actually improved the results. 
The fact that real nonuniformities can exist on a local scale has been demonstrated by other investigations. One of the earlier Argonne reports ${ }^{27}$ indicates that "important local wind anomalies do occur (mostly lake breezes) and that their magnitude is such that TAM measurements are accurate enough to detect them." Lyons ${ }^{28}$ has found complex flow patterns during the summer resulting from the influence of the lake. He has demonstrated that such spatial dependences of the wind field can have important effects on the transport of pollutants.

Consequently, it is recommended that these local WD anomalies be further investigated and that an attempt be made to introduce spatially dependent wind fields into the dispersion model.

One final comment regarding the effect of WD is worth mentioning. The fact that a dispersion model places a plume at an incorrect location on the map may or may not be significant, depending upon what the dispersionmodel calculations are being used for. If, for example, one were trying to evaluate the effect of an air-quality regulation on the basis of calculated concentrations at a particular receptor, then the effect of the WD would be important. On the other hand, if calculations were performed over a reasonably fine mesh grid of receptors and isopleths were drawn in, then the precise location of the large plumes would not be very important.

\section{3 Sensitivity to Changes in Lid Height}

The effect of changing the lid height on the plume-model calculations was examined for the same short-term periods as in Sect. 8.2. To obtain an idea of the kind of errors that are typical when various techniques are used to estimate the lid height, the results of the Objective Estimate of the Mixing Height method ${ }^{17}$ was compared with results based on Midway soundings. ${ }^{18}$ This study indicated that most of both the morning and afternoon mixing-height estimates based upon the two techniques were within $50 \%$. For the small mixing heights, a value of $300 \mathrm{ft}$ seemed a reasonable estirnate of the error. (We used $250 \mathrm{ft}$ in the sensitivity analysis.)

Following these results, we compared calculations of $\mathrm{SO}_{2}$ concentrations using the original lid-height ( $\mathrm{LH}$ ) estimates (objective estimates) with those obtained by making the following modifications of $\mathrm{LH}$ :

$$
\begin{aligned}
& \text { if } L H \geq 500(\mathrm{ft}), \mathrm{LH} \rightarrow \mathrm{LH} \times(1 \pm 0.5) ; \\
& \text { if } \mathrm{LH} \leq 500(\mathrm{ft}), \mathrm{LH} \rightarrow \mathrm{LH} \pm 250 \mathrm{ft} ; \\
& \text { if } \mathrm{LH}<250(\mathrm{ft}), \mathrm{LH} \rightarrow 0 \text {, or } \mathrm{LH}+250 \mathrm{ft} .
\end{aligned}
$$

Figure 18 is a plot of the hourly values of LH for January 18-19, 1967, along with the $\mathrm{SO}_{2}$ concentrations calculated at TAM 2 with the standard LH values (solid line) and the reduced values (broken line). For $\mathrm{LH} \geq 500 \mathrm{ft}$, 
the concentration increases with decreasing LH. However, for lower values, because of the effects of stacks (either the physical or effective stack height) penetrating the lid, the concentrations at TAM 2 (80 ft above ground level) actually decreases with decreasing LH. That is, account is taken, in the model, of the fact that pollutants emitted in or above an inversion layer do not mix down into the lower layers (unless something subsequently happens to the inversion layer).

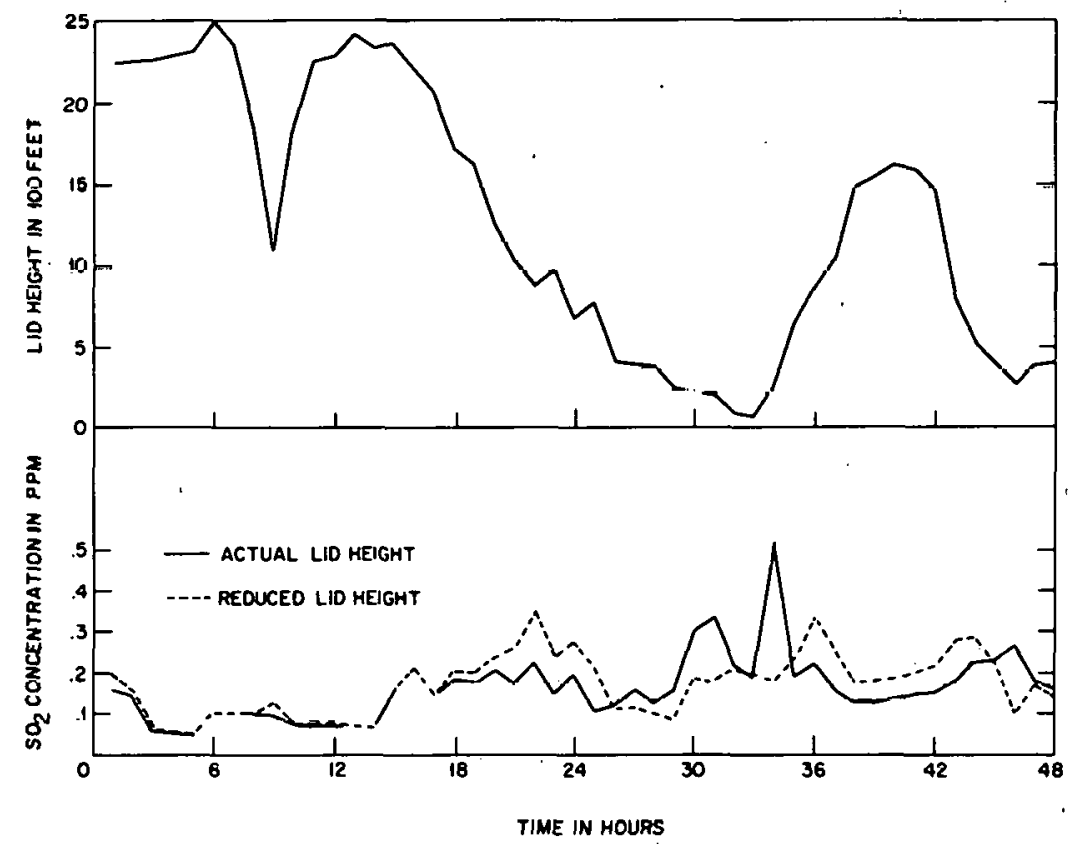

Fig. 18. Fffect of Reduring lid Height on Plume-model Cal-

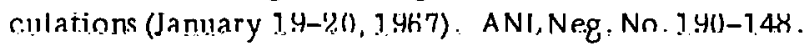

Table 8.5 compares the means $\left(\mu_{e}, \mu_{0}\right)$ and relative standard deviations $\sigma_{\mathrm{oe}} / \mu_{\mathrm{O}}$ (see Appendix $\mathrm{D}$ for definitions of these quantities) obtained

TABLE 8.5. Comparison of Calculations for Different Lid-hoight (LH) Modifications

\begin{tabular}{|c|c|c|c|c|c|c|c|c|c|}
\hline \multirow[b]{2}{*}{ TAM } & \multirow{2}{*}{$\begin{array}{c}\text { Dates, } \\
\text { January } 1967\end{array}$} & \multirow{2}{*}{$\begin{array}{l}\text { Interval, } \\
\text { hr }\end{array}$} & \multirow{2}{*}{$\begin{array}{l}\mu_{\mathrm{O}^{\prime}} \\
\mathrm{ppm}\end{array}$} & \multicolumn{3}{|c|}{ Mc.ppm } & \multicolumn{3}{|c|}{ roc/lio } \\
\hline & & & & LH $=50 \%$ & LH & $\mathrm{LH}+50 \%$ & LH $-50 \%$ & $\mathbf{L H}$ & $\mathrm{LH}+50 \%$ \\
\hline \multirow[t]{4}{*}{2} & $12-15$ & 1 & 0.128 & 0.098 & 0.104 & 0.087 & 0.78 & 0.67 & 0.76 \\
\hline & & 6 & & & & & 0.70 & 0.33 & 0.70 \\
\hline & $18-21$ & 1 & 0.169 & 0.166 & 0.158 & 0.144 & 0.61 & 0.49 & 0.44 \\
\hline & & 6 & & & & & 0.51 & 0.34 & 0.31 \\
\hline \multirow[t]{4}{*}{4} & $12-15$ & 1 & 0.170 & 0.181 & 0.174 & 0.147 & 0.50 & 0.52 & 0.47 \\
\hline & & 6 & & & & & 0.43 & 0.40 & 0.43 \\
\hline & $18-19$ & 1 & 0.235 & 0.269 & 0.212 & 0.198 & 0.76 & 0.51 & 0.45 \\
\hline & & 6 & & & & & 0.79 & 0.46 & 0.40 \\
\hline \multirow[t]{2}{*}{5} & $12-15$ & 1 & 0.072 & $0.059^{\circ}$ & 0.059 & 0.053 & 0.76 & 0.76 & 0.75 \\
\hline & & 6 & & & & & 0.54 & 0.49 & 0.53 \\
\hline
\end{tabular}


for the various LH modifications. The means are seen to be inversely proportioned to $\mathrm{LH}$, although this proportionality is somewhat mitigated by the lid-penetration effects. The dependence of $\sigma_{o e} / \mu_{0}$ on the modifications to $\mathrm{LH}$ indicates that the spread of the differences remains essentially unchanged for $\mathrm{LH}+50 \%$ (a slight reduction occurs in some cases) and is increased for $\mathrm{LH}-50 \%$. Note that the slight reductions in spread $\left(\sigma_{\mathrm{oe}} / \mu_{\mathrm{o}}\right)$ occurring for certain cases when $\mathrm{LH} \rightarrow \mathrm{LH}+50 \%$ is accompanied by a significant overall reduction in the concentrations as indicated by the reduced mean values. Consequently, such overall changes in LH do not seem to produce any systematic improvement.

Table 8.6 shows the percent changes calculated from the results given in Table 8.5. From Table 8.6 it is seen that for the magnitude of variations of $\mathrm{LH}$ considered $( \pm 50 \%)$, one can expect changes in the concentration of the order of $15 \%$ on the short-term basis (periods of 2-4 days).

TABLE 8.6. Percent Changes in Mean Concentration Calculated for Selected Short Periods When Lid Height Is Modified

\begin{tabular}{cccc}
\hline & Dates, & \multicolumn{3}{c}{$\%$ Change in $\mu_{\mathrm{e}}$} \\
\cline { 3 - 4 } TAM & January 1967 & $\mathrm{LH} \rightarrow \mathrm{LH}-50 \%$ & $\mathrm{LH} \rightarrow \mathrm{LH}+50 \%$ \\
\hline 2 & $12-15$ & -6 & -16 \\
4 & $18-21$ & 5 & -9 \\
4 & $12-15$ & 4 & -16 \\
& $18-19$ & 27 & -7 \\
5 & $12-15$ & 0 & -10 \\
\hline
\end{tabular}




\section{STRUCTURE OF STEADY-STATE PLUME COMPUTER CODE}

The structure of the plume computer code is essentially the same as that of the puff-model code described in detail in Ref. 1. Figure 19 is a flow diagram indicating critical calculations and major subroutines in the model. It is not a traditional computer flow chart, in that some of the calculations (for example, the simulation of hourly emissions from major sources) are

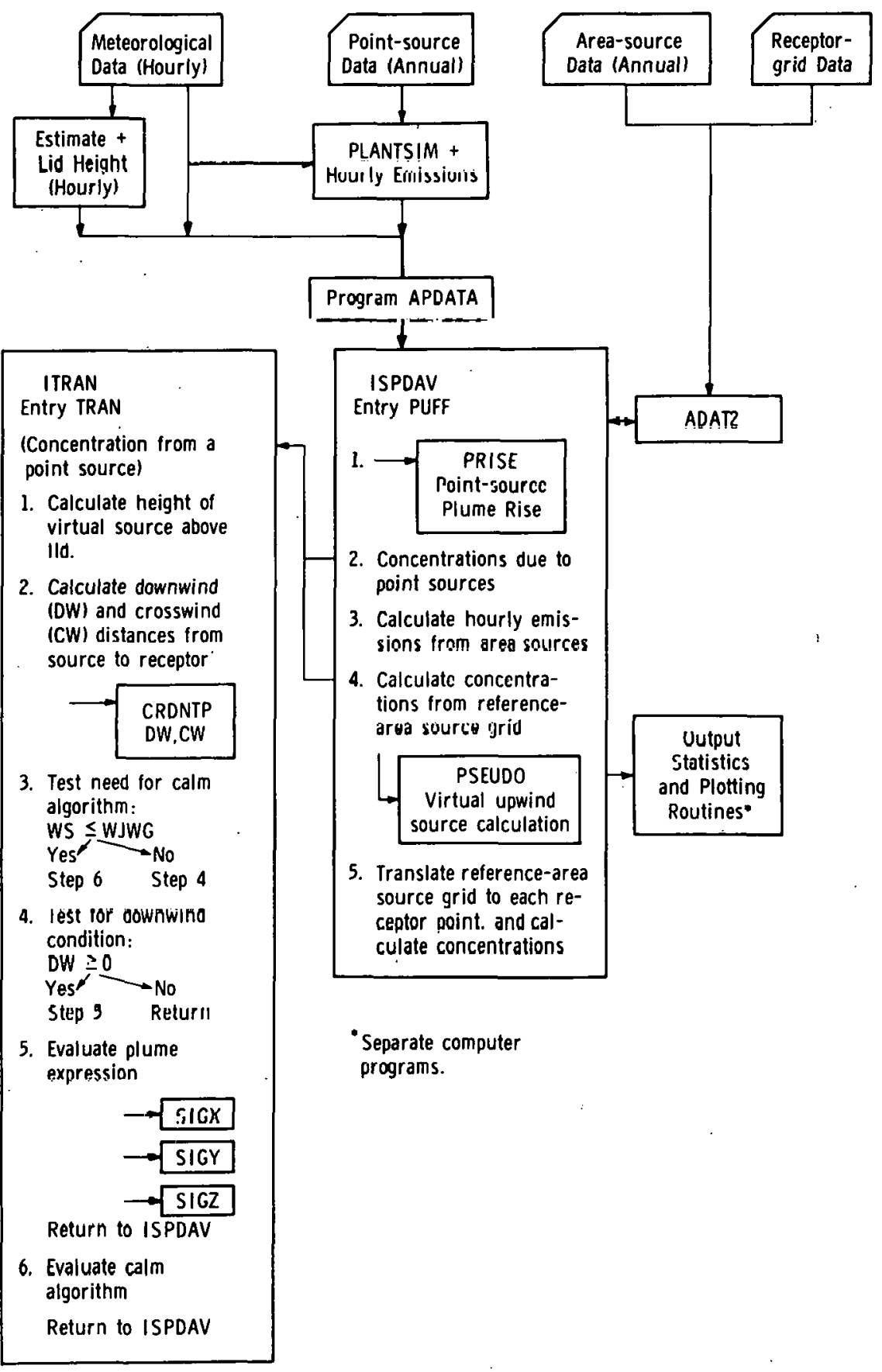

Fig. 19. Flow Chart of Plume-model Code 
performed by separate codes. The dispersion code begins with PROGRAM APDATA, a routine witten in PL/1, which reads and organizes hourly source and meteorological data stored on magnetic tape. This routine reflects the special features of the Argonne Master Air Pollution Information and Computation (APICS) system, ${ }^{29}$ and, for the purposes of this report, its main feature is the transmittal of the input data, one hour at a time, to the FORTRAN subroutine ISPDAV via the entry PUFF. The calculation of pollution levels over the receptor grid is then managed by ISPDAV according to Fig. 19. Listings for all routines appear in Appendix B. The code is designed to be coupled with the APICS system and is in developmental stage. The logic can easily be made more efficient, and the multiplicity of DATA statements (for example, those describing additional point sources not already in the PLANTSIM file) could be handled as card input.

Subroutine ADAT 2 is called from ISPDAV in order to read card input specifying the geometry of the region. Three grids are defined at this point:

(1) The area-source grid for the region.

(2) The receptor grid.

(3) A standard area-source overlay grid to facilitate calculations of concentrations from actual area sources.

Comparing Fig. 19 with Fig. 1 in Ref. l, it will be noted that subroutines INTEGl, which is a numerical integration routine, and KERN, which evaluates the puff kernel, have been deleted. In addition, the tasks performed by subroutine ITRAN have been significantly modified. The detailed programming changes required to implement the plume model occurred insubroutines ISPDAV, ITRAN, and ADAT2. These changes are described in Sect. 9.1. Another subroutine, CRDNTP, has been added to calculate the downwind and crosswind distances $D W$ and $C W$, respectively.

\subsection{Subroutine ISPDAV (Entry PUFF)}

Subroutine ISPDAV, which is normally entered from APDATA via entry PUFF (see Fig. 19 and listing in Appendix B), is the principal subroutine of the dispersion code. It performs or controls eight major functions via other subroutines. These are denoted in the ISPDAV listing by numbered comment cards:

(1) Initialize all arrays, including specifications of receptor grid and area-source data read in via subroutine ADAT2.

(2) Store all meteorological data for hour $M$.

(3) Calculate effective stack height for each major point source specified by PLANTSIM. 
(4) Calculate concentration at each receptor point from point sources specified by PLANTSIM and from additional point sources.

(5) Calculate hourly emissions from area sources.

(6) Evaluate coupling coefficients between each square in a standard area-source grid and a reference receptor point.

(7) Apply the coupling coefficients to calculate concentrations due to actual area sources by applying the standard area-source grid to each receptor point.

(8) Print out concentrations at each receptor point, and, if desired, punch cards to serve as input to statistical codes.

These eight functions are described in dctail in Ref. 1.

The parameter NMAX (see listing in Appendix B of ISPDAV) controls the amount of look-back time in the puff code. To implement the steadystate plume model, we set NMAX = l hr. That is, by restricting the lookback time to $1 \mathrm{hr}$ we can calculate hourly concentrations in the standard way with the assumption that meteorological and emission data remain constant for 1 -hr intervals, and that steady-state conditions are established by the end of each hour.

The original puff-model code, as described in Ref. 1, calculated concentrations over a receptor grid whose vertices coincided with the areasource grid. To save computer time and to concentrate on the detailed calculations at particular TAM stations, suitable changes were made in subroutines ISPDAV and ADAT2 (which reads in data cards specifying the receptor grid) so that the code would calculate concentrations at the exact location of one TAM station at a time using the wind measured at that TAM station.

\subsection{Function ITRAN (Entry TRAN)}

A statement in entry PUFF of the form

$$
C H I=\operatorname{EMIS}(\operatorname{JSUD}(M-N+1), \mathrm{K}, \mathrm{J}) * \operatorname{TRAN}(N, M, K, J, N T R A N) * 0.381 \mathrm{E}-4
$$

calculates the concentration CHI (ppm) at hour $M$ due to a steady emission EMIS (lb/hr) between the hours $M-N$ and $M-N+1$ from stack $K$ at plant $\mathrm{J}$. In the steady-state plume model, $N=1$. Entry TRAN of function ITRAN thus calculates the normalized $(\dot{X} / Q)$ concentration at a single receptor due to a given point source. ITRAN is linked to ISPDAV by common statements which transmit the source and receptor coordinates and all pertinent meteorological variables. In addition, if the source is actually a virtual source 
located upwind of a physical stack or area source, the time increments TX, $\mathrm{T} Y$, and $\mathrm{TZ}(\mathrm{hr})$ as determined by solving the equations

$$
\sigma_{\mathrm{xo}}=\sigma_{\mathrm{x}}(\mathrm{TX}), \sigma_{\mathrm{yo}}=\sigma_{\mathrm{y}}(\mathrm{TY}), \text { and } \sigma_{\mathrm{zo}}=\sigma_{\mathrm{z}}(\mathrm{TZ})
$$

are alșo specified. These equations are solved for values of the time in crements associated with pseudoupwind point sources in subroutine PSEUDO which is called by ISPDAV before ITRAN is called.

Function ITRAN (entered via TRAN) performs the following major calculations:

(1) Calculates the location of the virtual sources simulating re flection from the ground and the lid with the following restrictions:

a. If the physical stack penetrates the lid, the lid is set equal to $10,000 \mathrm{ft}$ (effectively infinite) and the stability classes set $=5$ (very stablẹ).

b. If the physical stack is below the lid but the effective stack height is above the lid, then proceed as in a) except stability class $=4$.

c. If effective stack height is below lid and receptor is above, ignore source (TRAN $=0.0)$.

(2) Calculates downwind (DW) and crosswind (CW) distance using CRDNTP.

(3) Calculates the normalized concentration $\chi / Q$ at a receptor due to a single point source. First the wind speed is compared with a critical value WJWG. If WS < WJWG, then the "calm algorithm" is used. Otherwise, the plume expression is used. If WS $>$ WJWG but $D^{\prime} W<0$ (source is downwind of receptor), the source is ignored and TRAN $=0.0$.

Evaluation of the plumie expression proceeds as follows:

First, the sum of three terms, namely the source term $\left(\chi_{1}\right)$, the first virtual image below ground $\left(\chi_{2}\right)$, and the first virtual image above lid $\left(\chi_{3}\right)$, are compared with a parameter EPS $(=0.001$ ppm $)$. If $\chi_{1}+\chi_{2}+\chi_{3}<\operatorname{EPS}$, the source is ignored and TRAN $=0.0$. If the sum exceeds EPS, then higher-order multiple images are calculated by standard Gaussian exponential factors;i.e., given $\mathrm{X}_{3}=$ [concentration at receptor from a source - image located $Z_{3}$ miles above the receptor], then the concentration $X_{4}$ due to the image located $Z_{4}$ miles above the receptor is given by

$$
\mathbf{x}_{4}=\mathrm{x}_{3} \exp \frac{\mathrm{Z}_{3}^{2} \cdot \mathbf{Z}_{4}^{2}}{2 \sigma_{z}^{2}}
$$


All the image terms (up to nine terms) are then summed to obtain the total concentration returned as TRAN = ADD $1+$ ADD $2+\ldots+$ ADD 9 where, $A D D$ 1, $A D D 2$, etc., represent the normalized concentrations from the various image terms.

\subsection{Input Data}

The kinds and methods of handling of input data in the plume model code are identical to the puff-mode code of Ref. l. Consequently, such items will be discussed only briefly here. The FORTRAN computational subroutines, of which the principal one is ISPDAV, are linked to the Master File of the APICS data management system by the PL/1 routine APDATA. The Master File contains historical meteorological data and annual emissinn data for the major point sources. The annual major point-source emission data is processed by PLANTSIM, which returns hourly emission rates for the historic period of interest (specified by input data cards). APDATA returns meteorological and point-source emissions data hour by hour to ISPDAV via entry PUFF. Additional data not stored in the APICS system are the following:

(1) Additional point-source annual emission rates are stored in data statements in ISPDAV. These data are processed within ISPDAV to produce emissions hour by hour.

(2) Area-source annual emission rates are stored nn input. dat.a. cards, which are read in via ADAT 2 and passed to ISPDAV, where they are processed to obtain hour-by-hour emission rates.

(3) ADAT2 also reads a number of other bits of information from data cards including:

(a) Date limits.

(h) Ghoice of which TAM statione windo arc to bc uacd.

(c) Choice of TAM station at which calculations will be carried out.

(d) Specification of area and receptor grids and overlay area source grid.

Note: In the current program we have used the code to calculate concentrations at the exact location of a particular TAM station rather than over an array of uniformly spaced grid points.

Hence, the number of receptor grid points is set equal to one in ADAT2, and the location of that single receptor is specified within ISPDAV. Consequently, ADAT2 reads in the number of the TAM station of interest, passes this number to ISPDAV, which in turn selects the corresponding coordinates from DATA statements XTAM, YTAM, and ZTAM. 


\subsection{Example Problem}

To illustrate the use of the plume computer code (see Appendix B for listing), an example problem is given in Appendix C. For this example, we have selected the calculation of the $\mathrm{SO}_{2}$ concentrations at TAM 5 for February 17, 1967, which is one of the historic days used extensively in the present report for illustrating the effect of the "calm algorithm" and for comparing results of the puff and plume models. The necessary input data for this calculation not specific to February 17, 1967, can be found in Ref. 1. The remaining data are included in Appendix $\mathrm{C}$. 


\section{SUMMARY OF RESULTS AND RECOMMENDATIONS FOR FURTHER INVESTIGATION}

Since discussions of the results presented in this report have already been given in the relevant sections, we will only briefly summarize those results here. Furthermore, since these results suggest areas in which future work is necessary, we have included several specific recommendations for future research.

The initial milestone of the program was the development of a simple steady-state dispersion model based on the standard Gaussian plume expression which was to be used for comparison with the Argonne Integratedpuff Model. To specifically investigate the need for the sophistication of the puff kernel, the plume model was set up in such a way that it would share as many components in common with the original puff computer code as possible. After a number of calculations were performed with the plume code, it became clear that at very low wind speeds (calm periods) the model predicted unrealistically high $\mathrm{SO}_{2}$ concentrations. Consequently, to carry out a more realistic comparison between the puff and the plume models, especially on a short-term basis, it was necessary to develop a special lowwind-speed function called the calm algorithm. Comparisons carried out between the puff and plume model, augmented with the calm algorithm, showed remarkably good agreement for both long- and short-term analyses. For example, means calculated for periods ranging from 2 days to 1 month showed relatively little difference for the two models. However, in certain cases, the fit to the data indicated by such quantities as the relative standard deviation of the differences between hourly calculated and observed concentrations was somewhat better for the puff than the plume model. The general conclusion we have drawn from this relatively close agreement between the two models is that, for an urban source-emission inventory such as exists in Chicago, the precision of the model is not limited by the sophistication of the transport function, but rather by the combination of the remaining components of the model, which include a number of computational routines as well as the input-data base, i.e., the emission inventory, source-simulation routines, and meteorological data.

To better understand why the puff and plume models produced such remarkably similar results when applied to the Chicago source-emis sion inventory, we carried out a detailed analytical and numerical analysis of the relationship between puff and plume expressions under special circumstances, which included the restriction to a single source-receptor pair.

The results of the numerical experiments, which consisted of evaluating the integrated puff and plume expressions under a variety of input conditions, showed that, provided sufficient time was allowed for the attainment of steady-state conditions (a time interval greater than the transit time), the two expressions produced essentially identical results:. 
By carrying out a Taylor expansion of the puff kernel about the delay time equal to the transit time, we were able to obtain an approximate analytical integration of the puff kernel and to show that at least the form of the plume expression, including the $1 / \mathrm{u}$ dependence as well as the correct dependence of the dispersion coefficients on the transit time, could be derived. The general conclusion of these studies is that one can expect the puff and plume models to yield nearly the same results provided that certain conditions are satisfied.

Before specifying those conditions, we point out that it is assumed that the input parameters are constant for the duration of a basic time step and that both models use the same time step. As to the conditions, first, hour-by-hour calculations will be quite similar, provided the transit time for most of the significant sources affecting a receptor are less than the time step. Otherwise, the plume model will violate the causality condition and overpredict compared to the puff model. Second, if the transit times from significant sources to the receptor is approximately equal to or greater than the time step, then even though hourly concentrations predicted by the two models differ, averages over two or more consecutive hours may be reasonably close, provided the input conditions remain constant for several hours, since the integrated puff will approach steady-state conditions as the exposure time increases. On the other hand, if transit times are of the order or greater than the time step and if the input conditions are quite variable hour to hour, then the plume model will consistently overpredict the puff model.

In regard to the use of the calm algorithm, there is a basic inconsistency in that whereas the wind speed is assumed to be zero, the plumerise formula used is not valid for wind speeds $<4 \mathrm{mph}$. One should probably make use of one of the more recent plume-rise formulas designed for calm periods, such as given by Briggs. ${ }^{23}$

The use of the travel-time-dependent dispersion coefticients of Turner ${ }^{9}$ in both models has been described in detail, but the relationship between these coefficients and actual dispersion in the real atmosphere in the urban boundary layer is not at all understood. This topic clearly deserves further investigation.

Several. conclusions can be drawn from the results of the sensitivity analysis of the plume model to the meteorological input data. With respect to the replacement of the TAM measured winds with the Midway measured winds, it was found that there was relatively little difference for the long term (monthly statistics). On the other hand, short-term results were considerably better when the TAM winds were used. With respect to the effect of making changes in the TAM measured wind directions of $\pm 15^{\circ}$, during certain periods of $2-4$ days it was actually possible to improve the results. 
This was found to be connected with the existence of real nonuniformities in the Chicago wind field. The nature of these nonuniformities needs furthe $r$ investigation, and the fact that they can have a significant effect on the dispersion-model calculation indicates that they should be taken into account in at least an approximate way.

The effect of the lid height was examined by varying hourly values by a preset amount. A realistic assessment of the magnitude of the change in lid height to be used for the sensitivity analysis was obtained by performing a series of comparisons of different techniques for estimating the lid height based on remote and local radiosonde measurements. ${ }^{18}$ It was found that errors of $25-50 \%$ could be expected on the basis of these studies. Systematic errors of $\pm 50 \%$ in the lid height were introduced into the input data, and the means of hourly concentrations calculated over 2- and 4-day periods varied by about $15 \%$ and in one case by as much as $27 \%$. Provided such errors in the concentration are tolerable, then the corresponding errors in the lid height are acceptable. On the other hand, if it is desired to improve the dispersion-model calculation, then one should attempt to attain somewhat better estimates of the lid height. This should include a prescription for estimating hourly values of the lid height based upon local soundings. Such effects as the urban heat island and mechanisms that suppress the ordinary diurnal heating pattern should be better understood and taken into account in estimating the hourly lid height. Finally, although time did not permit, it would have been interesting to examine the effect of using a much cruder estimate of the lid height, based on some sort of simple diurnal pattern, or simply a single daily value or perhaps even an annual average value such as is currently used in the $\mathrm{AODM}^{30}$ (Air Quality Display Model).

A copy of the plume-model computer cude is included in this report along with an example problem. Since this code has been demonstrated to be a reliable tool for prediction of air-pollutant concentration but is presently not in its most efficient state, it would seem worthwhile to develop a more user-oriented version of the code. Such a code sonit find a multitude of uses, including serving as a reference for comparison with other dispersion models.

Some effort was expended in attempting to speed up the puff-model computer code, and it was found that, by restricting the "look-back" time in the case of the area sources to $1 \mathrm{hr}$ one could substantially reduce computer time. Other suggestions for reducing computer run time are provided in Appendix A. 


\section{APPENDIX A}

\section{Reduction of Computer Run-time Requirements of Puff Model}

In an attempt to reduce the computer run-time requirements of the puff model, it was found that the run time for a particular hour was inversely proportional to the wind speed. This resulted from two effects. First, the number of sources making a significant contribution to the concentration at a given receptor increased. Second, the look-back time was automatically increased for lower wind speeds to allow for increased travel times and concentration buildup phenomena. This, in turn, increased the number of integrations required. Furthermore, whereas the increase of the look-back time (greater than $\mathrm{l} \mathrm{hr}$ ) was necessary to properly account for the contributions of the major point sources when $u \leq 5 \mathrm{mph}$, an increase was not necessary for the area sources. Hence, a substantial amount of computer time could be saved by limiting the look-back time for the area sources to $\mathrm{l} \mathrm{hr}$. In addition, the mesh size needed to obtain a given accuracy for the numerical integration of the puff kernel was inversely proportional to the wind speed. That is, the greater the wind speed, the more integration points were required and therefore the more time required to perform an integration. This resulted from the fact that as the wind speed increases, the integrand (puff kernel) approaches a "Dirac Delta" function. Although it was not tried, a more careful treatment of the choice of integration limits guided by the peaked behavior of the integrand could substantially reduce the increase in integration time caused by the finer mesh size. On the other hand, for the low-wind-speed cases, some computer run time could be saved by using a numerical integration routine such as a "Gauss Quadrature, "whichachieves the same accuracy as the original "INTEGl" subroutine (which is a variablemesh Simpson's Rule method) with far fewer integration points.

Furthermore, it has been suggested by Hanna ${ }^{31}$ that a much simpler treatment of the area sources could be used. However, the treatment he suggests substantially overpredicts when compared with the puff model, and it is not clear under what circumstances such a simplified treatment would be valid. 


\section{APPENDIX B}

Listings of Steady-state Plume-model Computer Routines

This appendix contains listings of the following six computer routines used in the steady-state plume model:

ADAT2
ISPDAV
ITRAN
CRDNTP
SIGY
SIGZ

These routines are modified or corrected versions of the routines used in the original puff-model code, except for CRDNTP, which is a new routine. The remaining routines used in the steady-state plume model code are identical to those used in the original integrated puff-model code and are given in Ref. 1 .

1. Subroutine ADAT2

C

SUBROUTINE ADAT2

ZERO OTOT ARFAY

DIMENSION TITLE(20)

COMMON/ASGRID/NSGFID, XSGRID $(100)$, YSGRID 1100$)$

COMMCN/QHWWW/PCTHW, DCAVG

C DRAVG IS AYG NUMBER DF DEG -DAYS/YEAR(TODO IA CHICAGOI.

C PCTHW IS FRACTION OF ANNUAL FUEL USED FOR HOT WATER

C CHICAGO HOT WATER REQ. $=20$ PCT DF ANNUAL FUEL COMMON/NUMBPT/NPOW.NIND

C POINT SCURCES SHOULD BE LISTED WITH POW PLANTS $J=1$, NPOW,

C INDUSTRY FROM J=NPOW+1 TO NIND, FOLLOWED BY RES/COML. COMMON/METREF/ZWS

C ZWS IS HEIGHTIFTIOF AEROVANE COMMON/RGR/XRORIG, YRORIG, NWEST, NSTH,ORGRID, ZREC COMMCN/AREAS/QTOT $(3,1004)$, HAVG ( 3$)$, OGRID, XSORIG, YSORIG,

2 NSXMAX, NSYMAX, EMAX $(5,3)$

COMMON/MINQ/EMINPT

C THE AREA SOURCE GRID COORDINATE SYSTEM HAS BEEN FORMED WITH \&X WEST AND +Y SOUTH.

THE GFID SYSTEM ORIGIN XSORIG,YSORIG NEED NOT BE $D, 0$.

DGRID IS THE GRID SPACING IN MILES.

NSXMAX AND NSYMAX DEFINE MAX GRID COORDINATES. THE COORDINATES

OF THE LOWER LEFT CORNER OF GRID SQUARE NX, NY ARE

$(X S O F I G+P X * D G R I D)$; $(Y S O R I G * N Y$ \&OGRID).

ORIGIN OF GRID SYSTEM SHOULD BE LOCATED SO THAT WHOLE

REGION LIES IN THIRD QUADRANT (HERE $+X,+Y$ ).

EACH AREA OF SIZE DGRID**2 MUST BE ASSIGNEO A PCLLUTANT

EMISSION RATE (LB/YR) FOR THREE TYPES OF EMISSIONS.

LOW PRESSURE SPACE HEATERS, HIGH RISE SPACE HEATERS AND

INDUSTRIAL. CCMMERCIAL EMISSIONS CAN BE INCLUDEU IN

EITHER OF THE FIRST TWO CATEGORIES.OTOTINCL, NAREAIIS THE ARRAYNAME

A SINGLE STACK HEIGHT IS INPUT FOR EACH CLASS OF AREA SOURCES

NSGRID $=8 \mathrm{e}$

DGR I $D=1$

XSORIG $=-2$.

YSORIG $=-12$

NSXMAX $=20$ 


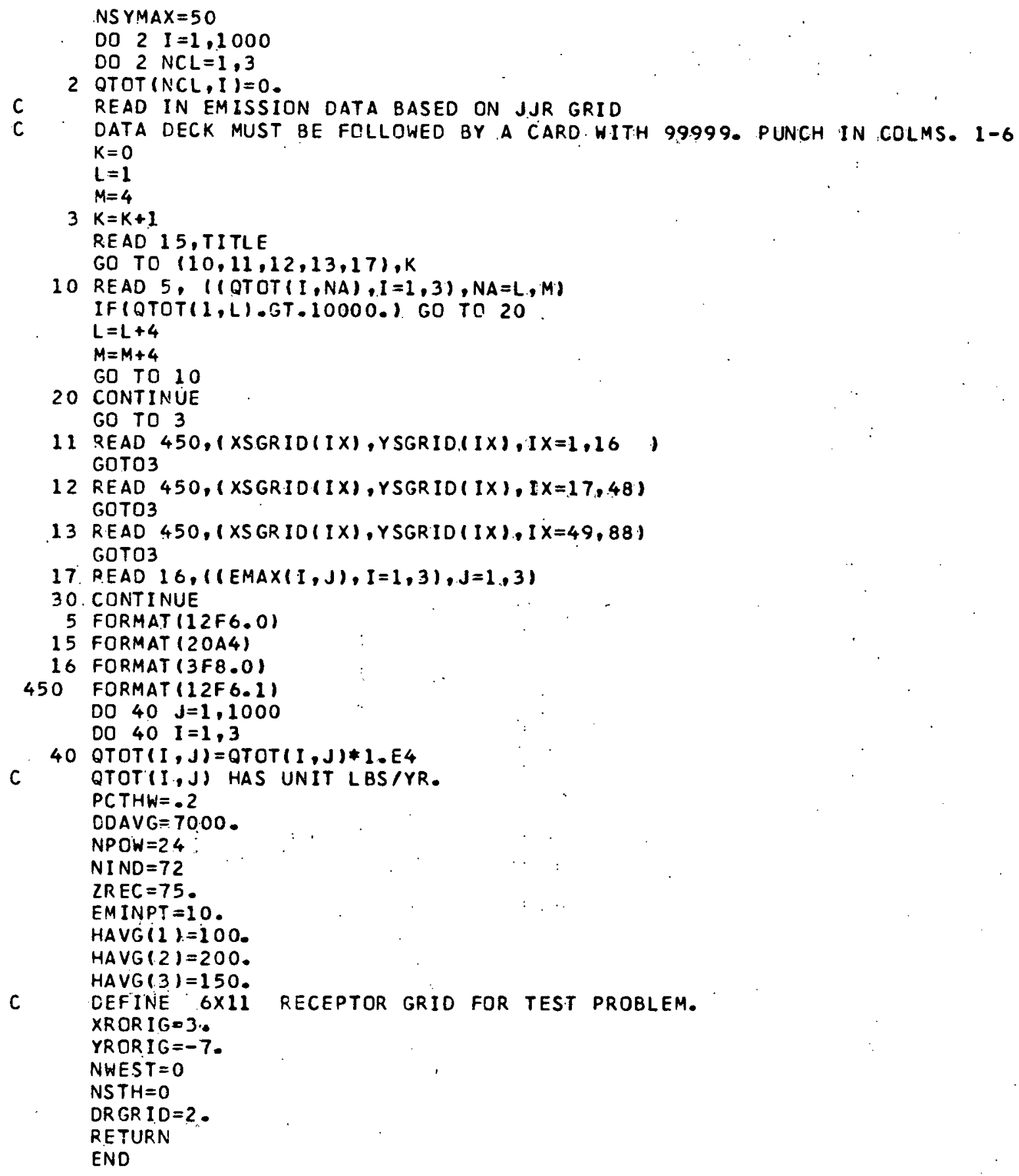

2. Subroutine ISPDAV

SUBROUTINE ISPUAVIEMIS, HEFF)

C THIS VERSION USED FOR STEADY STATE PLUME MODEL

REAL $* 8$ SNAMES $(1)$

COMMON/KTROUB/KTRO

DIMENSION KTAM(8)

COMMON/MXC/MX

DIMENSION A $(12,8), B(12,8), C(12,8), W \triangle B A R(12, R)$

REAL*4 EMIS $(12,4,1), \operatorname{HEFF}(12,4,1)$ 
c

C

C

DIMENSION WD(8),WS(8)

REAL *4 XS(1),YS(1),ZS(4,1),QSO2(1), QHEAT (1),

1 SOZVAL (1), WDA 1 ), WSAI 1 ), PERCENT $(4,1)$,SOBS (1)

COMMON/TIMEI MMAX,NMAX,M,N

COMMON/KERNEL/X, Y, Z,U( 24),V(24),W(24),JS(24),HMIX (24),WSBAR ( 24$), W Z$ COMMON/RISE/ZSS

COMMON/POUT/I

COMMON/XTR AN/KSTAB

COMPDN / SUEDO/TX,TY,TZ,DX,DY,DZ

COMMON/HALF/THALF

DIMENSION TEM(12)

DIMENSION KSTAP $(6,100)$

DIMENSION TXX(6,6),T $Z Z(6,6,3), D X X(6,6)$, DYY $(6,6)$,

$2 \operatorname{EMIT}(6,3,1000)$

DIMENS ION PP $(7)$, USAVE $(24), V S A V E(24)$

DIMENSIDN NDW $(12,4,100)$

DIMENSION WSSAVE (24)

DATA PP./.2,.2,.2,. $3, .4, .5, .5 /$

DATA KPS/I/

DATA NCLID/1/

DIMENS ION NTMP $(4,8), \operatorname{NHRP}(4) ; \operatorname{MPU}(4), \operatorname{PREC}(4,8), \operatorname{OBSC}(4,8)$

DATA NCOUNT/1/

DI MENS IONXPT (30), YPT (30), ZPT (30), QPTOT $(30)$,

$X Q P H R(12,30)$, HEFPT $(12,30), N P A T(30), N S(30), \operatorname{HKEE}(12)$,

XEKEE(12),SPCT(30)

DATA NPTS/28,

DATA NS $/ 1,1,1,1,1,0,0,1,0,1,1,1,1,1,1,1,1,1,1,1,1,1,2,0,4,4,8$, $\times 1 /$

DATA NPAT/3,3,3,3,3,2,2,1,2,1,1,1,1,2,1,1,1,1,2,2,2,2,2,2,1,1,1, $X 11$

DIMENSION IIND(100)

DATA I IND/ $2,2,2,2,2,3,3,2,3,2,2,2,2,3,2,2,2,2,3,3,3,3,3,3,1,1,1$, $\times 1 /$

DATA XPT/9.8,11.0,5.5,9.8,8.0,5.6,10.3,18.,6.0,15.1,6.7,7.2,8.8, $X 8.8,7,0,15.5,16.2,16.7,9.2,6.0,4.2,5.0,3.5,5.4,15.2,29.2,30.4$, $X 11.71$

UATA YPT/ $0.8,-6.0,12.0,-2.0,5.1,0.3,-0.5,-2.0,4.5,7.0,4.5,2.8,2.7$

$x, 2.8,17.4,5.2,5.9,6,0,0.7,0.3,-0.6,0.1,6,4,-0.5,-35.2,16: 0,24.8$

$x,-16.61$

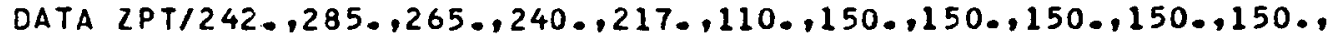

$\times 150,150 \ldots, 150,150 \ldots, 150,150,150,150,, 150,150 \ldots, 85 \ldots, 160 \ldots, 380 \ldots$

$1400 \ldots, 450 \ldots, 500,1247.1$

DATA SPCT/ $2.2,2.2,2.2,2.2,2.2,3.4,2.4,2.2,2.9,2.7,3.2,3.2,3.2$,

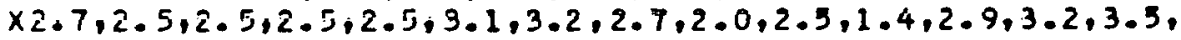

$x 1.21$

QPTOT UNITS ARE M LBS.SO2/YR.

DATA QP.TOT $/ 2.34,2.42,2.10,2.02,1.89,8.00,2 \cdot 73,4.12,4.26,31.89,4.59$

$x, 1.88,2.59,2.38,4.78,1.74,4.78,4.32,2.78,3.53,2.06,2.04,3 \cdot 80, .42$,

$\times 232 ., 397 . .560 ., 1.011$

ADDITIONAL POINT SOURCES INCLUDE:

PUMPING STATIONS (CENTRAL PK.. MAYFAIR, ROSELAND, SPRINGFIELD, HESTEZN AVE.), UNION STATION POWER PLANT, CHICAGO-NORTHWESTERN RR, INTERNATIONAL HARVESTER, PRODUCE TERMINAL, CORN PRODUCTS, SWIFT, DIAMOND GLUE, CELOTEX, MUN. HEATING PL., WYMAN GOPDOON, REYNOLDS, STANDARD LIME, ELECTROMOTIVE DIV., SEARS ROEBUCK, UNIV. OF ILL., NO. WESTERN UNI V. I.GOLDBLATT BROS., UNIV. OF CHICAGO,

MERCHANDISE MART., POWER PLANTS (HAUKEGAN, WILL COUNTY, JOILET).

WINETKA POWER PLANT ADDED

EACH ADDITIONAL POINT SOURCE IS IDENTIFIED BY A

PATTERN OF EMISSION. 1=UNIFORM, 2=TEMP DEPENDENT, $3=$ PUMPING STA.

EACH ADOITIONAL POINT SOURCE MUST BE

IDENTIFIED BY A CLASSIFICATION NUMBER. $i=U T I L I T Y, \quad 2=$ INDUSTRY, $3=$ RES / COML.

DIMENSION NOSTK(5O)

DATA NOSTMX/9I 
c

DATA VPPP/O/, NPRINT/1/

C RESULTS FOR GRID PRINTED EVERY NPRINT HOURS. COMMON / AREAS/OTOT $(3,1004)$, HAVG (3), DGRID,XSORIG,YSORIG,

2 NSXMAX, NSYMAX, EMAX 15,3$)$

COMMON/QHWWW/PCTHW, DEAVG

COMMON/NUMBPT/NPOW,NIND

COMMON /SO2DAT/RECDAT $(4,500)$

COMMON /RGR / XROR I G, YRORIG, NHEST, NSTH, DRGRID, ZREC

COMMON/MINQ/EMINPT

COMMON / ASGRID/NSGRID, XSGRID(100), YSGRID(100)

DI MENSI ONC CUP $(100,3,6)$

DIMENS ION VQ $(6,3)$

COMMON / METREF/ZWS

C ZWS IS HEIGHT(FT)OF AEROVANE

C IF VALOP.GT.O THEN SO2VAL=RECDAT (4, NRTAM) IS RETURNED TO

C APDATA FOR EVENTUAL PRINTOUT ALONGSIDE SO2 DATA FROM

$\mathrm{C}$

$c$
$c$

C NMAX MUST BE -LE.6 HOURS

C SET NMAX=1 FOR STEADY STATE PLUME MODEL

CALL ADAT2

C ADAT 2 READS IN RECEPTOR AND AREA SOURCE DATA. NTEST $=1$

IF INTEST.GT.O )

2 PRINT 401, QTOT $(1,50)$, OTOT $(3,300)$, HAVG $(2)$, DGRID, XSORIG,

2 YSORIG,NSXMAX, NSYMAX, EMAX $(2,2)$

401 FORMAT $(10 \times, 6 E 10.2,2110, E 10.2)$

DTINTEST.GT.O

1 PRINT 402,XSGRID(20), YSGRID(20), ZWS

402 FORMAT $(10 X, 3 E 10.2 / 1)$

RETURN

C CODE COORDINATES, PLUS FOR $X$ LEFT AND $Y$ DOWN

C 22222

ENTRY PUFFINR, TEMP, WSA, WDA, STAB,HLID, NSRC, XS, YS, ZS,

1 PERCENT, QSO2, QHEAT,

2 SO2 VAL, MM, KTAM, SOBS, SNAMES )

C SOBS IS THE ACTUAL DBSERVEO SO2. USED HERE ONLY IN PUNCHED

C DUTPUT FOR STATISTICAL COMPARLSON HITH CALCILLATED VALUES $K T R O=0$

C UNITS ARE F, DEG,MPH, ,FT, MI, MI,FT, FRACTION,LB/HR, TH/HR, ,MI, MI, FT,, $C * * * * * * * * * *$

C ONLY ONE AEROVANE REAOING IS USED PER PROBLEM.

C THIS IS SPECIFIED BY RECEPTOR CARO IN DATA DECK.

$C \$ \$ \$ \$$

C ZERO THE EMIT ARRAY

$0021=1,6$

DO $2 I=1,3$

DO $2 \mathrm{~K}=1,1000$ 
$2 \operatorname{EMIT}(L, I, K)=0$.

$I=1$

IR $R=1$

WS (I ) =WSA(IRR) *ADJWS

$W D(I)=W D A(I R R)+A D J W D$

IF (WS II) -LT . . OI)

3 CONT INUE

WS $(I)=.1$

$H L I D=H L I D * A D J H L$

$M=M M$

$M X=M I N O(N M A X, i 4)$

$J S M=J S U B(M)$

c

IR $R=0$

TEMI JSM I TEMP

$W Z=1$.

$H R=N R$

$I R=0$

$T X=0$.

$T Y=0$.

$T Z=0$.

$\mathrm{DX}=0$.

OY $=0$.

$\mathrm{DZ}=0$.

$I=1$

4DRAD=WD(I)*.01745

$A(J S M, I)=W S(I) * S I N(W D R A D)$

$B(J S M, I)=W S(I) * \operatorname{COS}(W D R A D)$

$C(J S M, I)=0$.

5 WABAR $(J S M, I)=W S(I)$

JSTAB $=S T A B$

JSIJSM J = JSTAB

C CORRECTION FOR MISSING MIXING HT IN MASTER FILE.

IFIM.EQ.1. AND. (HLID.GT . 10000 ..OR.HLID.LT.0.1) HLID $=9999$.

IF (M.GT.1.AND. (HLID.GT.10000..OR.HLID.LT.0.1) HLID =HMIX (JSUBIM-1) ) HMIXIJSM $\quad 1=H L I D$

Cosisis

C THIS VERSION CALCULATES CONCENTRATIONS AT THE EXACT LOCATION. OF

C THE TAM STATION. ONLY ONE RECEPTOR POINT CAN BE CONSIDERED AT A TIME. DO 6450 ITAMIS $=1$, 8

6450 IFIKTAMIITAMSI.EQ.1) GO TO 6451

6451 NNTAM=ITAMS

$I X R=X T A M(N N T \cdot A M)+0.5$

I $Y R=Y T A M(N N T A M)$

$X R O R I G=I X R$

YROR IG $=I Y R$

DXR $=X T A M(N N T A M)-X R D R I G$

$D Y R=Y T A M(N N T A M)=Y P, O P . I G$

ZREC $=2$ TAM (NNTAM)

$Z W S=Z R E C$

DO $8 \quad \mathrm{~J}=1$, NSRC

IF (MM.EQ.5) PRINT $681, \operatorname{SNAMES}(J), J, N R, X S(J), Y S(J)$

681 FORMAT $(3 X, A B, 2 X$, 'NSRC, HOUR, $X, Y=-, 213,2 X, 2 E 12.5)$

DO $8 \quad K=1,4$

IRR $=0$

$Z S S=25(K, J)$

EMIS $(J S M, K, J)=Q S O 2(J) * \operatorname{PERCENT}(K, J)$

WSSSS $=$ WS $(1)+.1$

$K S T A B=0$

DHMIN = PR.ISE(WSSS S, 5, OHEAT $(J)$ *PERCENT $(K, J))$

IF (HLID.LT . 2SSIKSTAB =1

C IF KSTAB.GT. O , WE HAVE CASE OF STACK ABOVE LID OR PENETRATION

C

C

INTO LID. USE JSTAB=5 FOR PRISE AND SIGMAS.

UNTIL LID RISES TO HEFF. THEN TREAT AS A PLUME

REFLECTED AS USUAL.

IF (HLID.LT . (ZSS+DHMIN) . AND.KSTAB.EQ.0) KSTAB $=2$

HEFF $(J S M, K, J)=Z S S+D H M I N$

IFIKSTAB.GT.OIGO TO 7 


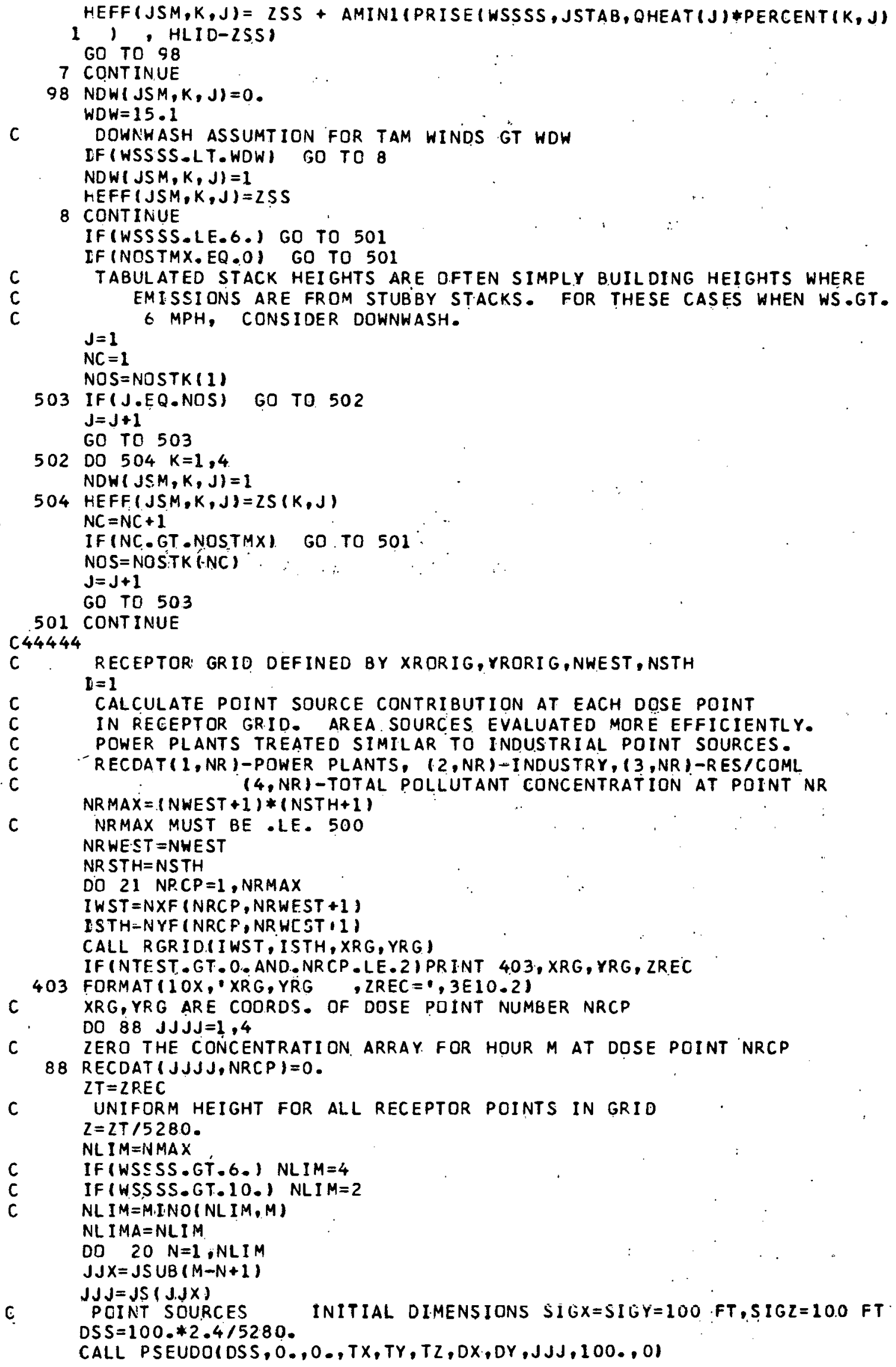




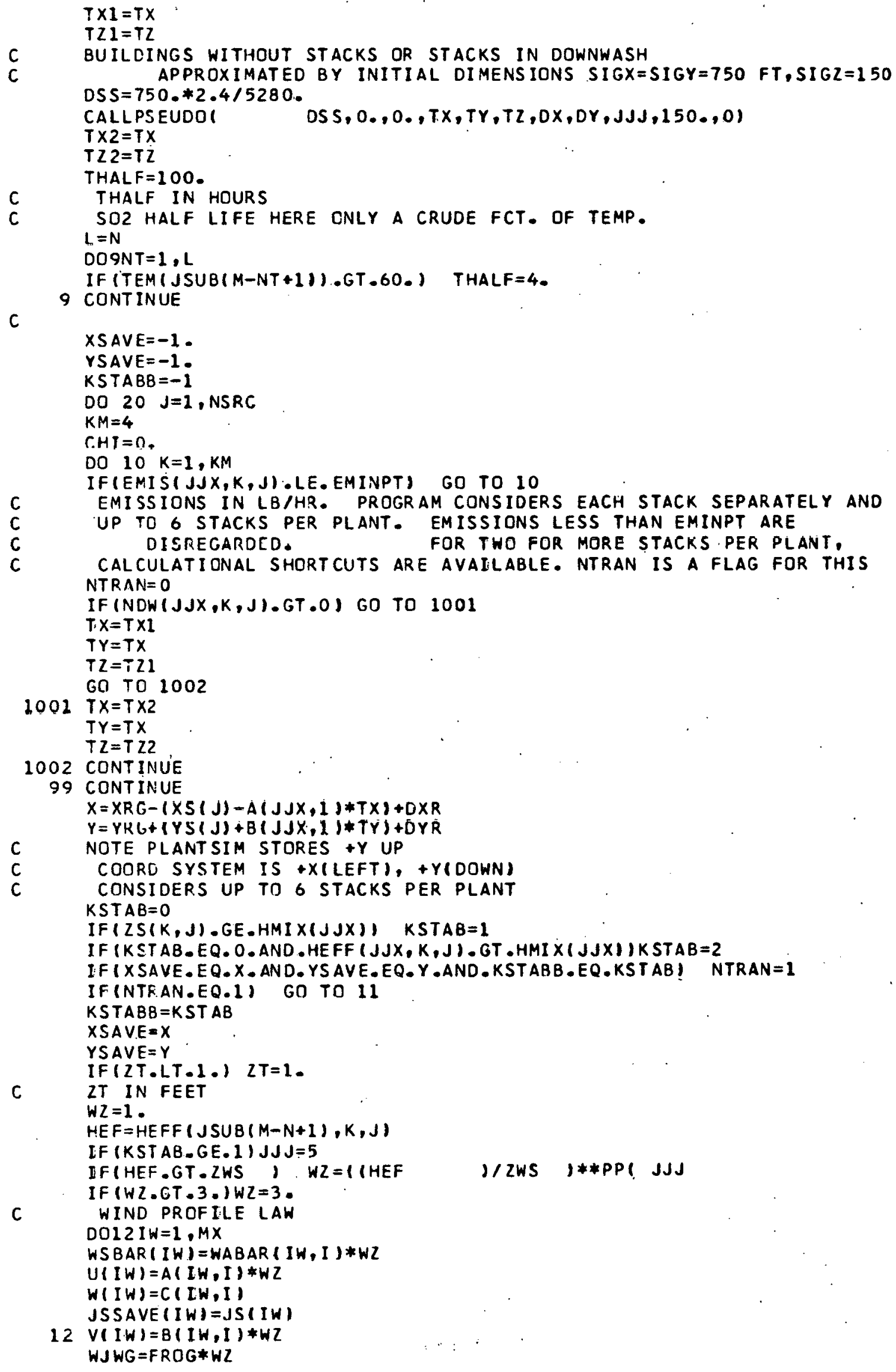




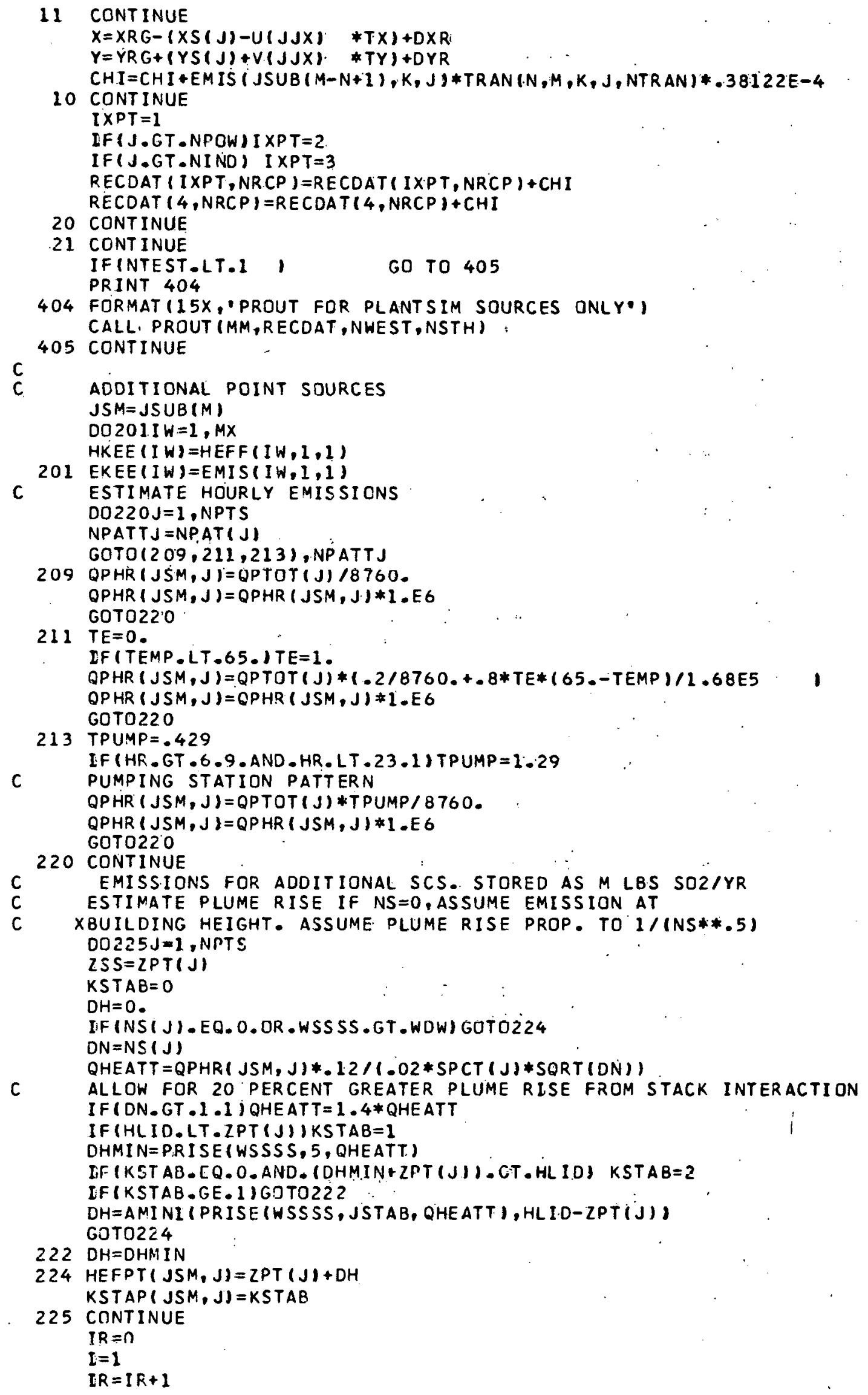




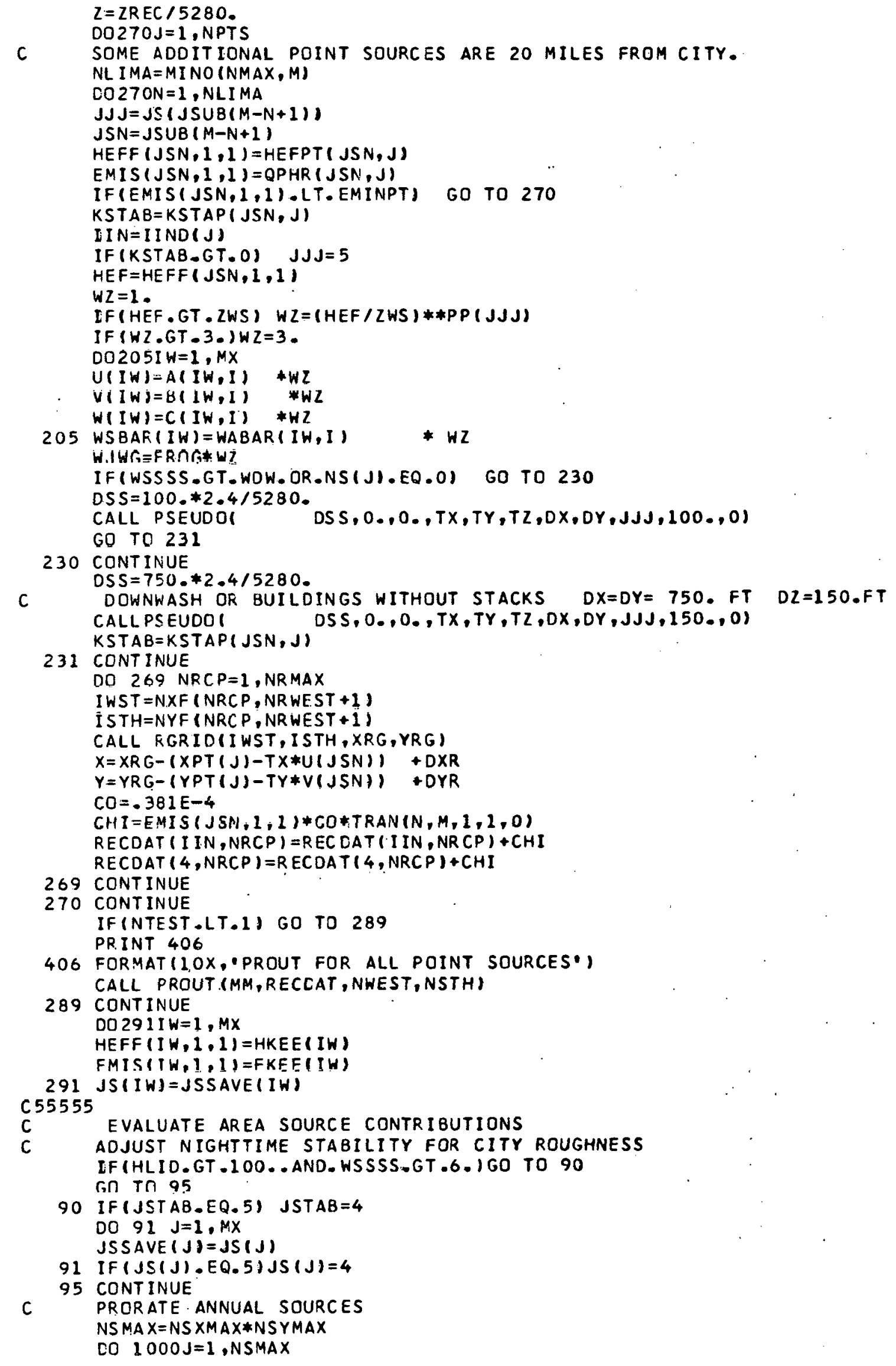




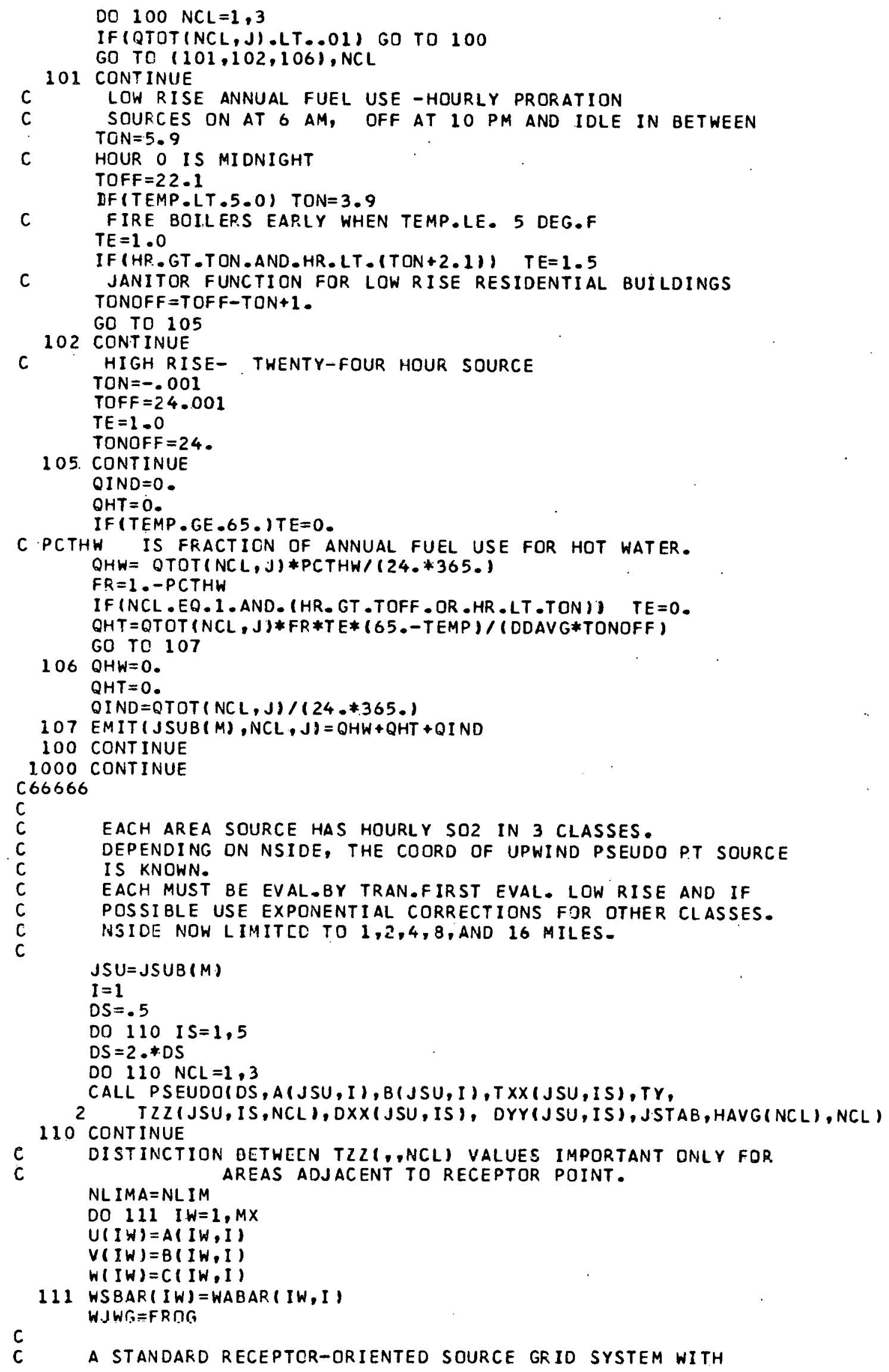




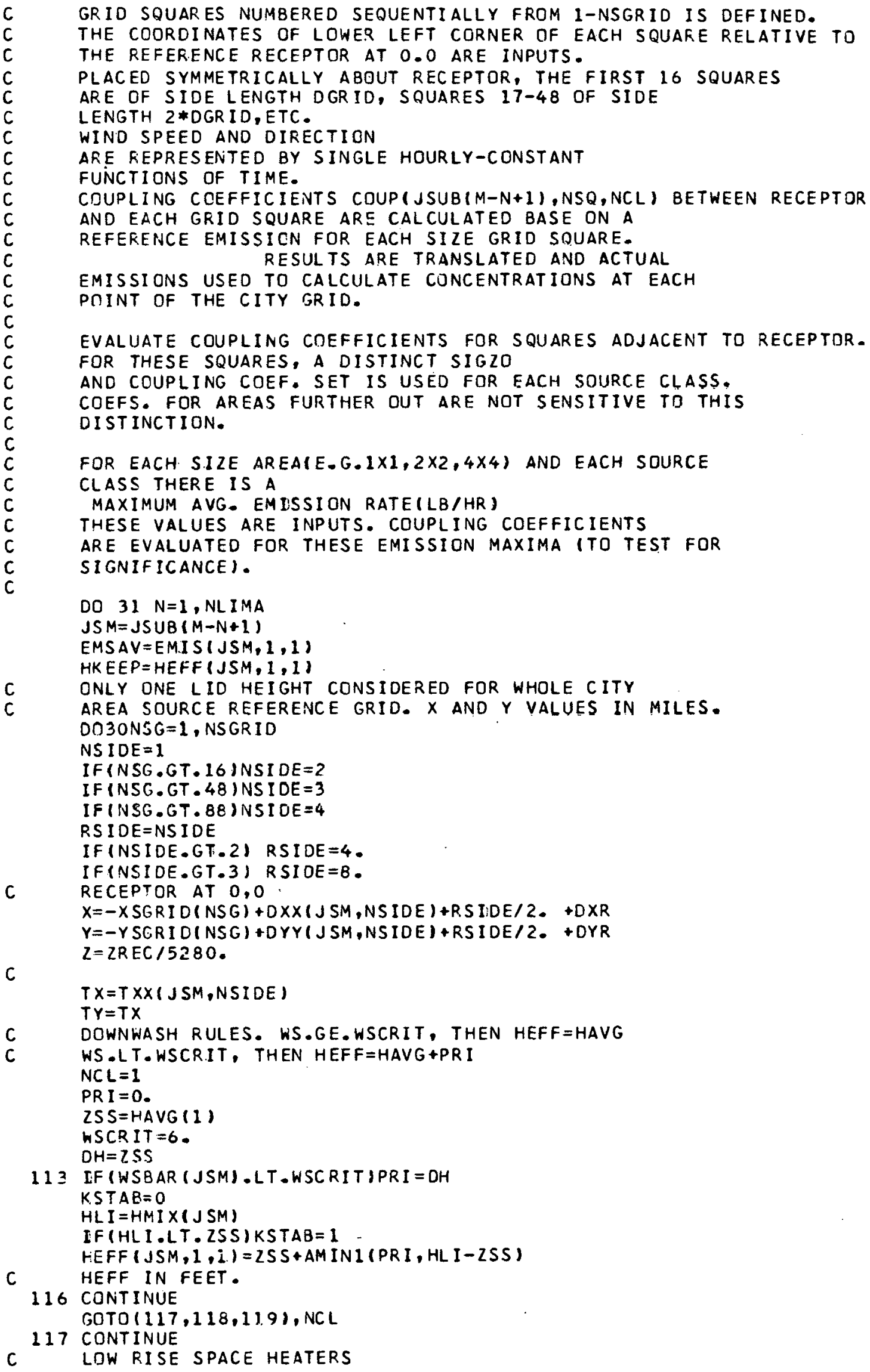




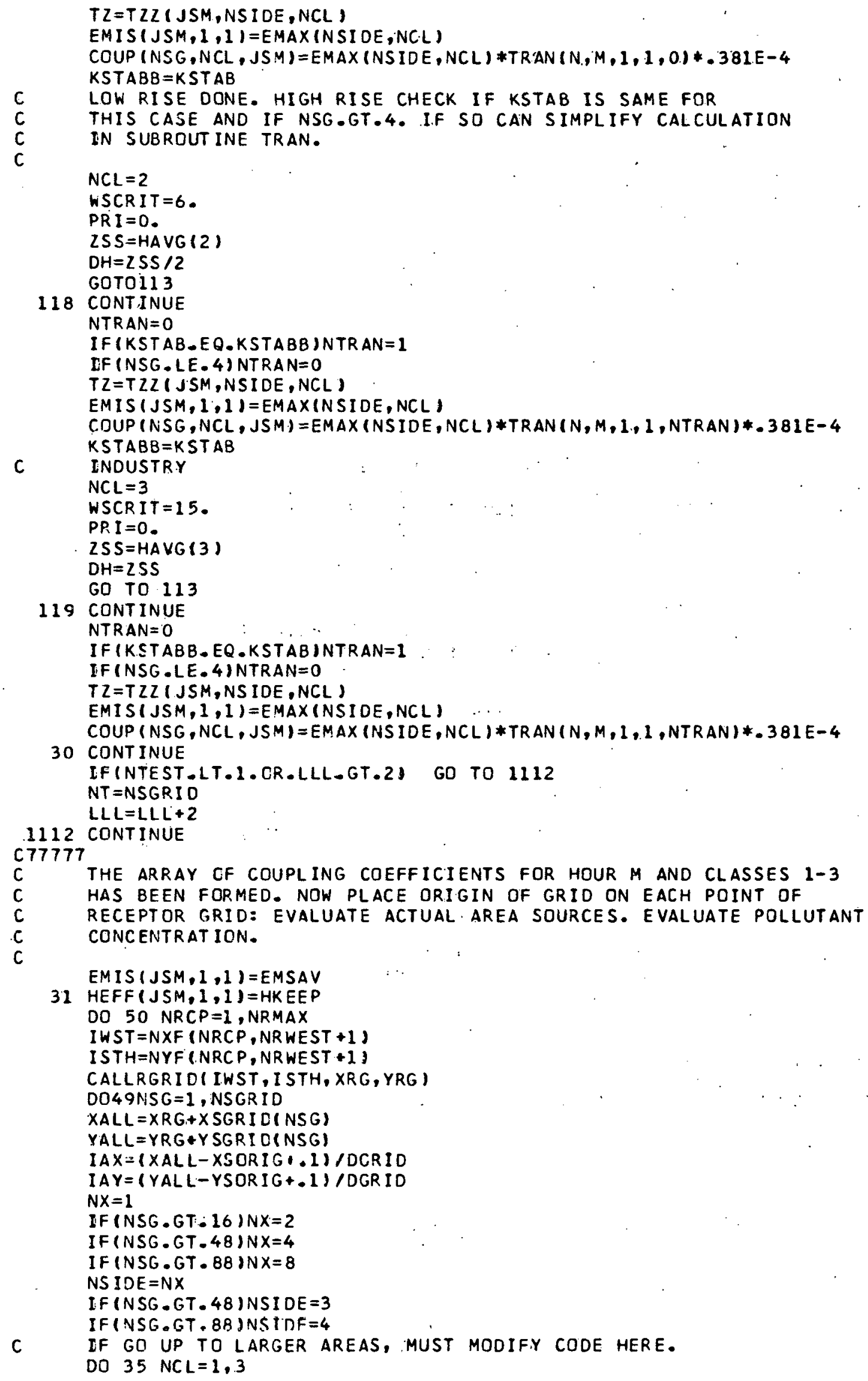


DO $35 \mathrm{~N}=1$, NLI IMA

$J S M=J S U B(M-N+1)$

$35 V Q(J S M, N C L)=0$

DO 45 NSIX $=1$, NX

DO 45 NSIY $Y=1, N X$

I $A X X=I A X-(N S I X-1)$

I $A Y Y=I A Y-(N S I Y-1)$

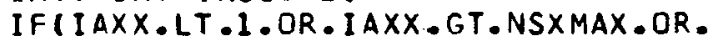

2IAYY.LT.1. OR.IAYY.GT.NSYMAX) GO TO 45

NAREA $=$ NS XMAX * (I AYY -1$)+1$ AXX

DO $44 \mathrm{NCL}=1,3$

DO $44 N=1$, NLIMA

$J S M=J S U B(M-N+1)$

$44 V D(J S M, N C L)=V Q(J S M, N C L)+E M I T(J S M, N C L, N A R E A)$

45 CONT INUE

IF (NTEST•LT.1.OR.LLL.GT.2) GO TO 1115

1115 CDNTINUE

$\mathrm{CHII}=0$

CHII $=0$

$\mathrm{CH} 13=0$

DO $47 \mathrm{~N}=1$, NLIMA

$J S M=J S U B(M-N+1)$

$(H I I=C H I 1+\operatorname{COUP}(N S G, 1, J S M) * V Q(J S M, 1) / E M A X(N S I D E, 1)$

CHI $2=C H I 2+C O U P(N S G, 2, J S M) * V Q(J S M, 2) / E M A X(N S I D E, 2)$

$47 \mathrm{CHI} 3=\mathrm{CHI} 3+\mathrm{COUP}(\mathrm{NSG}, 3, \mathrm{JSM}) * V Q(J S M, 3) / E M A X(N S I D E, 3)$

RECDAT $(3, N R C P)=R E C D A T(3, N R C P)+C H I 1+C H I 2$

RECDAT $(2, N R C P)=R E C D A T(2, N R C P)+C H I 3$

49 RECDAT $(4, N R C P)=R E C D A T(4, N R C P)+C H I ;+C H I 2+C H I 3$

50 CONT INUE

C 88888

C POLLUTANT CONCENTRATIONS CALCULATED FOR EACH POINT DN RECEPTOR

C GRID. CONTRIBUTIONS FROM MAJOR SOURCE CLASSES IS KNOWN.

$I R=\mathbf{l}$

C I=NNTAM

C PRINT469,M, I, RECDAT ( 4, NRTAM), HLID

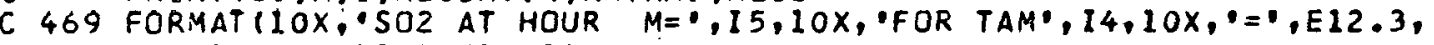

C $X \quad 10 X,{ }^{\circ} H L I D={ }^{\prime}, E 10.21$

$N P P P=N P P P+1$

IF(NPPP..LT.NPRINT) GO TO 6666

$N P P P=0$

C. IN DRDER TO IISF SIJRROUTINE PROUT TO PRINT GONCFNTRATTINNS

C IN GRID FORMAT, MUST LIMIT NRWEST +1 •LE.12

CALL PROUT (MM,RECDAT, NWEST, NSTH)

I JOHN=5

C PUNCH $1919, N N T A M, N R, M M,(R E C D A T(I, 1), I=1,4), 1 J O H N$

Ob66 CUNIINUE

C PUNCHED OUTPUT - ONE TAM STATION AT A TIME. FQUR HOURS PER CARD IF (VALOP.GT . O) SOZVAL ( I)=RECDAT (4,NRTAM)

IF (PNCHOP.EQ.O) GO TO 513

C $\quad I=N N T A M$

NTMP (NCOUNT, IR ) =I

PREC (NCOUNT, IR) = SO2VAL (I)

OBSC (NCOUNT, IR ) = AMIN $1(9.999$, SOBS (IR))

$295 \operatorname{MPU}($ NCOUNT $)=M$

NC OUNT $=$ NC OUNT +1

IF (NCOUNT.LT.5) RETURN

NC OUNT $=1$

DO 298 IR $=1,1$

PUNCH 470, (NTMP (NC, IR), NHRP (NC), MPU(NC),PREC(NC,IR), OBSC(NC,IR),

$x$ $N C=1,41$

298 CONTINUE

470 FORMAT $(4(11,13,14,2 F \cdot 5.3,2 x))$

513 CONTINUE

293 CONTINUE

191. FORMATII $1,2 \mathrm{X}, 13,2 \mathrm{X}, 14,412 \mathrm{X}, \mathrm{F} 6,3), 35 \mathrm{X}, 11)$

RETURN

END 
3. Function ITRAN

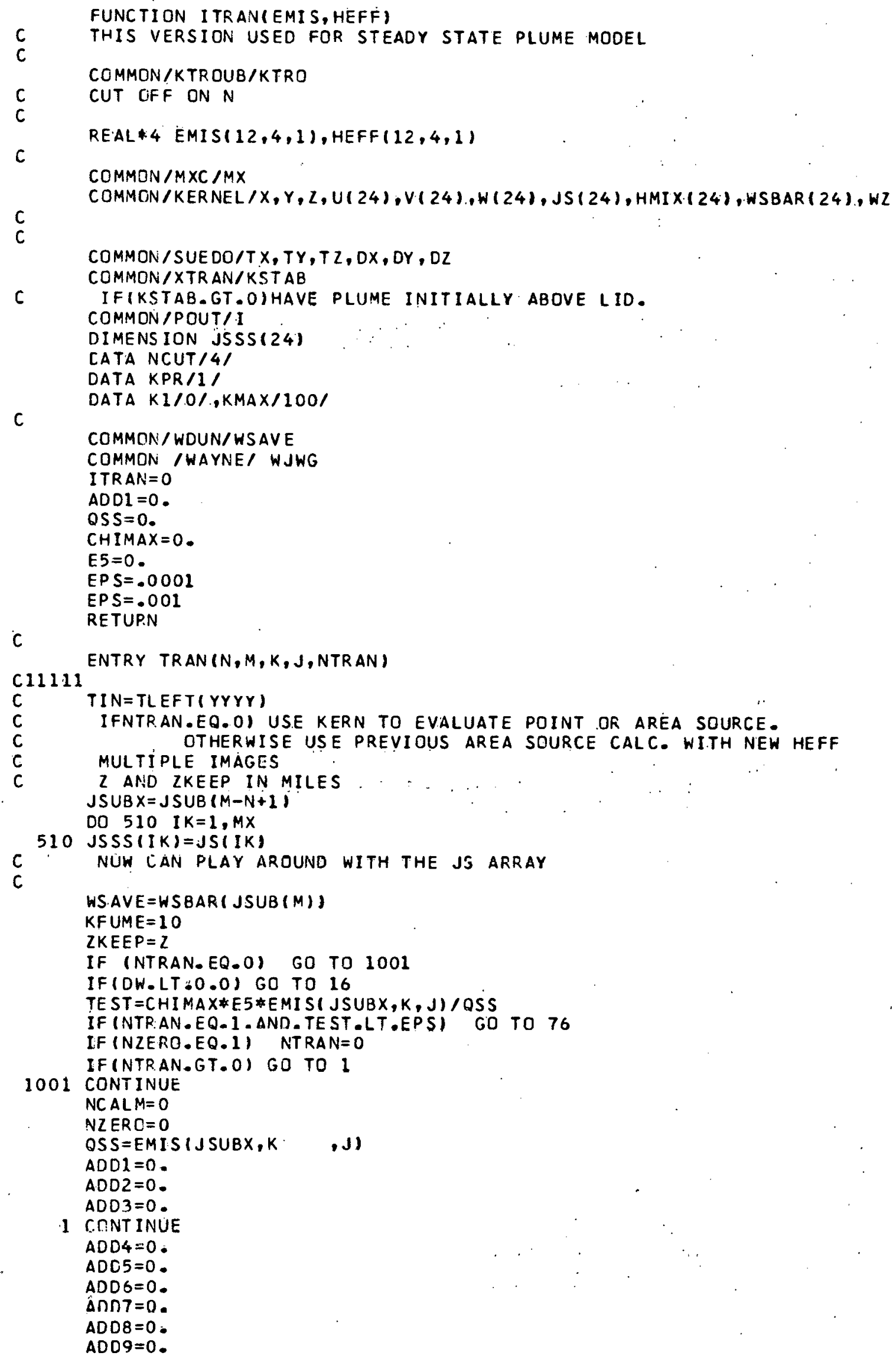




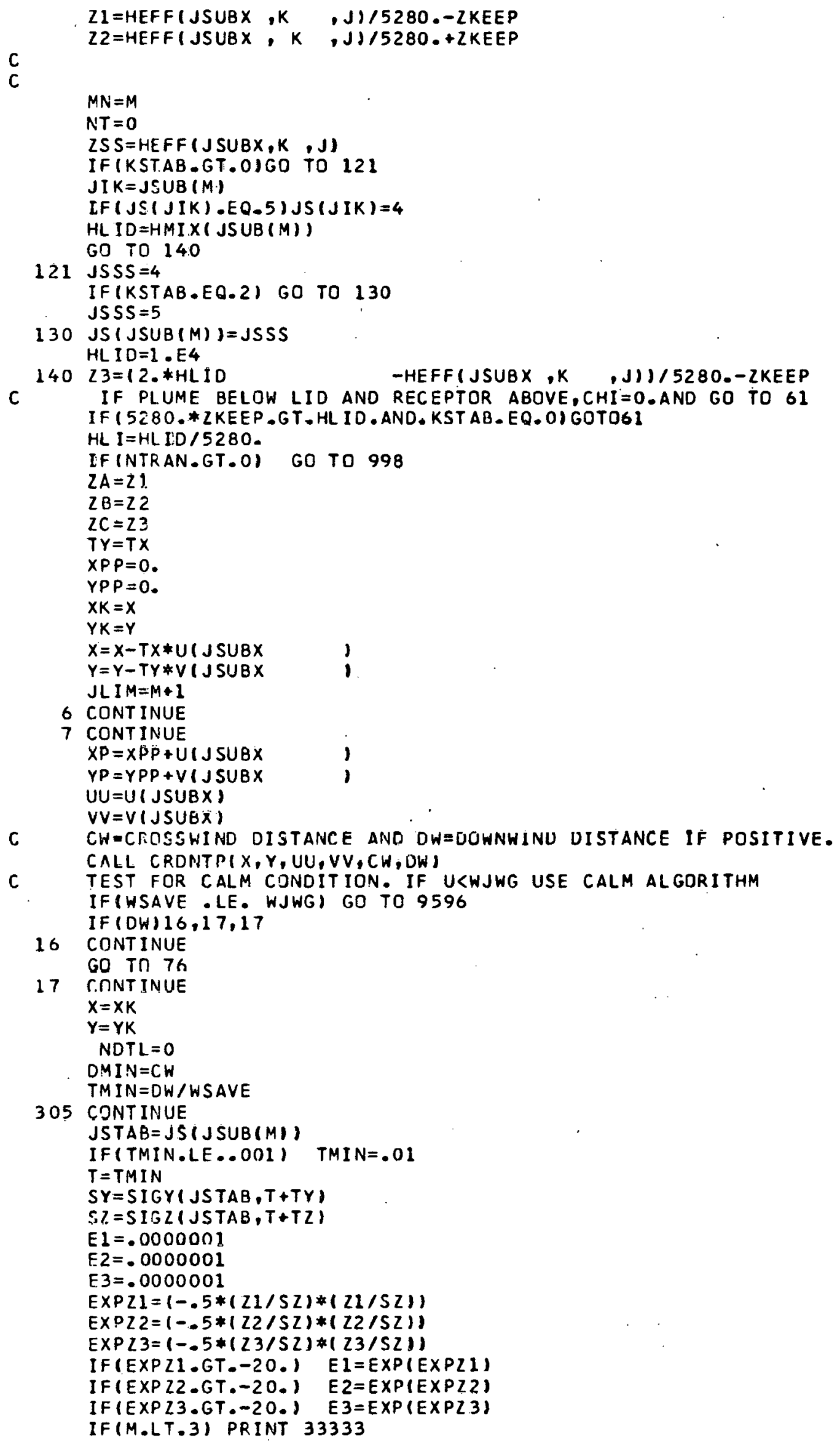




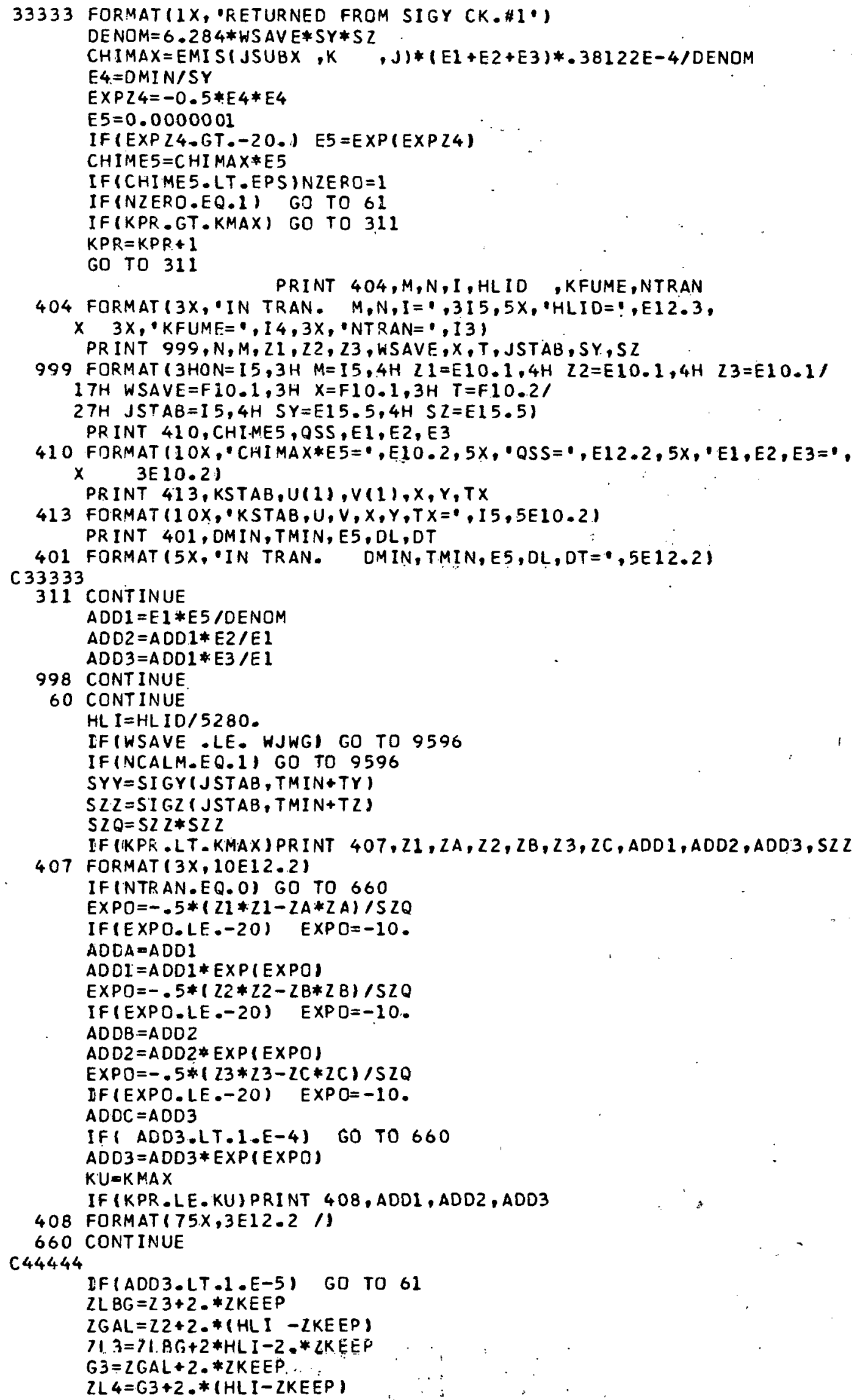




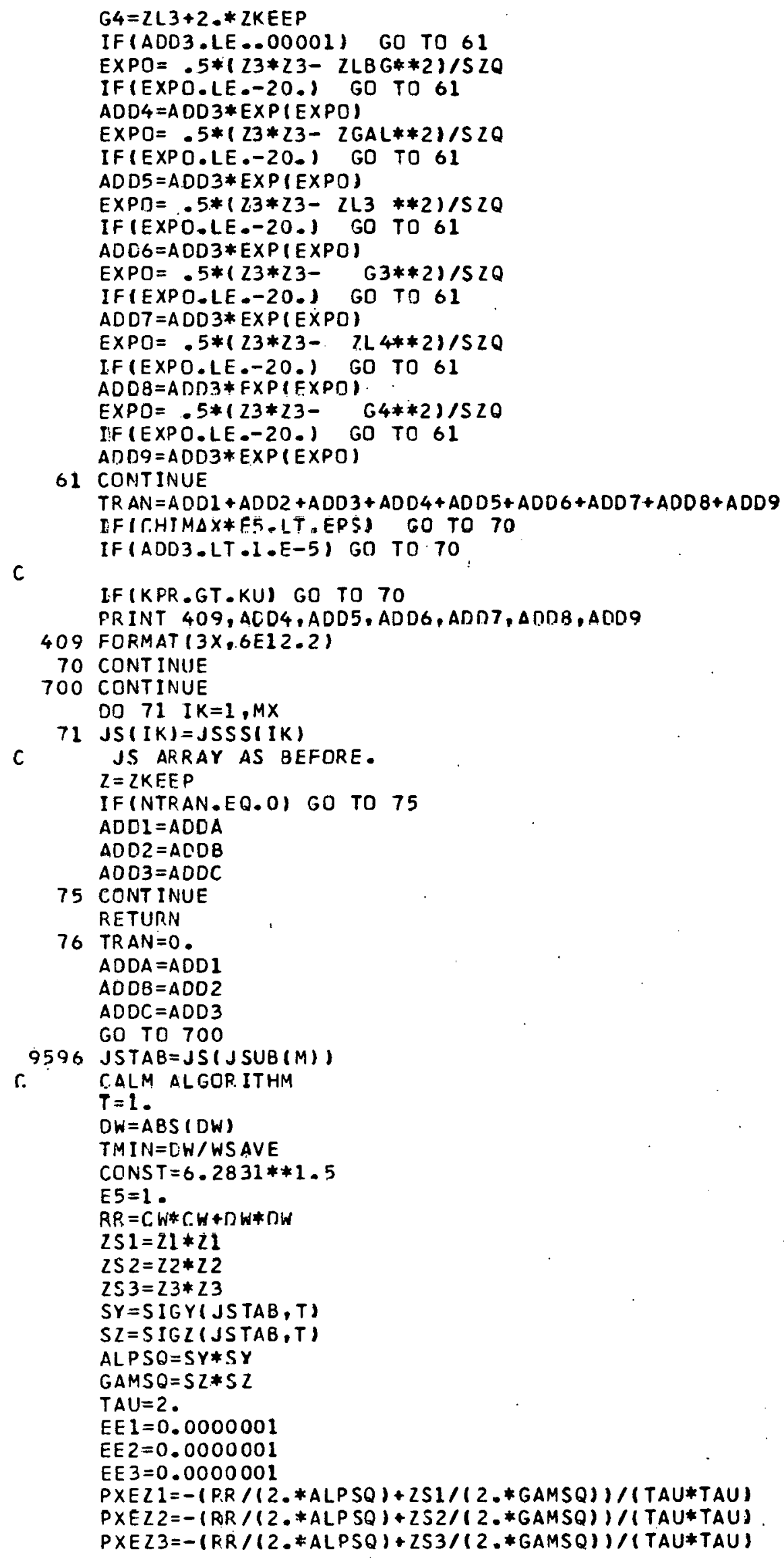




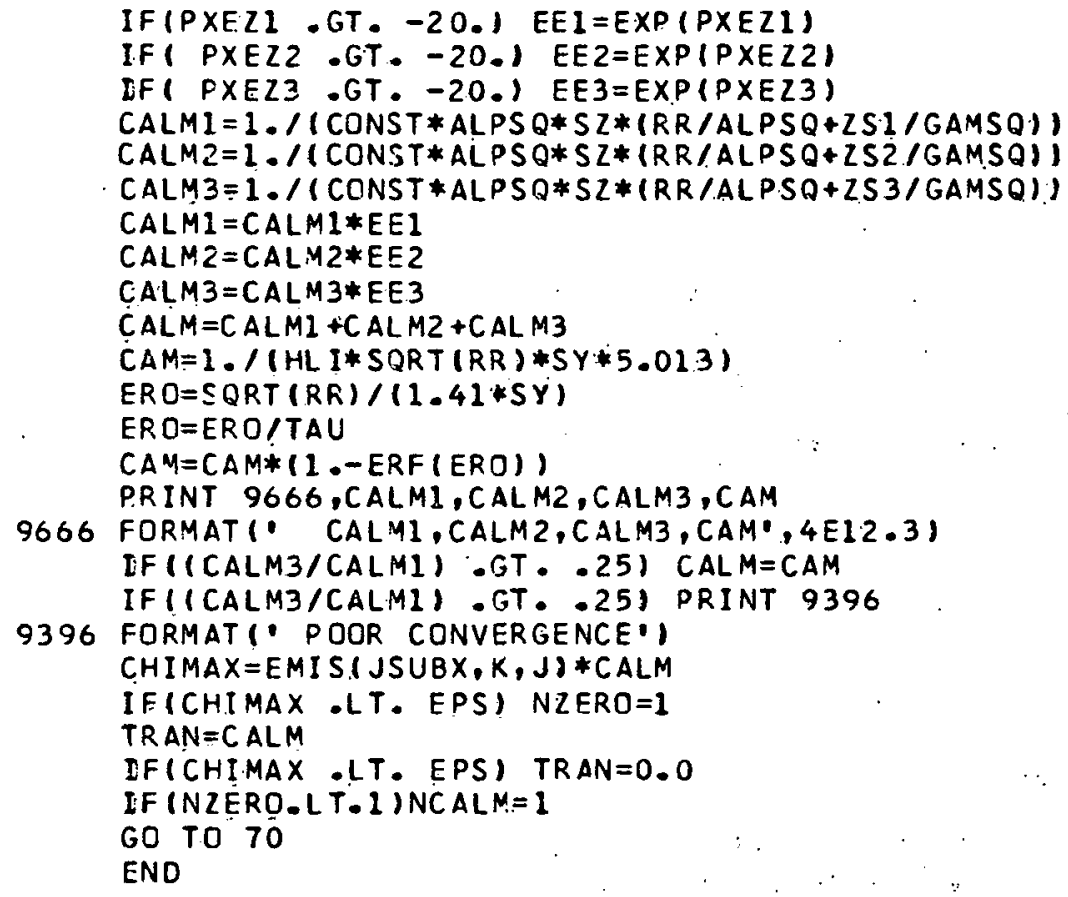

4. Subroutine CRDNTP

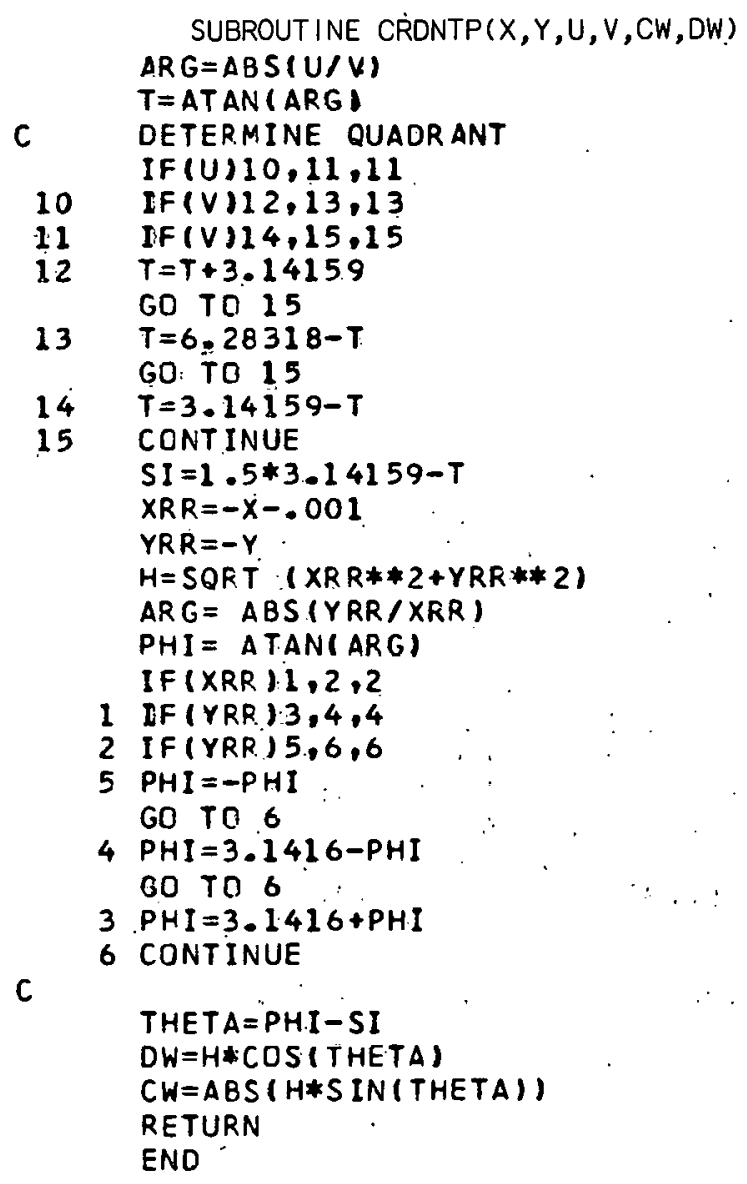


5. Function SIGY

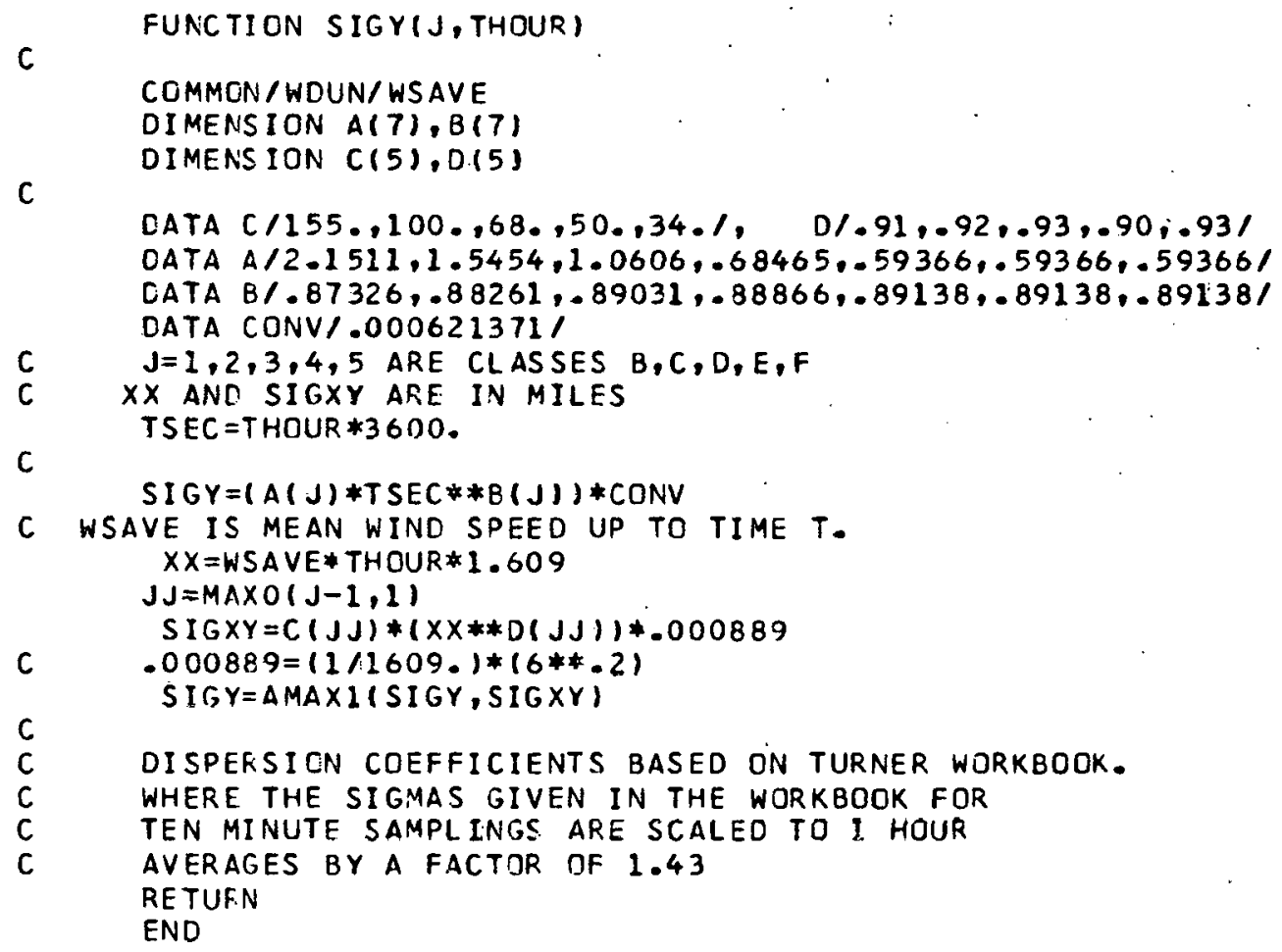

6. Function SIGZ

C

\section{FUNCTION $S I C Z(J, T H O U R)$}

COMMON/WDUN/WSAVE

C DISPEFISION COEF. BASED ON TURNERS WORKBOOK

$C \quad J=1,2,3,4,5$ ARE CLASSFS $B, C, D, E, F$

C $X$ AND SIGZ AR.E IN MILFS

DI MENSION $C(3,5), D(3,5)$

REAL TIME(7),A $(7,6), B(7,6)$

C

$$
\begin{aligned}
& \text { CATA TIME/0.,300,1000, 3000,,10000,130000,172000:1 } \\
& \text { DATA A/.17122,.27668,.41219,.51921..50963,.47639,.52140. } \\
& .11062, .39953, .41219, .57145, .76485, .71936, .88886 \text {. } \\
& .01338, .16640, .41219,1.0813,1.9467,2.3901,1.8877 \text {. } \\
& .01338, .16640, .41219,2.2830,2.9850,3.8684,6.7452 \text {, } \\
& .01338, .16640, .41219,2.3333,5.7990,16.897,20.673 \text {, } \\
& .01338, .16640, \ldots 41219,5.6801,14.599,64.577,54.1491 \\
& \text { DATA B/1.2098,i.0572,.92365,.84130,.79689,.76308,.69839. } \\
& 1.2864, .99275, .92365, .82449, .72571, .69082, .60486, \\
& 1.5922,1.1195, .92365, .73217, .59047, .51700, .49583 . \\
& 1.5922,1.1195, .92365, .63883, .53708, .45686 . .33677 \text {, } \\
& 1.5922,1.1195, .92365, .63646, .46497, .29621, .21517 \text {. }
\end{aligned}
$$

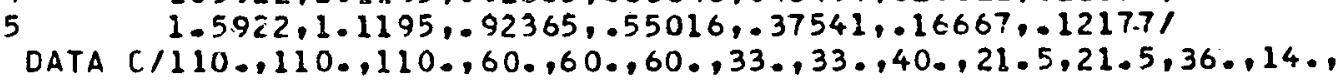




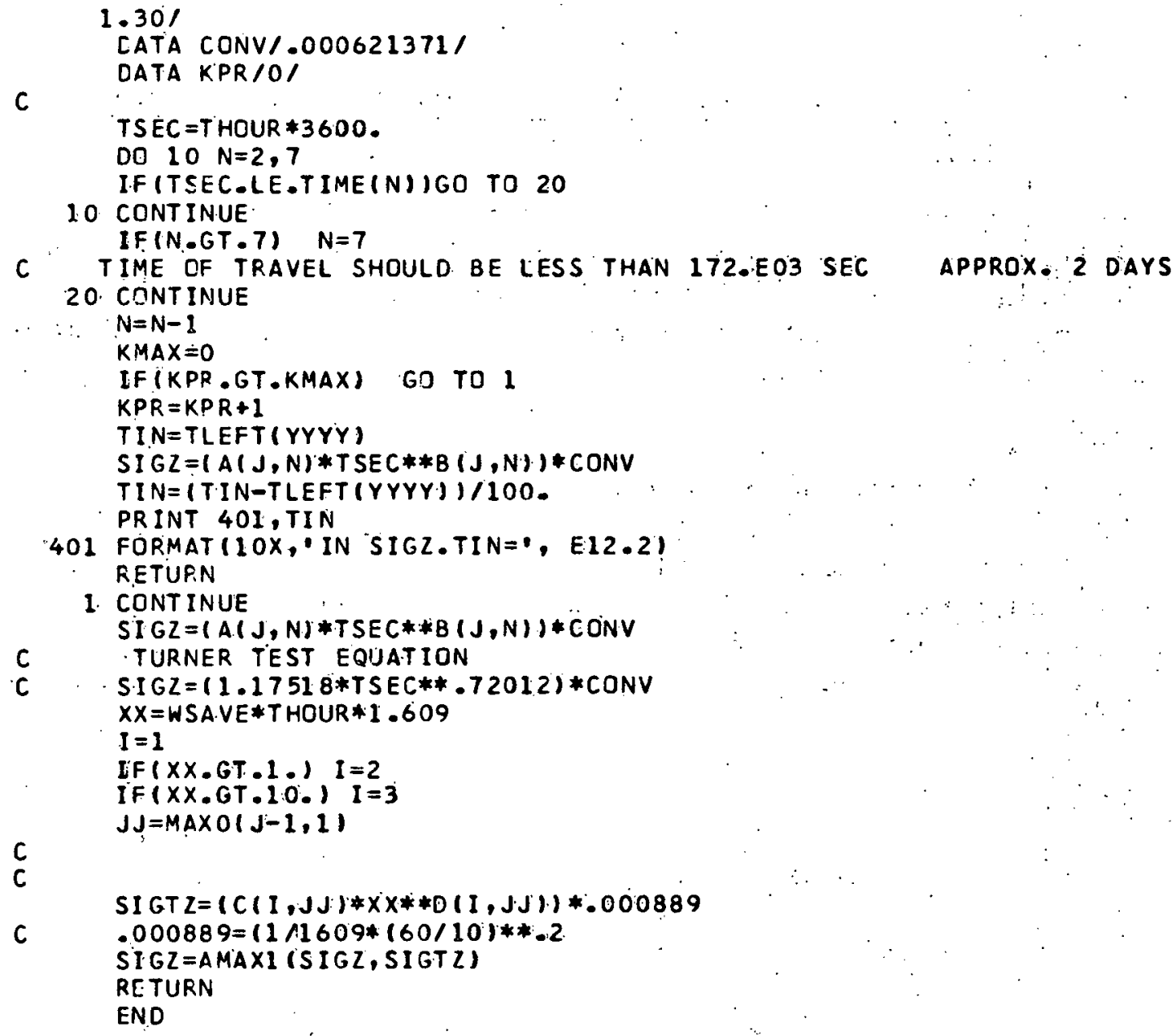




\section{APPENDIX C}

Example Computation of Hourly $\mathrm{SO}_{2}$ Concentrations at TAM 5 for February 17, 1967, Using the Plume Code

This appendix describes the calculation of hourly $\mathrm{SO}_{2}$ concentrations a't TAM 5 using the steady-state plume-model code (see Appendix B for computer program listings) with the calm algorithm operative whenever $W S \leq 1 \mathrm{mph}$. The calculations refer to the exact location of the TAM 5 aerovane using the winds measured at that location.

This appendix is divided into two parts. The first (Tables C.1-C.3) describes the input data necessary to carry out the computation. Some of these data are tabulated in Ref. 1 and will not be repeated here. The remaining data are included in this report. The second part (Table C.4) is a tabulation of the results. These results are a portion of the results obtained for the historical episode of February 16-18, 1967, which were displayed graphically and analyzed statistically in the text. (See Figs. 8 and 10 and Table 4.1.)

1. Input Data

a. Emission Data

(1) Power Plants

Arnual emission rates (p. 62 of Ref. 1).

Stack parameters ('I'able C.2).

Hunrly emisston rates (Table L.1).

(2) Major Point Sources

Annual emission rates (Table 7.3 of Ref. 1).

Stack parameters (Table 7.3 of Ref. 1).

Hourly emission rates (Table C.l).

(3) Additional Point Sources

Annual emission rates (Table 7.4 of Ref.. 1 ).

Stack parameters (Table 7.4 of Ref. 1).

Hourly emission rates (calculated in ISPDAV). 
(4) Area Sources

Annual emission rates (Figs. 7.2 and B.3 of Ref. 1).

Stack parameters (Table 1.4 of Ref. 1).

Hourly emission rates (calculated in "ISPDAV").

The coordinates of the various sources referred to in the tables are with respect to the coordinate system given in Fig. 7.1 of Ref. 1.

b. Meteorological Data

The meteorolngical data are shown in Table C.3.

c. Receptor (TAM 5) Coordinates

Coordinates for the TAM 5 receptor are given in Table C.2.

2. Results

The results are shown in Table C:4. There are two colums

labeled ${ }^{\mathrm{T}} \mathrm{SO}_{2}$. . The first column is the observed, and the second the calculated, concentrations. 
IABLE C.1. PLANTSIM Output. Hourly emissions of $\mathrm{SO}_{2}$ in $\mathrm{lb} / \mathrm{hr}$ ) and heat emissions (in therms/hr) for February 1 $7,1967$. PLANTSIM ALL SCUREES 167 FE3 $16-18$
OATE:67/02/17

119.232

0.0

91.885

91.885
91.685

91.885

283.314

623.315

3264.135

3209.439

3291.480

3182.094

3100.051

3318.828

3264.135

3811.074

4002.502

358.012

4303.316

4384.543

1541.274

91.885

HOUR

F1SK
Q_SO2

0.0

0.0
0.0

0.0

0.0

105.420

1561.521

1504.643

1041.152

1868.667

1925.547

1538.770

1675.278

1663.903

1584.272

1584.272

1811.789

1618.400

1584.272

1618.400

1618.400

1015.483

1015.483
C.ECO-I 1

38.880
0.0

29.962

29.962

29.962

29.962

92.385
29.342

1064.392

1046.557

1073.310

1037.640

1010.887

1189.237

1082.227

1064. 392

1242.7 .42

$1+21.092$

$1+03.257$

1305.164

1331.917

502.590
29.962

FISK -4

\section{0}

0.0

0.0

0.0
34.376

34.376
.09

509.192

c35.158

$-35.158$

609.348

t.27.896

553.706

546.297

542.577

El6.t11

E16.611

E90.801

527.740

516.611

527.740
527.740

331.136

331.136
$C \equiv C O-2$

\subsection{2}

0.0

CECO

Q_HE. $\overline{A T}$

38.880

0.0

29.962

29.962

29.962

29.962

92.385
29.342

C64.392

1046.55

1073.310

1037.640

1010.887

1139.237

1082.22

1064.392

1242.742

1305.164

1421.092

1403.257

1305.164

502.590

29.962

FISK - 5

FISK ${ }^{5}$

4136.574

4135.660

3626.501

4212.031

4059.286

4352.051

4202.949

4101.117

4288.406

4268.406

4288.406

4224.762

4380.238

4301.137

4224.762

4186.574

4352.051

43.7 .508

4250.219

4237.492

4402.969

438.4 .781

4352.051

4313.863
FI Sk $\mathrm{SO}^{-1}$

0.0

0.0
0.0

0.0

0.0

105.420

1.561 .521

1504.643

1641.152

1868.667

1538.770

1698.030

1663.903

1584.272

1584.272

1911.729

1518.400

1584.272

1.518 .400

i.j 15.483

lij 15.483

CRAWF_1

7177.012

7058.043

5590.750

$6: 85.598$

7335.641

$8 \$ 83.965$

$8: 68.426$

9477.094

9199.500

9239.156

9] 59.844

96.80 .531

7692.547

7811.520

$9=18.469$

8 63.277

9120.188

. 80.531

9120.188

-HEA $\bar{T}^{1}$

0.0

0.0

0.0

0.0

34.376
509.192

509.192
490.645

535.158

609.348

627.896

501.773

553.706

546.287

542.577

516.611

590.801

527.740

516.611

527.740

527.740

331.136

CRAHF 1

2340.332

2301.537

1823.072

2314.469

2017.044

230.455

2392.058

2831.729

2663.619

3090.359

299.838

3012.770

2831.729

2986.907

291.044

2508.441

2547.236

3038.633

2857.592

2999.838

2961.044

2961.044

2973.976
FIsK -2

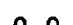

0.0

0.0 0.0

135.420

1551.521

16.1 .152

641.152

19.55 .547

1925.547

15.38 .770

1698.030

1603.903

1584.272

1584.272

$18: 1.789$

$16: 8.400$

$16: 8.400$

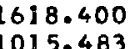

1015.483

CRAWF_2

$\subseteq D 2$

12713.836

$95 \div 7.586$

$121=0.660$

$120 C 0.480$

$132 \mathrm{Cl} .922$

11850.301

13427.191

13539.832

13389.645

13389.645

13352.098

13502.285

13464.738

13230.469

13652.461

1327.016

7382.422
2651.733

2651.730

D. 0
3.0

F: SK $\bar{T}^{2}$

0.0
0.0
0.0
0.0
0.0

34.376 
TABLE C.l (Contd.)

PLANTSIM ALL SCURCES 167 FEB 16-18

\begin{tabular}{|c|c|c|c|c|c|c|}
\hline HOUR & $\begin{array}{l}\text { RI DGL_1 } \\
\text { Q_SO2 }\end{array}$ & $\begin{array}{l}\text { RIDGL }{ }^{1} \\
Q_{-} \text {HEA } T\end{array}$ & $\begin{array}{l}R I D G L=2 \\
0_{-} 502\end{array}$ & $\begin{array}{l}\text { RIDGL_}{ }^{2} \\
\text { Q_HEAT }\end{array}$ & $\begin{array}{l}\text { RIDGL_-3 } \\
Q_{-} \mathrm{SO}_{2}\end{array}$ & $\begin{array}{l}\text { RIDGL } 3 \\
Q_{-} H E A T{ }^{3}\end{array}$ \\
\hline 1 & 2576.630 & 840.206 & 2576.630 & 840.206 & 2576.630 & 840.206 \\
\hline 2 & 2770.577 & 903.449 & 2770.577 & 903.449 & 2770.577 & 903.449 \\
\hline 3 & 2398.092 & 781.987 & 2398.092 & 781.987 & 2398.092 & 781.987 \\
\hline 4 & 2135.261 & 696.281 & 2135.261 & 696.281 & 2135.261 & 696.281 \\
\hline 5 & 2407.177 & 784.550 & 2407.177 & 784.950 & 2407.177 & 784.950 \\
\hline 6 & 2963.835 & 966.468 & 2963.835 & 966.468 & 2963.835 & 966.468 \\
\hline 7 & 2763.390 & 901.106 & 2763.390 & 901.106 & 2763.390 & 901.106 \\
\hline 8 & 3832.314 & 1249.668 & 3832.314 & 1249.668 & 3832.314 & 1249.668 \\
\hline 9 & 3490.649 & 1138.256 & 3490.649 & 1138.256 & 3490.649 & 1138.256 \\
\hline 10 & 3951.052 & 1288.387 & 3951.052 & 1288.387 & 3951.052 & 1288.387 \\
\hline 11 & 3903.786 & 1272.975 & 3903.786 & 1272.975 & 3903.786 & 1272.975 \\
\hline 12 & 3999.179 & 1304.081 & 3999.179 & 1304.081 & 3999.179 & 1304.081 \\
\hline 13 & 3939.379 & 1284.581 & 3939.379 & 1284.581 & 3939.379 & 1284.581 \\
\hline 14 & 3831.739 & 1249.481 & 3831.739 & 1249.481 & 3831.739 & 1249.481 \\
\hline 15 & 3843.412 & 1253.287 & 3943.412 & 1253.287 & 3843.412 & 1253.287 \\
\hline 16 & 3123.915 & 1018.668 & 3123.915 & 1018.668 & 3123.915 & 1018.668 \\
\hline 17 & 3478.114 & 1134.168 & 3478.114 & 1134.168 & 3478.114 & 1134.168 \\
\hline 18 & 4105.557 & 1338.899 & 4105.957 & 1338.899 & 4105.957 & 1338.899 \\
\hline 19 & 4106.242 & 1338.993 & 4106.242 & 1338.993 & 4106.242 & 1338.993 \\
\hline 20 & 3870.781 & 1262.212 & 3870.781 & 1262.212 & 3870.781 & 1262.212 \\
\hline 21 & 3894.126 & 1269.825 & 3894.126 & 1269.825 & 3894.126 & 1269.825 \\
\hline 22 & 3905.799 & 1273.631 & 3905.799 & 1273.631 & 3905.799 & 1273.631 \\
\hline 23 & 3882.167 & 1265.925 & 3882.167 & 1265.925 & 3882.167 & 1265.925 \\
\hline 24 & 3479.553 & 1134.637 & 3479.553 & 1134.637 & 3479.553 & 1134.637 \\
\hline HOUR & $\begin{array}{l}\text { RI DGL }=6 \\
Q_{-} \mathrm{SO}_{2}\end{array}$ & $\begin{array}{l}\text { R. IDGL } 6{ }^{6} \\
\text { O_HEAT }\end{array}$ & $\begin{array}{l}\mathrm{CALUM}_{-1} \mathrm{AL} \\
\mathrm{Q}_{-} \mathrm{SO2}\end{array}$ & $\begin{array}{l}\text { CALUM } 1 \\
\text { Q HEAT }\end{array}$ & ${ }_{Q_{\mathrm{SOL}}}^{\text {CALUM_2 }}$ & CAL UM ${ }^{2}$ \\
\hline 1 & 0.0 & $0.1 \quad 1$ & 1295.036 & 422.295 & 1295.036 & 422.295 \\
\hline 2 & 0.0 & 0.0 & 1072.511 & 349.732 & 1072.511 & 349.732 \\
\hline 3 & 2034.315 & 663.364 & 1097.236 & 357.795 & 109.7 .236 & 357.795 \\
\hline 4 & 3083.888 & 1005.616 & 1146.686 & 373.920 & 1146.686 & 373.920 \\
\hline 5 & 3696.136 & 1205.263 & $1 C 47.786$ & 341.670 & 1047.786 & 341.670 \\
\hline 6 & 4045.996 & 1319.347 & 1171.412 & 381.982 & 1171.412 & 381.982 \\
\hline 7 & 4133.457 & 1347.868 & 2086.234 & 680.295 & 2086.234 & 680.295 \\
\hline 8 & 5139.297 & 1675.859 & 2654.910 & 865.732 & 2654.910 & 865.732 \\
\hline 9 & 5576.621 & 1818.464 & 2630.186 & 857.670 & 2630.186 & 857.670 \\
\hline 10 & 6451.262 & 2103.674 & 2605.459 & 849.607 & 2605.459 & 849.607 \\
\hline 11 & 6188.871 & 2018.111 & 2704.359 & 881.857 & 2704.359 & 881.857 \\
\hline 12 & 6232.602 & 2032.372 & 2729.086 & 889.920 & 2729.086 & 889.920 \\
\hline 13 & 6232.602 & 2032.372 & 2729.086 & 889.920 & 2729.086 & 889.920 \\
\hline 14 & 6145.137 & 2003.851 & 2654.910 & 865.732 & 2654.910 & 865.732 \\
\hline 15 & 6101.406 & 1989.590 & 2729.086 & $8 B 9.920$ & 2729.086 & 889.920 \\
\hline 16 & 5532.887 & 1804.204 & 2729.086 & 889.920 & 2729.086 & 889.920 \\
\hline 17 & 5620.352 & 1832.725 & 2704.359 & 881.857 & 2704.359 & 881.857 \\
\hline 18 & 6713.656 & 2189.237 & 3495.559 & 1139.857 & 3495.559 & 1139.857 \\
\hline 19 & 6669.926 & 2174.577 & 3668.635 & 1196.294 & 3668.635 & 1196.294 \\
\hline 20 & 5970.211 & 1946.809 & 3643.910 & 1188.232 & 3643.910 & 1188.232 \\
\hline 21. & 5882.746 & 1918.287 & 3643.910 & 1188.232 & 3643.910 & 1188.232 \\
\hline 22 & 5970.211 & 1946.809 & 3693.359 & 1204.357 & 3693.359 & 1204.357 \\
\hline 23 & 5882.746 & 1918.287 & 3248.311 & 1059.232 & 3248.311 & 1059.232 \\
\hline 24 & 5882.746 & 1918.287 & 973.611 & 317.482 & 973.611 & 317.482 \\
\hline
\end{tabular}

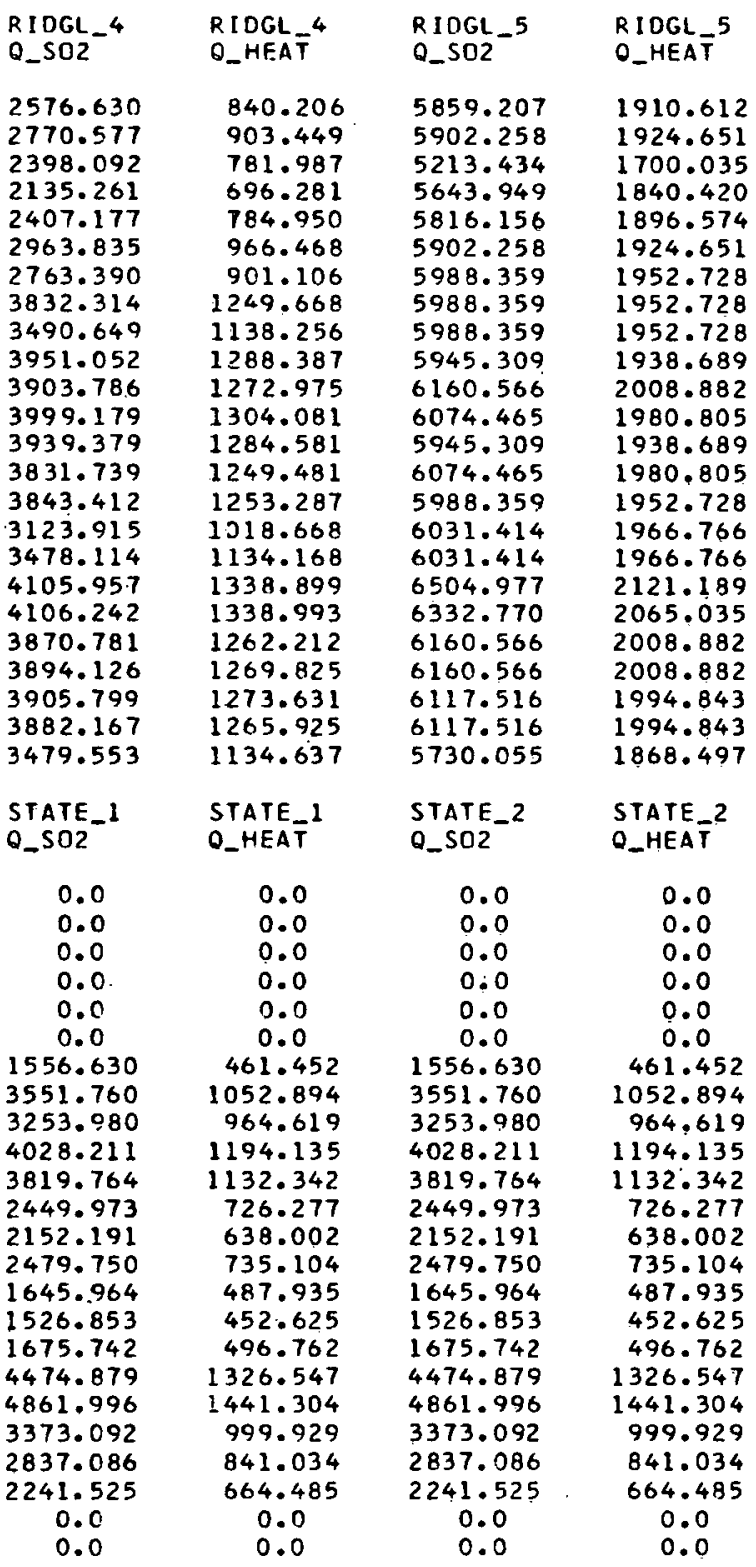


PLANTSIM ALL SCUREES - 67 FEB 16-18 [ATE: 67/02/17

\begin{tabular}{|c|c|c|c|}
\hline HOUR & $\begin{array}{l}\text { STATE } 3 \\
\text { O_SOL }^{3} \text {. }\end{array}$ & $\begin{array}{l}\text { STATE } 3 \\
\text { S_HEAT }\end{array}$ & $\begin{array}{l}\text { STATE_4 } \\
\text { Q_SOZ }\end{array}$ \\
\hline 1 & 2567.287 & 761.054 & 2567.287 \\
\hline 2 & 2567.287 & 761.054 & 2567.287 \\
\hline 3 & 2567.287 & 761.054 & 2567.287 \\
\hline 4 & 2567.287 & 761.054 & 2567.287 \\
\hline 5 & 2567.287 & 761.054 & 2567.287 \\
\hline 6 & 2567.287 & 761.054 & 2567.287 \\
\hline 7 & 2670.916 & 791.774 & 2670.916 \\
\hline 8 & 3422.225 & 1014.494 & 3422.225 \\
\hline 9 & 2567.287 & 761.054 & 2567.287 \\
\hline 10 & 3422.225 & $: 014.494$ & 3422.225 \\
\hline 11 & $344 \mathrm{~d} .133$ & 022.174 & 3448.133 \\
\hline 12 & 3474.039 & 1029.854 & 3474.039 \\
\hline 13 & 3085.432 & 914.654 & 3085.432 \\
\hline 14 & 3344.502 & 991.454 & 3344.502 \\
\hline 15 & 2670.916 & 791.774 & 2670.916 \\
\hline 16 & 2567.287 & 761.054 & 2567.287 \\
\hline 17 & 2904.082 & 860.895 & 2904.082 \\
\hline 18 & 3474.039 & 1329.854 & 3474.039 \\
\hline 19 & 3007.709 & 391.615 & 3007.709 \\
\hline 20 & 3137.246 & 330.014 & 3137.246 \\
\hline 21 & 2929.988 & 368.574 & 2929.988 \\
\hline 22 & 2981.803 & 383.935 & 2981.803 \\
\hline 23 & 2670.915 & 791.774 & 2670.916 \\
\hline 24 & 2670.915 & 791.774 & 2670.916 \\
\hline HOUR & $\begin{array}{l}\text { CAMPBELL } \\
Q_{-502}\end{array}$ & $\begin{array}{l}\text { CAMPBELL } \\
\text { O_HEAT }\end{array}$ & $\begin{array}{l}\text { PROC_GAM } \\
\text { O_SO2 }\end{array}$ \\
\hline 1 & 1063.779 & 358.246 & 483.105 \\
\hline 2 & 1060.359 & .357 .692 & 481.832 \\
\hline 3 & 1060.353 & 357.692 & 481.832 \\
\hline 4 & 1060.358 & 357.692 & 481.832 \\
\hline 5 & 1060.358 & 357.692 & 481.832 \\
\hline$t$ & 1067.199 & 360.000 & 484.379 \\
\hline 7 & 1070.619 & 361.154 & 485.653 \\
\hline 8 & 1067.199 & 360.000 & 484.379 \\
\hline 9 & 1454.058 & $\angle 90.500$ & 556.830 \\
\hline 10 & 1447.217 & 488.192 & 554.282 \\
\hline 11 & 1440.376 & $\angle 85.884$ & 551.734 \\
\hline 12 & 1430.114 & 482.423 & 547.912 \\
\hline 13 & 1426.694 & 481.269 & 546.639 \\
\hline 14 & 1423.274 & 480.115 & .545 .365 \\
\hline 15 & 1419.853 & 478.561 & 544.091 \\
\hline 16 & 1416.432 & 977.807 & 542.817 \\
\hline 17 & 1416.432 & 477.807 & 542.817 \\
\hline 18 & 1416.432 & 477.807 & 542.817 \\
\hline 19 & 1419.853 & 478.561 & 544.091 \\
\hline 20 & 1419.853 & 478.961 & 544.091 \\
\hline 21 & 1419.853 & 978.561 & 544.051 \\
\hline 22 & 1419.853 & 478.961 & 544.091 \\
\hline 23 & 1416.432 & $\therefore 77.807$ & 542.817 \\
\hline 24 & 1416.432 & 477.807 & 542.817 \\
\hline
\end{tabular}

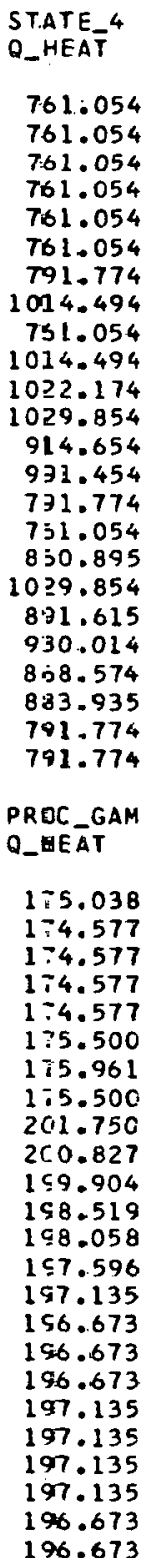

STATE_S
Q_SO2
9136.547
9136.513
9300.613
9095.531
9218.582
9177.563
9751.793
9546.715
9628.746
9628.746
9792.809
9628.746
9341.629
9792.809
9.528 .746
9974.840
9259.598
9828.746
9546.715
9095.531
9464.680
9628.746
9464.680
9628.746
9013.500

SHER
9 .

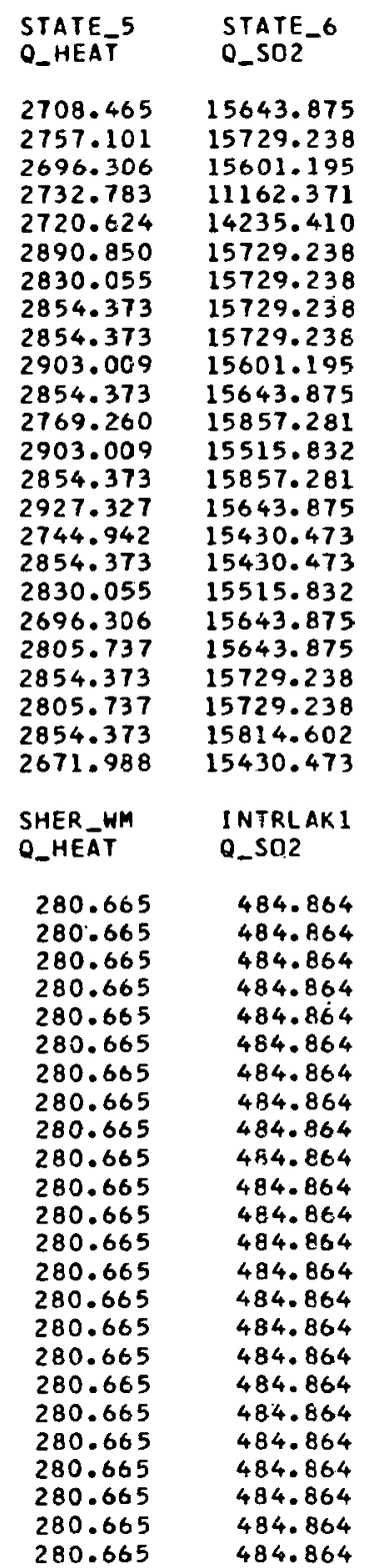

STATE 6

4637.516 4662.820 4624.863 3309.006 4219.984 4662.820 4662.820 4662.820 4662.820 4624.863 4637.516 4637.516
4700.777 4599.559 4599.559 4637.516 4637.516 4574.254 4599.559 459.559 4637.516 4662.820 4662.820 4688.125 4574.125

\section{INTRLAK 1} Q_HEAT

182.432
182.432
182.432
182.432
182.432
182.432
182.432
182.432
182.432
182.432
182.432
182.432
182.432
182.432
182.432
182.432
182.432
182.432
182.432
182.432
182.432
182.432
182.432
182.432
MARBHE

o_SO2

385.618 385.5 .94 385.594 385.594 385.594

385.642 385.665 385.642 385.642 385.594 385.547 385.547 385.453

385.429

(385.406

385.38

385.382

385.382

385.406 385.406 385.406 385.406 385.406

385.382

INT_HARI o_soz

539.659 53.8 .244 538.244 538.244 538.244 541.074 542.490 541.074 795.224 792.393 789.563 785.317 783.901 782.486 781.070 779.655 675.005 675.005 676.420 676.420 676.420 676.420 675.005
MARBHEAD Q_HEAT.

377.235 377.212 377.212 377.212 377.258 377.281 377.258 377.258 377.212 377.166 7.097 377.073
377.051 377.051 377.027 377.004 377.004 377.027 377.027 377.027 377.004 377.004
377.004

INT_HARI

175.976 175.514 175.514 175.514 176.437 176.899 176.437 259.312 258.389 257.466 256.082 255.620 255.159 254.697 254.235 220.110 220.110 220.572 220.572 220.572 220.572 220.110 
PLANTSIM ALL SCURCES 167 FES $16-18$

HOU







1
1
1
1
1
1
1
1
17
18
19
20
21
22
2
24

CON 1

Q_50 2

177.904
177.697
177.697
177.697
177.697
178.112
179.319
178.112
288.622
288.207
287.792
287.169
286.561
286.754
286.546
286.338
286.338
286.338
286.546
286.546
286.546
286.546
286.338
286.338

HOUR

INTRLAK 2

227.933

227.933

227.933

227.933

227.933

227.933

227.933

227.933

227.933

227.933

227.933

227.933

227.933

227.933

227.533

227.933

227.933

227.933

227.933

27.933

227.933

227.933

227.933
227.933
CON 1 CO US STEEL

_502

406.255

406.255

406.255

406.255

406.255

406.255

406.255

406.255

406.255

406.255

406.255

406.255

406.255

406.255

406.255

406.255

406.255

406.255

406.255

406.255

127.32

INTRLAK
Q HEAT

REP $5 T L$
G SOT2

86.605

86.605

86.605

86.605
6.605

86.605

86.605
86.605

86.605

86.605

86.605

86.605

86.605

86.605
86.605

86.605

86.605

86.605

86.605

86.605

86.605

86.605

86.605

86.605

86.605
86.605 Q_HEAT

931.540

931.540
931.540

931.540

931.540

931.540

931.540

931.540

931.540

931.540

9.31 .540
931.540

931.540

931.540

931.540
931.540

931.540

931.540

931.540

931.540

931.540

931.540

931.540

REP_STL

508.00

508.003

$5 \mathrm{C} 8.003$

508.003

508.003

508.003

508.003

$5 \mathrm{C8} .003$

508.003

508.003

508.003

508.003

508.003

508.003

508.003

508.003

508.003

508.003

08.003

08.003

$5 \mathrm{C8} .003$

508.003

508.003
508.003
INT_H

\subsection{0}

117.440

117.440

117.440

117.440

117.440

117.440

178.870

178.870

178.870

178.870

278.870

178.870

178.870

178.870

153.575

153.575

153.575

153.575

153.575

153.575

153.575

153.575

CRANE
Q_SO 2

221.30

219.144

219.144

219.144

219.144

223.462

225.620

223.462

773.553

764.918

758.442

756.282

754.123

754.123
751.964

751.964
749.805

290.235

290.235

290.235

292.394

292.394

292.394

292.394

290.235
290.235
INT_HAR 2

117.000

117.000

117.000
117.000

117.000

117.000

117.000

117.000

178.200

178.200

178.200

178.200

178.200

178.200

178.200

153.000

153.000

153.000

153.000

153.000
153.000

153.000

CRANE

QHEAT

70.966

70.273

70.273

70.273

71.658

72.350
71.658

71.658
248.057

246.672

246.672
245.288

245.288

243.211
242.519

241.826

241.134

240.442

93.070

93.070

93.763

93.763

93.763

93.763

93.070
93.070
CEN_SOYA

O_SO2

C.EN_SOYA

O_HEAT

DARL ING

Q_SO2

DARL ING

446.270

445.421
445.421

445.421

445.421

447.120

447.120

778.319

774.922

772.375

771.525

770.676

769.827

603.378

603.378

604.227

604.227

604.227

603.378
603.378

ARMOUR

0.0

0.0

0.0

0.0

0.0

0.0

0.0

0.0

0.0

0.0
0.0
0.0

0.0

0.0
0.0
0.0

0.0

0.0
0.0

0.0

0.0

0.0

0.0

0.0
0.0

145.523
145.246

145.246

145.246

145.246

145.800

146.077
145.800

253.800

253.246

252.692

251.861

251.584
251.308

251.031

250.754

196.754

196.754
197.031

197.031 
PLANTSIM ALL SCURCES

.67 FEB 16-18

\begin{tabular}{|c|c|}
\hline HOUR & $\begin{array}{l}\text { INT_HAR } 3 \\
Q_{-} \mathrm{SO}_{2}\end{array}$ \\
\hline 1 & 401.714 \\
\hline 2 & 396.052 \\
\hline 3 & 396.052 \\
\hline 4 & 396.052 \\
\hline 5 & 396.052 \\
\hline 6 & 407.375 \\
\hline 7 & 413.037 \\
\hline 8 & 407.375 \\
\hline 9 & 504.969 \\
\hline 10 & 493.646 \\
\hline 11 & 482.323 \\
\hline 12 & 465.338 \\
\hline 13 & 459.677 \\
\hline 14 & 454.015 \\
\hline 15 & 448.354 \\
\hline 16 & 442.692 \\
\hline 17 & 402.507 \\
\hline 18 & 402.507 \\
\hline 19 & 408.168 \\
\hline 20 & 408.168 \\
\hline 21 & 408.168 \\
\hline 22 & 408.168 \\
\hline 23 & 402.507 \\
\hline 24 & 402.507 \\
\hline HOUR & $\begin{array}{l}B I R O_{-} S C N \\
0 S_{2}\end{array}$ \\
\hline & \\
\hline 1 & 108.385 \\
\hline 2 & 108.385 \\
\hline 3 & 108.385 \\
\hline 4 & 108.385 \\
\hline 5 & 108.385 \\
\hline 6 & 108.385 \\
\hline 7 & 108.385 \\
\hline 8 & 108.385 \\
\hline$s$ & 108.385 \\
\hline 10 & 108.385 \\
\hline 11 & 108.335 \\
\hline 12 & 108.385 \\
\hline 13 & 108.385 \\
\hline 14 & 108.385 \\
\hline 15 & 108.385 \\
\hline 16 & 103.385 \\
\hline 17 & 108.385 \\
\hline 18 & 108.385 \\
\hline 19 & 108.385 \\
\hline 20 & 108.385 \\
\hline 21 & 108.385 \\
\hline 22 & 108.385 \\
\hline 23 & 108.385 \\
\hline 24 & 108.385 \\
\hline
\end{tabular}

INT_HAR 3 GLICDEN

$\begin{array}{ll}163.742 & 101.274 \\ 161.435 & 100.882 \\ 161.435 & 100.882 \\ 161.435 & 100.882 \\ 161.435 & 100.882 \\ 166.050 & 101.665 \\ 168.358 & 102.057 \\ 166.050 & 101.665 \\ 205.830 & 166.458 \\ 201.215 & 165.675 \\ 196.599 & 164.892 \\ 189.676 & 163.717 \\ 187.368 & 163.325 \\ 185.061 & 162.934 \\ 182.753 & 162.542 \\ 180.445 & 162.150 \\ 164.065 & 162.150 \\ 164.065 & 162.150 \\ 166.373 & 162.542 \\ 166.373 & 162.542 \\ 166.373 & 162.542 \\ 166.373 & 162.542 \\ 164 . C 65 & 162.150 \\ 164.065 & 162.150 \\ \text { BIRO SON } & \text { EJ_BRACH } \\ \text { Q_HEAT } & \text { G_S S02 }\end{array}$

42.412

42.412

42.412

42.412

42.412

$42.41 ?$

42.412

42.412

42.412

42.412

42.412

42.412

42.412

42.412

42.412

42.412

42.412

42.412

42.412

42.412

42.412
42.412 Q_HEAT

44.755
44.582
44.582
44.582
44.582
44.928
45.101
44.928
73.561
73.215
72.869
72.350
72.177
72.004
71.831
71.658
71.658
71.658
71.831
71.831
71.831
71.831
71.658
71.658
EJ B.RACH

135.212

132.905

132.705

132.905

132.905

137.520

139.828
137.520

137.520

137.520
132.905

132.905
128.289

128.289

121.366

119.058

116.751

114.443

112.135

112.135

114.64

114.443

114.443

112.135

112.1135
WF: IGLEY

Q_SO2

141.233

138.549

138.549

138.549

143.917

146.600
83.917

167.467

162.099

156.731

148.680

145.996

143.313

1.40 .629

137.945
137.945

137.945

140.629

140.629
140.629

140.629
140.629

140.629
137.945

137.945

IL:-MEAT

\subsection{0}

78.160

78.160

78.160

78.160

$? 8.160$

78.160

.8 .160

0.0
0.0

0.0

0.0
0.0

0.0
0.0

0.0

0.0

0.0

0.0
0.0
0.0

0.0

0.0
0.0
0.0
WR. IGLEY
Q_HEAT

97.154

95.308

95.308

95.308

99.000

100.846
99.000

99.000

111.508

111.508

111.815
102.277

102.277

100.431
98.585

96.738

94.892

94.892
94.892

94.892

96.738

96.738

96.738

96.738
94.892

94.892

ILL MEAT

Q_HEAT

34.081

34.081

34.081

34.081

34.081

34.081

34.081

34.081

0.0
0.0

0.0

0.0

0.0

0.0
0.0
0.0

0.0

0.0

0.0

0.0

0.0

0.0

0.0
DARLING 2

O_SO2

446.580

441.149

441.149

441.149

452.010

457.440

452.010

644.197

633.337
622.476

622.476

606.186

600.756

589.895

589.895

584.465
501.475

501.475
501.475

501.475
506.905

506.905

506.905

506.905

501.475
501.475

AM_CANCD

Q_SO2

456.706

449.181

449.181

449.181

449.181

464.231
471.757

464.231

716.090

701.040

685.990

663.415

655.889

648.364

640.839

633.314

488.175

488.175

495.700

495.70

495.700

495.700

488.175
DARLING

O_HEAT

151.829

149.983

149.983

149.983

153.675

155.521
153.675

219.015

215.323

211.630

206.092
204.246

204.246

200.553

198.707

170.492

170.49

172.338

172.33

172.338

172.338

170.492
170.492

AM_CANCO

Q_HEAT

154.061

151.523

151.523

151.523

156.600

159.138

156.600

241.560

236.483

231.406

221.252

218.714

213.637

164.67

164.677

167.215

167.215

167.215
164.677

164.677
164.677

CDNT_
Q_SO 2

198.40

198.083

198.083
198.083

198.083

198.720

199.038

198.720

198.720

198.083

19.7 .446

19.4 .446

196.490

196.172

195.854

195.535

195.217

195.217

195.217

195.535

195.535

195.535

195.535

195.217
195.217

TRI BUNE

O_SO2

81.995

80.519

80.519

80.519

80.519

83.472

84.948

83.472

.

94.406

88.501

87.025

84.073

85.549

85.549

84.073

84.073 
TABLE C.1 (Contd.)

PLANTSIM ALL SCURCES IST FEB $16-18$

$\begin{array}{cc}\text { HOUR } & \text { GEN_ELEC } \\ & \begin{array}{l}\text { Q_SOZ } \\ 1\end{array} \\ 1 & 712.336 \\ 2 & 712.336 \\ 3 & 712.336 \\ 4 & 712.336 \\ 5 & 712.336 \\ 6 & 712.336 \\ 7 & 712.336 \\ 8 & 712.336 \\ 9 & 712.336 \\ 10 & 712.336 \\ 11 & 712.336 \\ 12 & 712.336 \\ 13 & 712.336 \\ 14 & 712.336 \\ 15 & 712.336 \\ 16 & 712.336 \\ 17 & 712.336 \\ 18 & 712.336 \\ 19 & 712.336 \\ 20 & 712.336 \\ 21 & 712.336 \\ 22 & 712.336 \\ 23 & 712.336 \\ 24 & 712.336\end{array}$

GEN_ELEC

HOR WEEN

232.284

79.101
78.807 232.284

232.284

232.284

232.284

232.234

232.284

232.234

232.284

232.284

232.284

232.284
232.284

232.284

232.284

232.284
232.284

232.284
232.284

232.284

232.284

232.284

232.28 .4

HOUR

HAM_WHSE
Q_SO 2

HAM-WHSE
Q_HEAT

78.807
78.807

78.807

78.807

79.394

79.687
79.394

79.394

78.807

78.221

77.341

76.754

76.461

76.167

76.167

76.167

76.461

76.461

76.461

76.167
76.167

Q_502

JD.WESTN

US_STEE2

US STEE2

AVEY_COR

31.115
30.999

30.999

30.999

30.999

31.230

31.345
31.230

31.230

30.999

30.768

30.307

30.192

30.076

29.961

29.961

30.076
30.076

30.076

30.076

29.961
29.961

394.449
385.250

$148.413 \quad 334.139$

333.606

385.250

385.250

144.952

144.952
144.952

144.952

.

412.849

151.875

155.336

403.649

536.405

518.005

499.605

472.005

462.805

444.405

435.205

365.240

365.240

374.439

374.439

374.439
365.240

365.240

151.875

201.825

194.902

187.979

17.594

174.133

167.210

333.606

333.606
333.606

334.673

335.206

334.673

333.606

332.540

330.406

330.406

329.339

163.748

328.805

137.423

328.805

$140.885 \quad 329.339$

140.885

329.339

140.885

329.339

329.339

328.805

137.423

32.8 .805

GT_LAKEC

GT-LAKEC

Q_SO2

WESSON

RHEEM
Q_SO2

58.393

169.598

116.666

32.541

O_HEAT

44.769

44.538

32.373

116.624

116.624

32.373

169.537

86.992

57.009

57.009

169.537

116.624

116.707

91.218

$61.163 \quad 169.658$

$-116.749$

169.718
169.658

116.707

62.667

59.898

57.128
52.975

51.590

50.205

169.658
169.537

16.707

32.708

32.876

32.708

67.597

67.262

116.541

169.416
169.235

116.541
116.417

116.375

169.175

116.334

66.926

66.423
66.255

66.088

65.920

65.752

116.250

116.250

65.752
48.308

48.308

48.475

48.475

116.292

116.292

48.475

48.475

48.308

48.308

173.807

170.117

170.117

170.117

44.538

45.000

45.231

93.000

92.538

92.07 .7

91.385

91.154

90.923

90.461

66.461

66.461

66.692

66.692

66.46

66.461

177.497

181.187

177.497

191.409
184.029

176.648

165.578

161.888

158.197
154.507

150.81 ?

150.817

150.817

154.507

154.507

154.507

150.817

150.817

766.180

764.958

764.958
764.958

764.958

767.404

768.627

767.404

767.404

764.958

758.842

757.619

756.396

755.173

753.949

753.949

755.173

755.173

755.173

753.949

753.949

RHEEM
O_HEAT

108.692

108.692
106.385
106.385

106.385

106.385

111.000

113.308

111.000

115.085

110.469

103.546

98.931

96.623

94.315

94.315

96.623

96.623

96.623

94.315

04.315

19.318

9.318

19.318

19.318

19.318

19.318

19.318

19.318

19.318

19.318

19.318

19.318

19.318

19.318

19.318

19.318

19.318

19.318

19.318
19.318

$\mathrm{ROCK}_{\mathrm{S}} \mathrm{OLA}$

86.973 
PLANTSIM ALL SCUREES $\quad 677$ FEB $16-18$ CATE: 67/02/17

HOUR

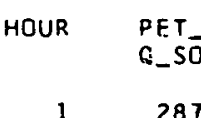

$\begin{array}{lr}287.767 & 97.823 \\ 281.657 & 95.746 \\ 281.657 & 95.746 \\ 281.657 & 95.746 \\ 281.657 & 95.746 \\ 293.876 & 99.900 \\ 299.986 & 101.977 \\ 293.876 & 99.900 \\ 405.073 & 137.700 \\ 392.854 & 133.546 \\ 380.634 & 129.392 \\ 362.305 & 123.161 \\ 356.196 & 121.085 \\ 350.086 & 119.008 \\ 343.976 & 116.931 \\ 337.866 & 114.854 \\ 282.263 & 95.954 \\ 282.268 & 95.954 \\ 288.378 & 98.031 \\ 288.378 & 98.031 \\ 288.378 & 98.031 \\ 288.378 & 98.031 \\ 282.268 & 95.954 \\ 282.268 & 95.954\end{array}$

MAT_BIS

269.956

266.601

266.601

266.601

266.601

276.665

273.311

273.311

259.892

249.828

243.118

243.118

236.409

236.409

236.409

239.764

239.764

23.0764

236.409

236.409

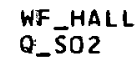

WIFHALL

GEN_REND G_SÖ2

290.510
289.000

289.000

289.000

289.000

292.020
293.529

292.020

292.020

289.000

285.981

281.452

279.943

278.433

276.923

275.414

275.414

275.414
276.923

276.923

276.923

275.414
275.414

275.414

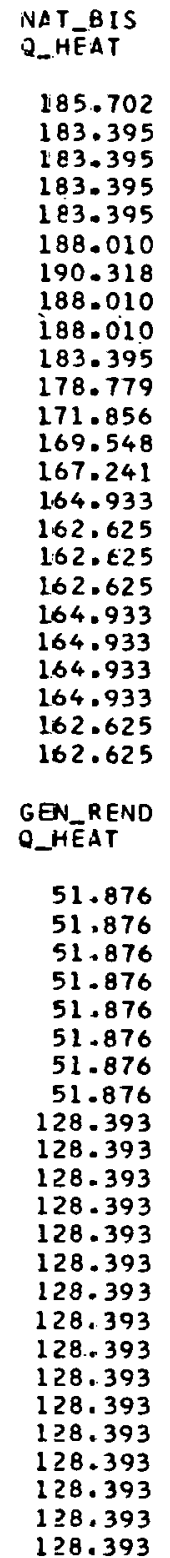

.

SUP_TAN
Q_S02
5.020
4.888
4.888
4.888
4.888
5.152
5.284
5.152
124.163
123.899
123.634
123.238
123.106
122.974
122.842
122.710
75.827
75.827
75.959
75.959
75.959
75.959
75.827
75.827

CUNEO

Q_SO2

$\begin{array}{ll}15.920 & 18.252 \\ 15.920 & 18.252 \\ 15.920 & 18.252 \\ 15.920 & 18.252 \\ 15.920 & 18.252 \\ 15.920 & 18.252 \\ 15.920 & 18.252 \\ 15.920 & 18.252 \\ 39.401 & 45.174 \\ 39.401 & 45.174 \\ 39.401 & 45.174 \\ 39.401 & 45.174 \\ 39.401 & 45.174 \\ 39.401 & 45.174 \\ 39.401 & 45.174 \\ 39.401 & 45.174 \\ 39.401 & 45.174 \\ 39.401 & 45.174 \\ 39.401 & 45.174 \\ 39.401 & 45.174 \\ 39.401 & 45.174 \\ 39.401 & 45.174 \\ 39.401 & 45.174 \\ 39.401 & 45.174 \\ & \end{array}$

SUP_TAN

3.069

2.988

2.988
2.988

2.988

3.150

3.231
3.150

75.915

75.915

75.753
75.592

75.592

75.350
75.269

75.269
75.188

75.188
75.107

7.026

46.361

46.361

46.442

46.442

46.442

46.442

46.361

CUNEO

59.576
59.249
59.249
59.249
59.249
59.903
60.230
59.903
59.903
59.249
58.595
57.614
57.287
56.959
56.632
56.305
56.305
56.305
56.632
56.632
56.632
56.632
56.305
56.305

ST BROS

Q_SO2

356.944
353.887

353.887

353.887
353.887

360.001

363.058

360.001

353.887

347.773

338.602

332.488

332.488

329.431

326.374
326.374

326.374

329.431

329.431

329.431

329.431

326.374
326.374

H_BUTTON

D_SO2

117.493

114.401

114.401
114.401

114.401
114.401

120.585

123.677

120.585

120.585

114.401

108.217

98.942

95.850

92.758

89.666

86.574

86.574
86.574

86.574

89.666

89.666

89.666

89.666

86.574

86.574
ST_BRDS

134.728

133.574

133.574

133.574

135.882

137.036

135.882

135.882
133.574

133.574
131.267

131.267

127.805

126.651

125.497

123.190

123.190

123.190

123.190

124.343

124.343

124.343

124.343

123.190
123.190

H_BUTTON

Q_HEAT

47.442

46.193

46.193

46.193

46.193

48.690

.

48.690

48.690

43.193

43.696

39.951

38.702

36.454

34.957

34.957

34.957

36.205

36.205

36.205

36.205

34.957
34.957 
TABLE C.1 (Contd.)

PLANTSIM ALL SCURCES 67 FEB 16-18
$A M-O I L$
$Q_{-} S O Z$

19.887

$$
19.363
$$

19.363
19.363

19.363
19.363

20.410

20.933

20.410

20.410
19.363

19.363
18.317

16.747

16.223
15.700

15.177

14.653

14.653
14.653

15.177

15.177

15.177

15.177

14.653
14.653

NGERSOL

Q_SO2

$112.4 \in 3$

$112.4 t 3$

$112.4 t 3$

112.463

112.463

112.463

$112.4 \in 3$

112.463

112.463

112.463

112.463

112.463

112.463
112.463

112.463

112.463

112.463

112.463
112.463

112.463

112.463

112.463
112.463
AM_OIL

10.523

10.246

10.246

10.246

10.246

10.800

11. 077

10.800

10.800

10.246

8.862

8.565

8.308

8.031

7.754

7.754
7.754

8.031

8.031

8.031

8.031

7.754
7.754

INGER SOL
O_HEAT

91.016

91.016

91.016

91.016

91.016

91.016

91.016

91.016

91.016

91.016

91.016

91.016

91.016

91.016

91.016

91.016
91.016

91.016

91.016

91.016

91.016
CHGC RAH

54.504

54.268

54.268

$5 c .268$

52.268

56.740

$5<.976$

54.740

$5 C .740$

52.268

53.796

53.089
52.853

52.617

5 c. 381

52.145

52.145

52.145

$5 \hat{2} .381$
$5 \mathrm{c} .381$

5 C. 381

52.381

52.381

52.145

CHGO-RAW

Q_HEAT

LIN_BELT
$Q_{-} S O 2$

SO2

LIN_BELT
O_HEAT

SQ DINGE

53.088

53.088

53.088

6.072

6.072

6.072

6.072

6.072

6.072

6.072
4.554

4.554

4.554

4.554
4.554

4.554

4.554

4.554
4.554

4.554

4.554
4.554

4.554

4.554

4.554
4.554

2.376
2.376

2.376
2.376

2.376

2.376

2.376

2.376

2.376

1.782

1.782

1.782

1.782
1.782

1.782

1.782

1.782
1.762

1. 782

1.782

1.782

1.782

1.782

1.782
1.782

51.011

4.554
502

\subsection{6}

5.079
5.079

5.079

5.079

5.353

5.491

33.458

33.458

33.184

32.909

32.497

32.360

32.223

32.086

31.948

31. 948

32.086

32.086

32.086

32.086

31.948
31.948 QTEAT

3.508

3.415

3.415

3.415

3.415

3.692

3.600

22.500

. 315

2.131

21.854

21.76

21.669

21.577

21.485

21.485

21.485
21.577

21.577

21.577

21.577
21.485

21.485

ELEC
SO2

420.812

420.812

420.812

420.812

420.812

420.812

420.812

420.812

420.812

420.812

420.812

420.812

420.812

420.812

420.812

420.812

420.812

W_ELEC

197.000

197.000

197.000

197.000

197.000

197.000

197.000

197.000

197.000

197.000

197.000

197.000

197.000

197.000

197.000

197.000

197.000

197.000

197.000

197.000

197.000

197.000 
TABLE C.2. Stack Coordinates and Physical Parameters

\begin{tabular}{|c|c|c|c|c|c|}
\hline Name & $\mathrm{x}, \mathrm{mi}$ & $\mathrm{Y}, \mathrm{mi}$ & Stack No. & Height & $\begin{array}{c}\text { Inside } \\
\text { Diameter } \\
\text { ft }\end{array}$ \\
\hline CECO-NW & 8.5 & -4.2 & $\begin{array}{l}1 \\
2\end{array}$ & $\begin{array}{l}303.83 \\
303.83\end{array}$ & $\begin{array}{l}14 . \\
14 .\end{array}$ \\
\hline Fisk & 6.4 & +1.9 & $\begin{array}{l}1 \\
2 \\
3 \\
4 \\
5 .\end{array}$ & $\begin{array}{l}291 . \\
291 . \\
291 . \\
291 . \\
450 .\end{array}$ & $\begin{array}{l}11 . \\
11 . \\
11 . \\
11 . \\
14 .\end{array}$ \\
\hline Crawford & 9.9 & +3.5 & $\begin{array}{l}1 \\
2 \\
3\end{array}$ & $\begin{array}{l}346 . \\
378 \\
378\end{array}$ & $\begin{array}{l}- \\
- \\
-\end{array}$ \\
\hline Ridgeland & 13.0 & $\begin{array}{l}+4.5 \\
\therefore\end{array}$ & $\begin{array}{l}1 \\
2 \\
3 \\
4 \\
5 \\
6\end{array}$ & $\begin{array}{l}213 . \\
213 . \\
213 . \\
213 . \\
213 . \\
213 .\end{array}$ & $\begin{array}{l}8 . \\
8 . \\
8 . \\
8 . \\
9.83 \\
9.83\end{array}$ \\
\hline Calumet & 1.0 & +11.6 & $\begin{array}{l}1 \\
2\end{array}$ & $\begin{array}{l}302.5 \\
302.5\end{array}$ & $\begin{array}{l}9 . \\
9 .\end{array}$ \\
\hline Stateline & 0.0 & +11.9 & $\begin{array}{l}1 \\
2 \\
3 \\
4 \\
5 \\
6\end{array}$ & $\begin{array}{l}301 \\
301 \\
301 \\
301 \\
400 . \\
396.5\end{array}$ & $\begin{array}{l}18 . \\
18 . \\
18 . \\
18 . \\
16.5 \\
13.5\end{array}$ \\
\hline TAM 5 & 7.4 & +6.8 & \multicolumn{3}{|c|}{ Height of aerovane is $75 \mathrm{ft}$. } \\
\hline
\end{tabular}


TABLE C.3. Meteorological Data for February 16-18, 1967. The columns labeled Turner and Norco represent the Turner stability class ${ }^{8}$ and mixing height ${ }^{17}$ (in $\mathrm{ft}$ ), respectively.

\begin{tabular}{|c|c|c|c|c|c|c|}
\hline & & $\begin{array}{l}\text { MIOWAY } \\
\text { TEMP }\end{array}$ & $\begin{array}{l}\text { MI DWAY } \\
\text { WIND_DIR }\end{array}$ & $\begin{array}{l}\text { MIDWAY } \\
\text { WIND_VEL }\end{array}$ & $\begin{array}{l}\text { TURNER } \\
\text { TURNER_C }\end{array}$ & $\begin{array}{l}\text { NORCO } \\
M I X \_H T\end{array}$ \\
\hline $\begin{array}{l}67 / 02 / 16 \\
67 / 02 / i 6\end{array}$ & $\begin{array}{l}0 \\
1\end{array}$ & $\begin{array}{l}15.000 \\
14.000\end{array}$ & $\begin{array}{l}310.000 \\
310.000\end{array}$ & $\begin{array}{l}20.000 \\
15.000\end{array}$ & \multicolumn{2}{|c|}{$\begin{array}{l}4.000 * * * * * * * * * * * * \\
4.000 * * * * * * * * * * * *\end{array}$} \\
\hline $67 / 02 / 16$ & 2 & 13.000 & 310.000 & 15.000 & 4.000 & 778.000 \\
\hline $67 / 02 / 16$ & 3 & 12.000 & 310.000 & 15.000 & 4.000 & 1249.000 \\
\hline $67 / 02 / 16$ & 4 & 11.000 & 300.000 & 17.000 & 4.000 & 1548.000 \\
\hline $67 / 02 / 16$ & 5 & 10.000 & 300.000 & 13.000 & 4.000 & 1671.000 \\
\hline $67 / 02 / 16$ & 6 & 8.000 & 300.000 & 12.000 & 4.000 & 1696.000 \\
\hline $67 / 02 / 16$ & 7 & 7.000 & 310.000 & 10.000 & 4.000 & 1566.000 \\
\hline $67 / 02 / 16$ & 8 & 7.000 & 300.000 & 10.000 & 4.000 & 1456.000 \\
\hline & 19 & $\begin{array}{r}9.000 \\
10.000\end{array}$ & $\begin{array}{l}310.000 \\
290.000\end{array}$ & 10.000 & 4.000 & 1629.000 \\
\hline $\begin{array}{l}67 / 02 / 16 \\
67 / 02 / 16\end{array}$ & 11 & $\begin{array}{l}10.000 \\
13.000\end{array}$ & $\begin{array}{l}290.000 \\
240.000\end{array}$ & $\begin{array}{l}4.000 \\
3.000\end{array}$ & $\begin{array}{l}3.000 \\
2.000\end{array}$ & $\begin{array}{l}1669.000 \\
1989.000\end{array}$ \\
\hline & 12 & 14.000 & 260.000 & & & $\begin{array}{l}1989.000 \\
2073.000\end{array}$ \\
\hline $67 / 02 / 16$ & 13 & 16.000 & 200.000 & 6.000 & 3.000 & 2267.000 \\
\hline $67 / 02 / 16$ & 14 & 17.000 & 240.000 & 4.000 & 3.000 & 2347.000 \\
\hline $67 / 02 / 16$ & $1 E$ & 17.000 & 270.000 & 6.000 & 3.000 & 2311.000 \\
\hline $67 / 02 / 16$ & 16 & 17.000 & 0.0 & 0.0 & 3.000 & 2275.000 \\
\hline $67 / 02 / 16$ & 17 & 17.000 & 0.0 & 0.0 & 5.000 & 2240.000 \\
\hline $67 / 02 / 16$ & 18 & 16.000 & 0.0 & 0.0 & 5.000 & 2091.000 \\
\hline $67 / 02 / 16$ & 19 & 16.000 & 260.000 & 4.000. & 5.000 & 1929.000 \\
\hline $67 / 02 / 16$ & 20 & 16.000 & 300.000 & 4.000 & 5.000 & 1791.000 \\
\hline $67 / 02 / 16$ & 21 & 16.000 & 0.0 & 0.0 & 5.000 & 1703.000 \\
\hline $67 / 02 / 16$ & 22 & 17.000 & 320.000 & 2.000 & 5.000 & 1846.000 \\
\hline $67 / 02 / 16$ & 23 & 17.000 & 280.000 & 3.000 & 5.000 & 1772.000 \\
\hline $\begin{array}{l}67 / 02 / 17 \\
67 / 02 / 17\end{array}$ & $\begin{array}{l}0 \\
1\end{array}$ & $\begin{array}{l}17.000 \\
18.000\end{array}$ & $\begin{array}{l}280.000 \\
210.000\end{array}$ & $\begin{array}{l}3.000 \\
5.000\end{array}$ & $\begin{array}{l}4.000 \\
4.000\end{array}$ & $\begin{array}{l}1718.000 \\
1816.000\end{array}$ \\
\hline $67 / 02 / 17$ & 2 & 18.000 & 180.000 . & 5.000 & 5.000 & 1765.000 \\
\hline $67 / 02 / 17$ & 3 & 18.000 & 190.000 & 5.000 & 5.000 & 1724.000 \\
\hline $67 / 02 / 17$ & $\begin{array}{l}4 \\
5\end{array}$ & $\begin{array}{l}18.000 \\
16.000\end{array}$ & $\begin{array}{c}190.000 \\
0.0\end{array}$ & $\begin{array}{l}3.000 \\
0.0\end{array}$ & $\begin{array}{l}5.000 \\
5.000\end{array}$ & 1690.000 \\
\hline $\begin{array}{l}67 / 02 / 17 \\
67 / 02 / 17\end{array}$ & 6 & 15.000 & 300.000 & 3.000 & 5.000 & 951.000 \\
\hline $67 / 02 / 17$ & 7 & 16.000 & 310.000 & 5.000 & 4.000 & 1053.000 \\
\hline $67 / 02 / 17$ & 8 & 16.000 & 330.000 & 5.000 & 4.000 & 807.000 \\
\hline $67 / 02 / 17$ & 9 & 18.000 & 0.0 & 0.0 & 4.000 & 1223.000 \\
\hline $67 / 02 / 17$ & 10 & 20.000 & 180.000 & 4.000 & 4.000 & 1577.000 \\
\hline $67 / 02 / 17$ & 21 & 23.000 & 130.000 & 8.000 & 4.000 & 1893.000 \\
\hline $67 / 02 / 17$ & 12 & 24.000 & 120.000 & .7 .000 & 2.000 & 1974.000 \\
\hline $67 / 02 / 17$ & 13 & 25.000 & 140.000 & 5.000 & 3.000 & 2072.000 \\
\hline $67 / 02 / 17$ & 14 & 26.000 & 100.000 & 4.000 & 3.000 & 2190.000 \\
\hline $67 / 02 / 17$ & 15 & 27.000 & 90.000 & 4.000 & 4.000 & 2298.000 \\
\hline $67 / 02 / 17$ & 16 & 27.000 & 90.000 & 7.000 & 4.000 & 2265.000 \\
\hline $67 / 02 / 17$ & 17 & 27.000 & 70.000 & 9.000 & 4.000 & 2231.000 \\
\hline $67 / 02 / 17$ & 18 & 26.000 & 80.000 & 7.000 & 4.000 & 1908.000 \\
\hline $67 / 02 / 17$ & 19 & 26.000 & 70.000 & 7.000 & 4.000 & 1838.000 \\
\hline $67 / 02 / 17$ & 20 & 26.000 & 1.40 .000 & 5.000 & 4.000 & 1777.000 \\
\hline $07 / 02 / 17$ & 21 & 20.000 & 130.000 & 6.000 & 4.000 & חסח . 1712 \\
\hline $67 / 02 / 17$ & 22 & 27.000 & 100.000 & 4.000 & 4.000 & 1976.000 \\
\hline $67 / 02 / 17$ & 23 & 27.000 & 190.000 & 4.000 & 4.000 & 1910.000 \\
\hline $67 / 02 / 18$ & 0 & 28.000 & 230.000 & 5.000 & 4.000 & 2151.000 \\
\hline $67 / 02 / 18$ & 1 & 28.000 & 0.0 & 0.0 & 4.000 & 2104.000 \\
\hline $67 / 02 / 18$ & 2 & 27.000 & 140.000 & 5.000 & 5.000 & 1769.000 \\
\hline $67 / 02 / 18$ & 3 & 25.000 & 170.000 & 5.000 & 5.000 & 1149.000 \\
\hline $67 / 02 / 18$ & 4 & 24.000 & $0.0^{\circ}$ & & 5.000 & 921.000 \\
\hline $67 / 02 / 18$ & 5 & 23.000 & 0.0 & 0.0 & 4.000 & 763.000 \\
\hline $\begin{array}{l}67 / 02 / 18 \\
67 / 02 / 18\end{array}$ & $\begin{array}{l}6 \\
7\end{array}$ & $\begin{array}{l}23.000 \\
24.000\end{array}$ & $\begin{array}{l}140.000 \\
160.000\end{array}$ & $\begin{array}{l}3.000 \\
3.000\end{array}$ & $\begin{array}{l}5.000 \\
4.000\end{array}$ & $\begin{array}{l}761.000 \\
822.000\end{array}$ \\
\hline $67 / 02 / 18$ & 8 & 25.000 & 140.000 & 9.000 & 4.000 & 894.000 \\
\hline $67 / 02 / 18$ & 9 & 25.000 & 140.000 & 10.000 & 4.000 & 805.000 \\
\hline $67 / 02 / 18$ & 10 & 26.000 & 180.000 & 12.000 & $4.00 \Omega$ & 892.000 \\
\hline $67 / 02 / 18$ & 11 & 27.000 & 170.000 & 11.000 & 4.000 & 991.000 \\
\hline $67 / 02 / 18$ & 12 & 28.000 & 170.000 & 12.000 & 4.000 & 1186.000 \\
\hline $67 / 02 / 18$ & 13 & 29.000 & 180.000 & 10.000 & 4.000 & 1460.000 \\
\hline $67 / 02 / 18$ & 14 & 29.000 & 170.000 & 8.000 & 4.000 & 1302.000 \\
\hline $67 / 02 / 18$ & 15 & & 130.000 & & 4.000 & 1117.000 \\
\hline $67 / 02 / 18$ & 16 & 30.000 & 140.000 & 8.000 & 4.000 & 1400.000 \\
\hline $67 / 02 / 1.8$ & 17 & 30.000 & 160.000 & 9.000 & 4.000 & 1208.000 \\
\hline $67 / 02 / 18$ & 18 & 30.000 & 150.000 & 8.000 & 4.000 & 914.000 \\
\hline $67 / 02 / 18$ & 19 & 31.000 & 190. ann & 10.000 & 4.000 & 1417.000 \\
\hline $07 / 02 / 10$ & 20 & 32.000 & 220.000 & 6.000 & 4.000 & 1783.000 \\
\hline $67 / 02 / 18$ & 22 & 32.000 & 220.000 & 6.000 & 4.000 & 1661.000 \\
\hline $67 / 02 / 18$ & 22 & 32.000 & 220.000 & 8.000 & 4.000 & 1582.000 \\
\hline $67 / 02 / 18$ & 23 & 30.000 & 220.000 & 6.000 & 5.000 & 749.000 \\
\hline
\end{tabular}


TABLE C.4. Results of Sample Computations of $\mathrm{SO}_{2}$ Concentrations at TAM 5 for February 16-18, 1967. Only the last four columns are of interest. Of the two columns labeled TAM $5 \mathrm{SO}_{2}$, the first is the observed and the second the calculated concentrations.

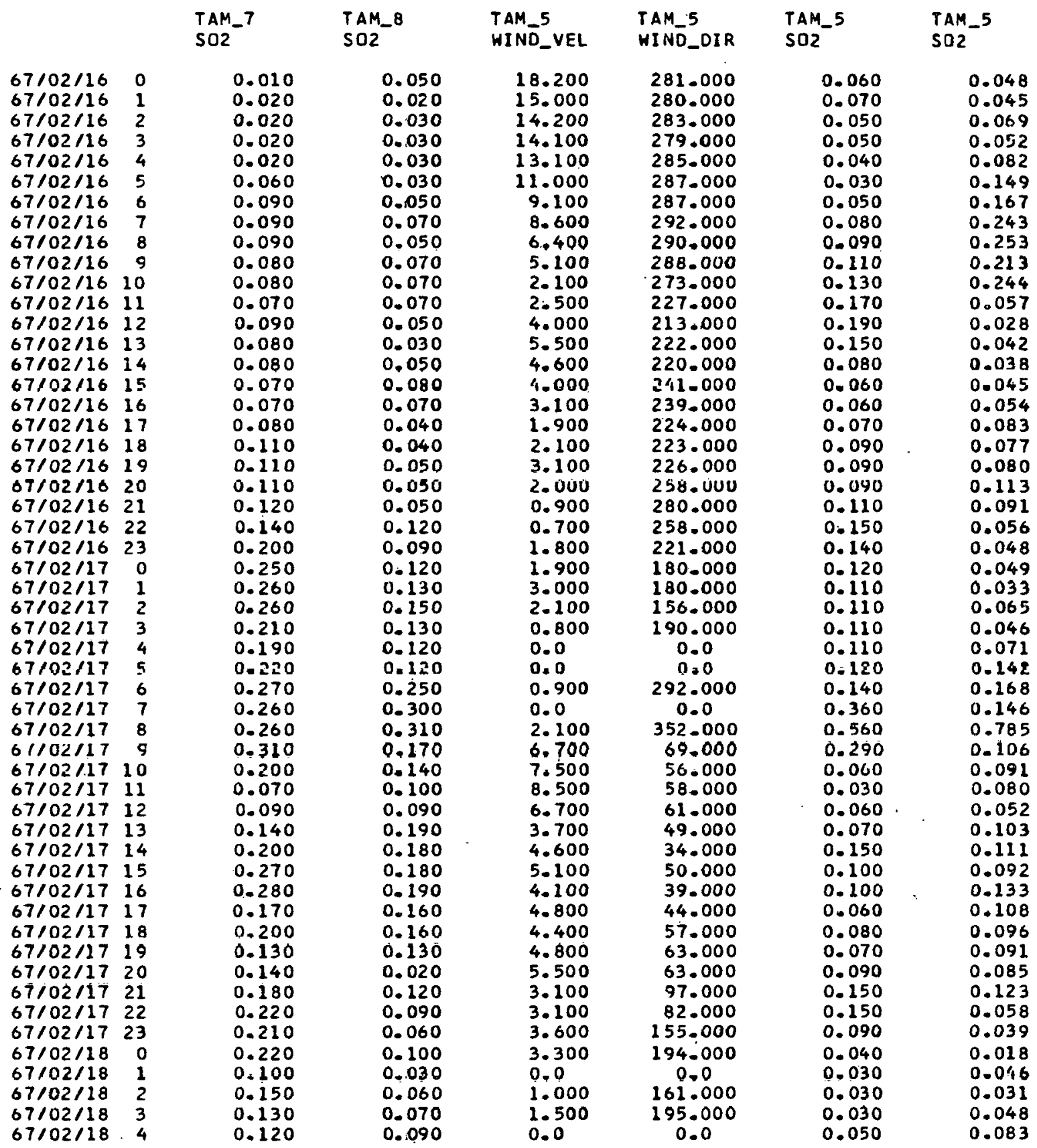


TABLE C.4 (Contd.)

DMR 7

TAM_5 FEB $16-18,1967$

TAM_ 7

$\mathrm{SO} 2$

${ }_{502}^{T A M}-8$

0.180

0.200 .

0.200

0.180

0.150

0.150

0.100

0.080

0.070

0.100

0.130

0.190

0.130

0.160

0.270

0.140

0.140

0.130

0.120
TAM_5

WIND_VEL

0.090

0.110

0.110

0.100

0.050

0.060

0.070

0.070

0.060

0.020

0.020

0.040

0.040

0.060

0.050

0.100

0.080

0.070

0.070

\subsection{0}

2.300

3.500

5.900

8.000

9.000

B. 300

8.600

7.000

5.100

4.900

5.200

6.700

6.000

6.500

6.600

5.300

4.400

4.400

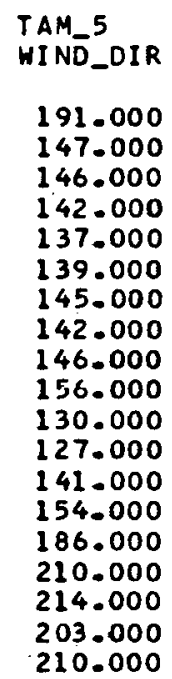

TAM 5

$S 02$

TAM 5

$\mathrm{SO} 2$

0.040

0.090

0.120

0.100

0.040

0.030

0.030

0.030

0.030

0.030

0.040

0.100

0.100

0.050

0.030

0.020

0.030

0.040

0.040
0.156

0.273

0.138

0.087

0.091

0.069

0.063

0.058

0.059

0.069

0.289

0.321

0.066

0.079

0.030

0.026

0.027

0.014
0.021 


\section{APPENDIX D}

\section{Definitions of Quantities Used in Analysis of Results}

Both the puff and the plume models calculate the $\mathrm{SO}_{2}$ concentrations on an hourly basis. However, to show the effects of averaging over $n$ consecutive hourly concentrations, we analyze the results in terms of the averaging intervals $\mathrm{n}=1,6$, and $24 \mathrm{hr}$. These averaged concentrations are in turn averaged over short- or long-term periods where appropriate. The following quantities are used in the analysis:

$$
\begin{aligned}
& \chi_{\text {ei }}\left(\chi_{\text {oi }}\right)=\text { estimated (observed) } \mathrm{SO}_{2} \text { concentration at the ith hour } \text { : } \\
& \begin{aligned}
\left.\mu_{\mathrm{ej}}^{(11}\right)= & \mathrm{n} \text {-hour average estimated concentration for the } \mathrm{jth} \mathrm{n} \text {-hour } \\
& \text { consecutive interval. }
\end{aligned} \\
& \mu_{n j}^{(n)}=n \text {-houx average observed concentration for the } j \text { th } n \text {-hour } \\
& \text { consecutive interval. } \\
& =\frac{1}{n} \sum_{i=k}^{n j} \chi_{i}, \quad \text { where } k=n(j-1)+1 . \\
& \sigma_{o e}^{(n)}=\text { standard deviation of the differences between the } n \text {-hour } \\
& =\frac{1}{\sqrt{N-1}}\left\{\sum_{j=1}^{N}\left[d_{j}(11)\right]^{2}-\frac{1}{N}\left[\sum_{j=1}^{N} d_{j}^{(n)}\right]^{2}\right\}^{1 / 2},
\end{aligned}
$$

where

$$
d_{j}^{(11)}=\mu_{o j}^{(n)}-\underset{c j}{\mu(n)}
$$

and

$$
\mathrm{n}=1,6 \text {, and } 24 \mathrm{hr} \text {. }
$$

If we are working with a total of $\mathrm{M} \mathrm{hr}$ of historical air-quality data, then $N=M / n$. In addition, we define the overall averages of calculated and observed concentrations

$$
\mu_{e}=\frac{1}{N} \sum_{j=1}^{N} \mu_{e j}^{(n)}, \mu_{o}=\frac{1}{N} \sum_{j=1}^{N} \mu_{o j}^{(n)}
$$


which are independent of $n$ (provided $N=M / n$ is used). A reasonably good measure of the spread of the differences $d_{j}(n)$ is the relative standard deviation given by $\sigma_{\mathrm{O}}(\mathrm{n}) / \mu_{\mathrm{o}}$.

The percentile distributions of the differences is described adequately by the following quantities:

$$
\begin{aligned}
50 \%= & \text { percent of the calculated results within } 50 \% \text { of the observed } \\
& \text { results. }
\end{aligned}
$$

$F 2=$ percent of the calculated results within a factor of 2 of the observed results.

PN025 = percent of the differences within $0.025 \mathrm{ppm}$.

PN050 $=$ percent of the differences within $0.050 \mathrm{ppm}$.

$\mathrm{PNl}=$ percent of the differences within $0.100 \mathrm{ppm}$. 


\section{ACKNOWLEDGMENTS}

We wish to acknowledge the guidance of and many helpful discussions with J. J. Roberts in the initial phase of this program. Further, numerous discussions with members of the Meteorology Group at Argonne National Laboratory including J. E. Carson, H. Moses, and B. Ackerman are most appreciated. In addition, A. Strong (Director of the Chicago Area EMSU station) has been very helpful through various private communications, as well as in providing us with some of his radiosonde data taken at Midway Airport.

Finally, we wish to thank the Chicago Department of Air Pollution Control for their cooperation in providing us with the TAM air quality and weather data. 


\section{REFERENCES}

1. J. J. Roberts, E. J. Croke, A。 S. Kennedy, J。E. Norco, and L. A. Conley, A Multiple-source Urban Atmospheric Dispersion Model, ANL/ES-CC-007 (May 1970).

2. J. J. Roberts, Ed., Chicago Air Polzution Systems Analysis Progrom: Final Report, ANL/ES-CC-009 (Feb 1971)。

3. J。 J. Roberts, E. J. Croke, and A. S. Kennedy, "An Urban Atmospheric Dispersion Model," in Proc. Symp. on Multiple-Source Urban Diffusion Models, Univ. North Carolina, October 27-30, 1969, Ed. A. C. Stern; U.S. Government Printing Office, Washington, D.C., 1970, pp. 6-1 to 6-72. Also, J. J. Roberts, J. E. Norco, and E. J. Croke, A Model for Simulation of Air Pollution Transients, presented at the 2nd International Air Pollution Conference, International Union of Air Pollution Prevention Association, December 1970, Washington, D.C.

4. R. G. Lamb, An Air PolZution Model of Los Angeles, M.S. thesis, University of California, Los Angeles (1968)。

5. L. Shieh, A Multiple-Source Model of Turbulent Diffusion and Dispersion in Urban Atmospheres, Report No. NR-69-11, Geophysical Sciences Laboratory, New York University (Dec 1969).

6. G. E. Start and E. H. Markee, Jr., "Relative Dose Factors from LongPeriod Point Source Emissions of Atmospheric Pollutants," Proc. USAEC Meteorological Information Meeting, Held at Chalk River Nuclear Laboratories, September 11-14, 1967, AECL-2787, pp.59-76.

7. J. F. Clarke, A Simple Diffusion Model for Calculating Point Concentrations from Multiple Sources, J. Air Poll. Contr. Assoc. 9 (Sept 1964).

8. D. B. Turner, A Diffusion Model for an Urban Area, J. Appi. Meteorol. 3, 83-91 (Feb 1964).

9. D. B. Turner, St. Louis Study, private communication (1970).

10. H. Moses, Mathematical Urban Air PolZution Models, ANL/ES-RPY-001 (Apr 1969).

11. D. B. Turner, Workbook of Atmospheric Dispersion Estimates, U.S. Dept. of Health, Education, and Welfare, U.S. Public Health Service Publication No. 999-AP-26.

12. F. Pasquil1, The Estimation of Dispersion of Windblown Material, Meteorol. Mag. 90(1063), 33-49 (1961).

13. F. A. Gifford, Uses of Routine Meteorological Observations for Estimating Atomospheric Dispersion, Nucl. Safety 2(4), 45-51 (1961).

14. Private communcation between F。 Pasquill and J.J. Roberts at the 2nd Internatlunal Cleall Ail Cungiess, Washington, D.C. (1971).

15. H. E. Cramer, G. M. DeSanto, R. K. Dumbauld, P. Morgenstern, and R. N. Swanson, Meteorological Prediction Techniques and Data System, Geophysics Corp. of America, GCA Tech. Report No.64-3-G, p. 34 (Mar 10, 1964).

16. D. H. Slade, Ed., Meteorology and Atomic Energy, TID-24190 (1968). 
17. J. E. Norco and J. E. Ash, "Objective Mixing Layer Depth Estimates," Sec. 3.3 in Chicago Air Polzution Systems Analysis Program: Fourth Quarterly Progress Report, ANL/ES-CC-004 (Mar 1969).

18. D. M. Rote, J。W. Gudenas, and J. Anderson, A Comparison of Two Methods for Estimating the Mixing Depths Over an Urban Area, presented at the 64 th Annual Meeting of the Air Pollution Control Association, Atlantic City, N.J., June 27-July 1, 1971。

19. J. E. Carson and $H_{0}$ Moses, "The Validity of Currently Popular Plume Rise Formulas," in Proc. USAEC Meteorological Information Meeting, Held at Chalk River Nuclear Laboratories, September 11-14, 1967, AECL-2787, pp. 1-20。(1967).

20. G. A. DeMarrais, Wind-Speed Profile at Brookhaven National Laboratory, J. Meteorol。16, 181-190 (Apr 1959)。

21. J. J. Roberts and E. J. Croke, Design of Regional Implementation PZans for Stationary Sources, Paper. No. 70-140, 63rd Annual Meeting of the Air Pollution Control Association Meeting, St. Louis, Mo., June 1970.

22. H. G. Fortak, "Numerical Simulation of the Temporal and Spatial Distributions of Urban Air Pollution Concentrations," in Proc. Symp. on Multiple-Source Urban Diffusion Models, Univ. North Carolina, October 27-30, 1969, tid。A。C。Stern; U。S。Government Printing Office, Washington, $D_{0} C_{0}, 1970$, pp. 9-1 to 9-34.

23. G。A。 Briggs, Plume Rise, TID-25075 (1969).

24. Ko J。 Marsh and V。 R。 Withers, An Experimental Study of the Dispersion of the Emissions from Chimneys in Reading--III: The Investigation of Dispersion Calculations, Atmos. Environ. 3, 281-302 (1969).

25. J。B。Koogler, R. S. Scholtes, A. L. Davies, and C. I. Harding, A Multivariable Model for Atmospheric Dispersion Problems, J. Air Poll. Contr. Assoc。17, 211-214 (1967).

26. A. Strong, private communication (1971)。

27. J. E. Carson, D。F。Gatz, and Ho Moses, "Meteorology," Sec. 3 in City of Chicago Air Polzution System Model: Third Quarterly Progress Report, ANL/ES-CC-003 (Oct 1968)。

28. W. A. Lyons, Mesoscale Transport of Pollutants in the Chicago Area as Affected by Land and Lake Breezes, Paper ME-3A, 2nd Intern. Clean Air Congress, Chicago, Iil。, Dec 6, 1970.

29. Co Chamot, A. S. Kennedy, E. J. Croke, J..J. Roberts, H. Moses, and $\mathrm{J}$ 。 B. Anderson, APICS, A Computerized Air Polzution Data Management System, ANL/ES-CC-006 (Feb 1970)。

30. TRW Systems Group, Air Quality Display Model, prepared for U.S. Dept. of Health, Education, and Welfare, U。S。Public Health Service, Consumer Protection and Environmental Health Service, National Air Pollution Control Admintstralion, Washington, D。C. (Nov 1969)。

31. S. R. Hanna, Simple Methods of Calculating Dispersion from Urban Area Sources, Paper 46, APCA Conf. on Air Pollution Meteorology, Raleigh, N.C., Apr 5-9; 1971。 